Florida International University

FIU Digital Commons

FIU Electronic Theses and Dissertations

University Graduate School

$11-9-2018$

\title{
Estimation and Prediction of Mobility and Reliability Measures Using Different Modeling Techniques
}

Fatema Hoque Farzana

Florida International University, ffarz001@fiu.edu

Follow this and additional works at: https://digitalcommons.fiu.edu/etd

Part of the Civil Engineering Commons, and the Transportation Engineering Commons

\section{Recommended Citation}

Farzana, Fatema Hoque, "Estimation and Prediction of Mobility and Reliability Measures Using Different Modeling Techniques" (2018). FIU Electronic Theses and Dissertations. 3880.

https://digitalcommons.fiu.edu/etd/3880

This work is brought to you for free and open access by the University Graduate School at FIU Digital Commons. It has been accepted for inclusion in FIU Electronic Theses and Dissertations by an authorized administrator of FIU Digital Commons. For more information, please contact dcc@fiu.edu. 


\title{
FLORIDA INTERNATIONAL UNIVERSITY
}

Miami, Florida

\section{ESTIMATION AND PREDICTION OF MOBILITY AND RELIABILITY MEASURES USING DIFFERENT MODELING TECHNIQUES}

\author{
A thesis submitted in partial fulfillment of \\ the requirements for the degree of \\ MASTER OF SCIENCE \\ in \\ CIVIL ENGINEERING
}

by

Fatema Hoque Farzana 
To: Dean John L. Volakis

College of Engineering and Computing

This thesis, written by Fatema Hoque Farzana, and entitled Estimation and Prediction of Mobility and Reliability Measures Using Different Modeling Techniques, having been approved in respect to style and intellectual content, is referred to you for judgment.

We have read this dissertation and recommend that it be approved.

$\begin{array}{r}\hline \text { Mohammed Hadi } \\ \hline \text { Albert Gan } \\ \hline \text { Yan Xiao }\end{array}$

Date of Defense: November 9, 2018

The thesis of Fatema Hoque Farzana is approved.

Dean John L. Volakis
College of Engineering and Computing

College of Engineering and Computing

Andrés G. Gil

Vice President for Research and Economics Development and Dean of the University Graduate School

Florida International University, 2018 
(C) Copyright 2018 by Fatema Hoque Farzana

All rights reserved. 


\section{DEDICATION}

I dedicate this dissertation to my parents, Nazmun Nahar and Md Fazlul Hoque, parentin-laws, Momena Begum and Md Solaiman, my sister, Fariha Hoque, and my husband Md Sakoat Hossan, for their unconditional love and support. 


\section{ACKNOWLEDGMENT}

First and foremost, I would like to express my sincere and humble gratitude to the Almighty Allah, for enabling me to carry out the research work and complete it without any problems.

I would like to express my deepest gratitude to my supervisor, Dr. Mohammed Hadi, Professor, Department of Civil Engineering and Environmental Engineering, Florida International University, for his continuous guidance, encouragement, support, and understanding at every stage of this dissertation. Without his dedication, enthusiasm, and persistent support, it would have not been possible to complete this research.

My deepest appreciation is extended to the committee members, Dr. Albert Gan, and Dr. Yan Xiao, for serving on my committee and for their invaluable contributions to my research work. I am thankful for their time and help in reviewing my work.

I am grateful to Dr. Tao Wang and Dr. Md Shahadat Iqbal, Research Associates at the Lehman Center for Transportation Research (LCTR), for helping me to process extensive data required for this research. I am also grateful to all of my friends and colleagues at LCTR. I had a wonderful time with them throughout these years. I would like to acknowledge the Florida Department of Transportation for providing the financial support for this research.

And finally, I would like to thank the inseparable part of my life: my parents, $\mathrm{Md}$ Fazlul Hoque and Nazmun Nahar, my parent-in-laws, Md Solaiman and Momena Begum, my younger sister, Fariha Hoque, and my husband, Md Sakoat Hossan, who endured this long process with me, always offering affectionate support, patience, careful assistance, and inspiration. 


\title{
ABSTRACT OF THE THESIS \\ ESTIMATION AND PREDICTION OF MOBILITY AND RELIABILITY MEASURES \\ USING DIFFERENT MODELING TECHNIQUES
}

\author{
by \\ Fatema Hoque Farzana \\ Florida International University, 2018 \\ Miami, Florida \\ Professor Mohammed Hadi, Major Professor
}

The goal of this study is to investigate the predictive ability of widely accepted and frequently used methods to estimate mobility and reliability measures. Mobility is a relatively mature concept in the traffic engineering field. Therefore, many mobility measure estimation methods are already available and widely accepted among practitioners and researchers. However, each method has their inherent weakness, particularly when applied and compared with real-world data. For instance, the Bureau of Public Roads (BPR) curves is a very popular method used in static route choice assignments and is a part of demand forecasting models, but this method is often criticized for underperforming in congested traffic conditions where demand exceeds capacity. This study applied several mobility estimation methods (BPR curve, Akcelik function, Florida State University (FSU) BPR, FSU Akcelik, FSU Conical Delay, FSU Davidson, Queuing Theory, and FREEVAL (Highway Capacity Manual-based procedures) for different facility types (i.e., Freeway and Arterial) and time periods (AM Peak, Mid-Day, PM Peak). The study findings indicate that the methods were able to accurately predict mobility measures (e.g., speed and travel 
time) on freeways, particularly when there was no congestion and the volume was less than the capacity. In presence of congestion, FREEVAL exhibited the best predictions, whereas the predictions from FSU Conical Delay and FSU Akcelik were the worst. In the case of arterials, none of the mobility estimation methods were able to predict measures closer to the real-world regardless of time periods. Interestingly, the FSU Conical Delay model predicted reasonably closer to real-world measures among all of the estimation methods.

To estimate reliability measures, the study applied three products from the Second Strategic Highway Research Program (SHRP2) projects (Project Numbers L03, L07, and C11) to estimate three reliability measures: the $50^{\text {th }}$ percentile travel time index, $80^{\text {th }}$ percentile travel time index, and $95^{\text {th }}$ percentile travel time index. A major distinction between the mobility estimation process and reliability estimation process lies in the fact that mobility can be estimated for any particular day, but reliability estimation requires a full year of data. Inclusion of incident days and weather conditions are other important considerations for reliability measurements. The study found that SHRP2 products predicted reliability measures reasonably well for freeways and arterials. On freeways, the L03 Data Poor Model provided the best reliability predictions, whereas, in general, most of the models predicted reliability closer to the real-world on arterials for all time periods, except for the calibrated C11 model. 


\section{TABLE OF CONTENTS}

CHAPTER

PAGE

Chapter 1

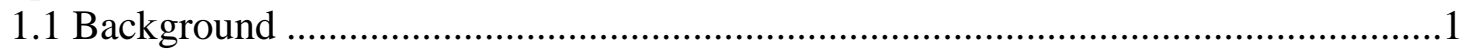

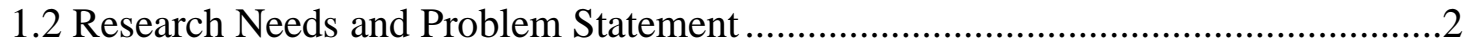

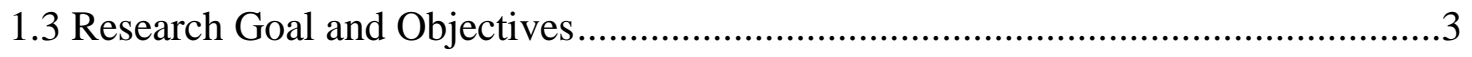

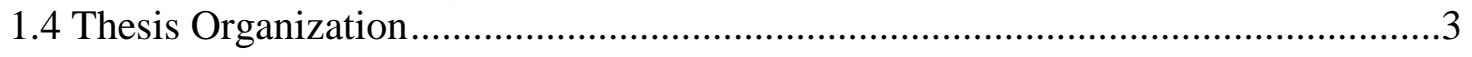

\section{Chapter 2}

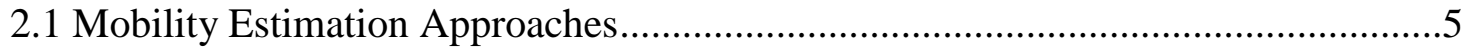

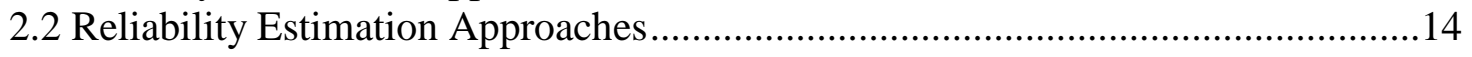

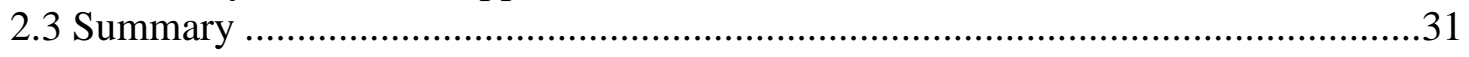

Chapter 3

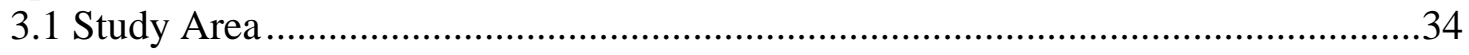

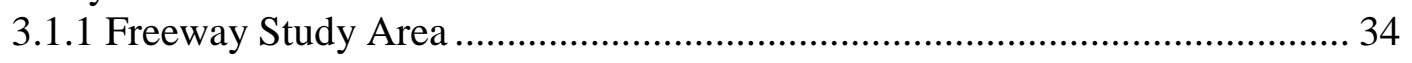

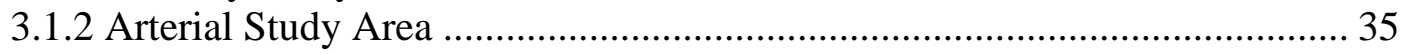

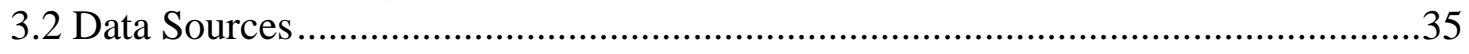

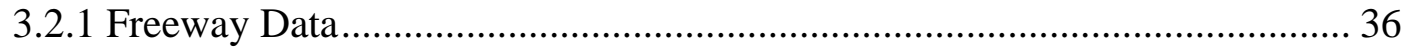

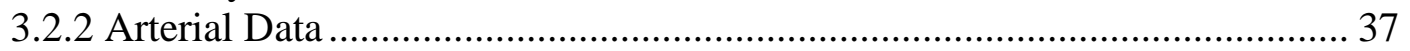

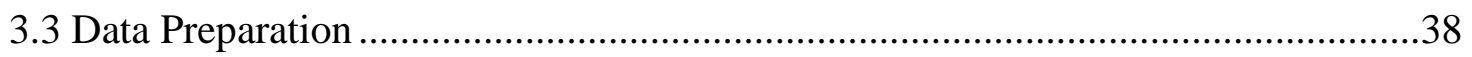

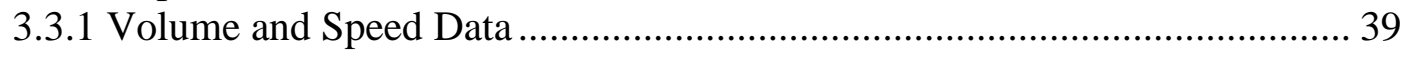

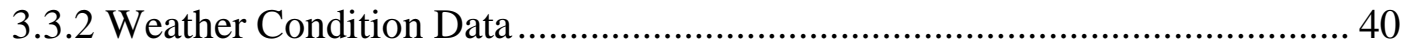

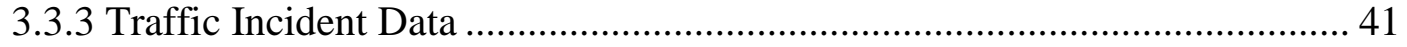

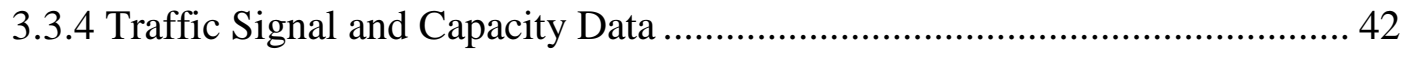

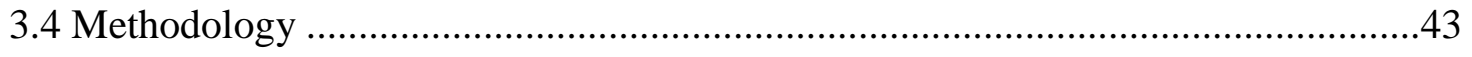

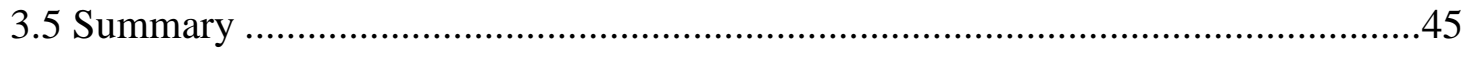

\section{Chapter 4}

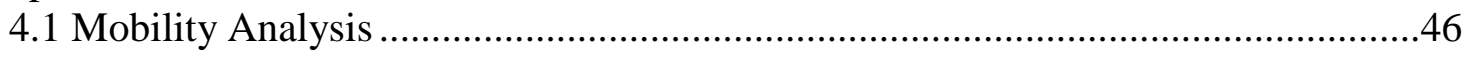

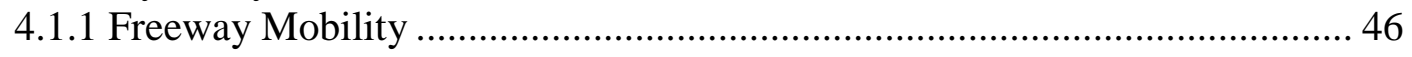

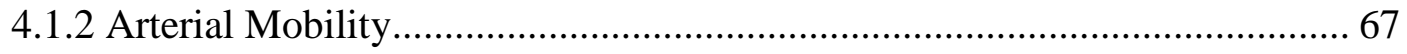

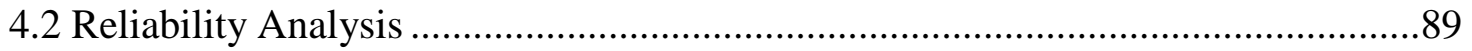

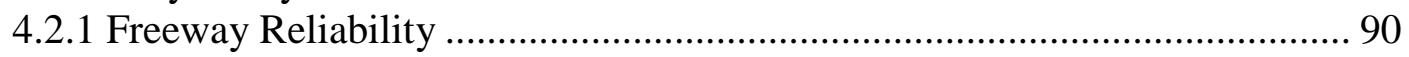

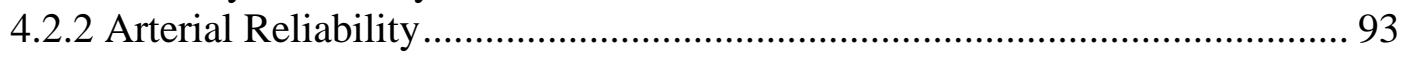

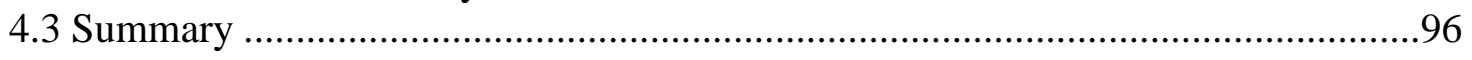

Chapter 5

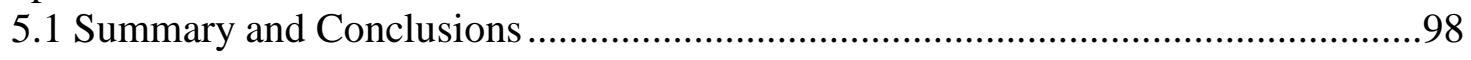

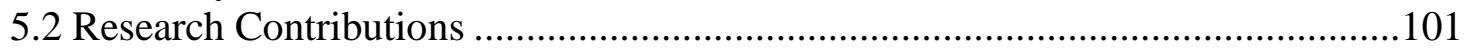

5.3 Recommendations for Future Research ................................................... 102

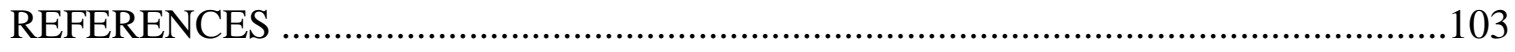




\section{LIST OF TABLES}

TABLE

PAGE

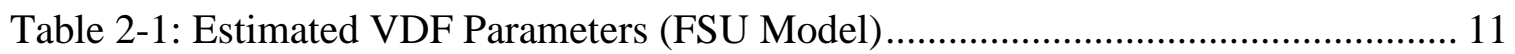

Table 2-3: Default co-efficient for L07 data-rich model ............................................ 18

Table 2-4: Calibrated co-efficient for data-rich model .............................................. 19

Table 2-5: Travel Time Reliability Estimation Methodology in SHRP 2 Projects .......... 24

Table 4-1: Performance Summary of Mobility Methods (Freeway, AM Peak) for

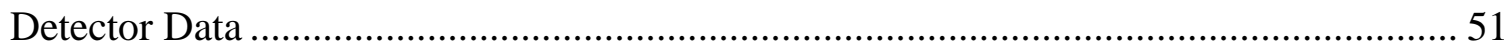

Table 4-2: Performance Summary of Mobility Methods (Freeway, AM Peak) for

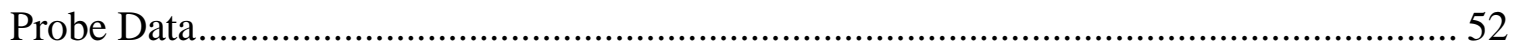

Table 4-3: Performance Summary of Mobility Methods (Freeway, Mid-Day) for

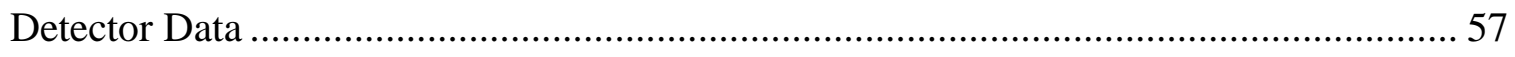

Table 4-4: Performance Summary of Mobility Methods (Freeway, Mid-Day) for

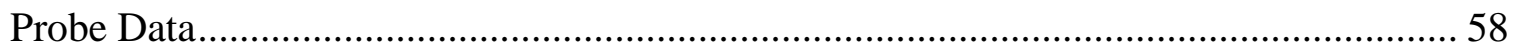

Table 4-5: Performance Summary of Mobility Methods (Freeway, PM Peak) for

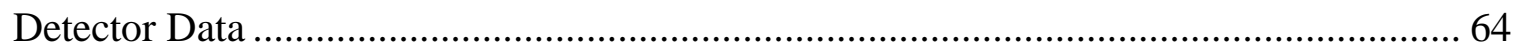

Table 4-6: Performance Summary of Mobility Methods (Freeway, PM Peak) for

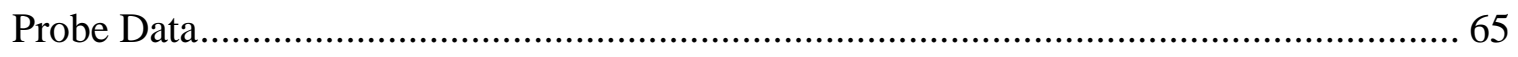

Table 4-7: Performance Summary of Mobility Methods During Incident ..................... 66

Table 4-8: Performance Summary of Mobility Methods (Arterials, AM Peak) for Capacity 800 VPHPL Used in Volume-Delay Functions ........................................... 71

Table 4-9: Performance Summary of Mobility Methods (Arterials, AM Peak) for Capacity 900 VPHPL Used in Volume-Delay Functions ............................................ 72

Table 4-10: Performance Summary of Mobility Methods (Arterials, AM Peak) for Capacity 1120 VPHPL Used in Volume-Delay Functions ........................................... 73

Table 4-11: Performance Summary of Mobility Methods (Arterials, AM Peak) for Capacity 1370 VPHPL Used in Volume-Delay Functions .......................................... 74 
Table 4-12: Performance Summary of Mobility Methods (Arterials, Mid-day) for Capacity 880 VPHPL Used in Volume-Delay Functions .......................................... 78

Table 4-13: Performance Summary of Mobility Methods (Arterials, Mid-day) for Capacity 900 VPHPL Used in Volume-Delay Functions ............................................. 79

Table 4-14: Performance Summary of Mobility Methods (Arterials, Mid-day) for Capacity 1120 VPHPL Used in Volume-Delay Functions ......................................... 80

Table 4-15: Performance Summary of Mobility Methods (Arterials, Mid-day) for Capacity 1370 VPHPL Used in Volume-Delay Functions ......................................... 81

Table 4-16: Performance Summary of Mobility Methods (Arterials, PM Peak) for Capacity 880 VPHPL Used in Volume-Delay Functions .............................................. 85

Table 4-17: Performance Summary of Mobility Methods (Arterials, PM Peak) for Capacity 900 VPHPL Used in Volume-Delay Functions ........................................... 86

Table 4-18: Performance Summary of Mobility Methods (Arterials, PM Peak) for Capacity 1120 VPHPL Used in Volume-Delay Functions .......................................... 87

Table 4-19: Performance Summary of Mobility Methods (Arterials, PM Peak) for Capacity 1370 VPHPL Used in Volume-Delay Functions ............................................. 88 


\section{LIST OF FIGURES}

FIGURE

PAGE

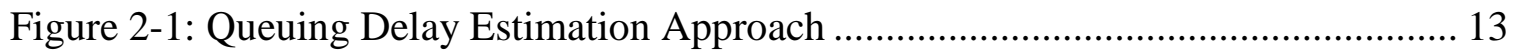

Figure 3-1: Detector location and coverage along the I-95 NB (Freeway Corridor)....... 35

Figure 3-2: Detector location and coverage along Sunrise Blvd EB (Arterial Corridor). 35

Figure 3-3: VISSIM Network for Arterial Roadways (Sunrise Blvd.) ........................... 38

Figure 4-1: Predictive ability of different mobility estimation methods - Travel Speed

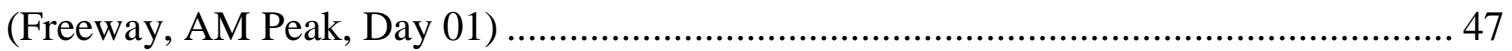

Figure 4-2: Predictive ability of different mobility estimation methods - Travel Time (Freeway, AM Peak, Day 01)

Figure 4-3: Predictive ability of different mobility estimation methods - Travel Speed

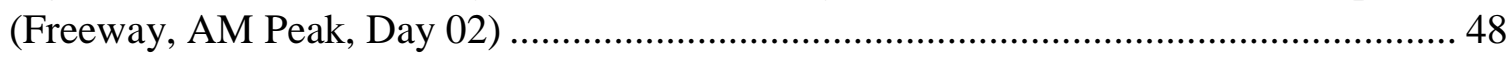

Figure 4-4: Predictive ability of different mobility estimation methods - Travel Time (Freeway, AM Peak, Day 02)

Figure 4-5: Predictive ability of different mobility estimation methods - Travel Speed (Freeway, AM Peak, Day 03)

Figure 4-6: Predictive ability of different mobility estimation methods - Travel Time

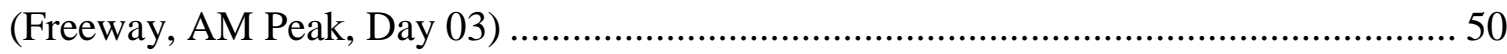

Figure 4-7: Predictive ability of different mobility estimation methods - Travel Speed

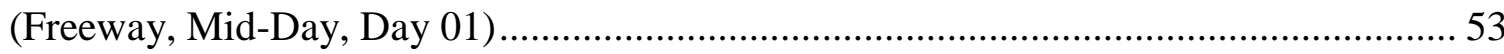

Figure 4-8: Predictive ability of different mobility estimation methods - Travel Time (Freeway, Mid-Day, Day 01).

Figure 4-9: Predictive ability of different mobility estimation methods - Travel Speed (Freeway, Mid-Day, Day 02)...

Figure 4-10: Predictive ability of different mobility estimation methods - Travel Time

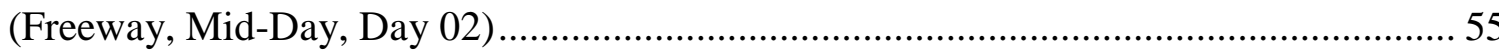

Figure 4-11: Predictive ability of different mobility estimation methods - Travel Speed (Freeway, Mid-Day, Day 03). 
Figure 4-12: Predictive ability of different mobility estimation methods - Travel Time (Freeway, Mid-Day, Day 03). 56

Figure 4-13: Predictive ability of different mobility estimation methods - Travel Speed (Freeway, PM Peak, Day 01)

Figure 4-14: Predictive ability of different mobility estimation methods - Travel Time (Freeway, PM Peak, Day 01)......

Figure 4-15: Predictive ability of different mobility estimation methods - Travel Speed (Freeway, PM Peak, Day 02).

Figure 4-16: Predictive ability of different mobility estimation methods - Travel Time (Freeway, PM Peak, Day 02)

Figure 4-17: Predictive ability of different mobility estimation methods - Travel Speed (Freeway, PM Peak, Day 03).

Figure 4-18: Predictive ability of different mobility estimation methods - Travel Time (Freeway, PM Peak, Day 03).

Figure 4-19 : Incident impact on predictive ability of different mobility estimation methods (Near 103rd Street)

Figure 4-20: Predictive ability of different mobility estimation methods - Travel Time (Arterial, AM Peak, Capacity 880 VPHPL Used in Volume-Delay Functions)

Figure 4-21: Predictive ability of different mobility estimation methods - Travel Time (Arterial, AM Peak, Capacity 900 VPHPL Used in Volume-Delay Functions)

Figure 4-22: Predictive ability of different mobility estimation methods - Travel Time (Arterial, AM Peak, Capacity 1120 VPHPL Used in Volume-Delay Functions)....

Figure 4-23: Predictive ability of different mobility estimation methods - Travel Time (Arterial, AM Peak, Capacity 1370 VPHPL Used in Volume-Delay Functions)

Figure 4-24: Predictive ability of different mobility estimation methods - Travel Time (Arterial, Mid-Day, Capacity 880 VPHPL Used in Volume-Delay Functions)

Figure 4-25: Predictive ability of different mobility estimation methods - Travel Time (Arterial, Mid-Day, Capacity 900 VPHPL Used in Volume-Delay Functions)..... 76

Figure 4-26: Predictive ability of different mobility estimation methods - Travel Time (Arterial, Mid-Day, Capacity 1120 VPHPL Used in Volume-Delay Functions) ............. 76 
Figure 4-27: Predictive ability of different mobility estimation methods - Travel Time (Arterial, Mid-Day, Capacity 1370 VPHPL Used in Volume-Delay Functions).

Figure 4-28: Predictive ability of different mobility estimation methods - Travel Time (Arterial, PM Peak, Capacity 880 VPHPL Used in Volume-Delay Functions) ............... 82

Figure 4-29: Predictive ability of different mobility estimation methods - Travel Time (Arterial, PM Peak, Capacity 900VPHPL Used in Volume-Delay Functions)

Figure 4-30: Predictive ability of different mobility estimation methods - Travel Time (Arterial, PM Peak, Capacity 1120 VPHPL Used in Volume-Delay Functions).....

Figure 4-31: Predictive ability of different mobility estimation methods - Travel Time (Arterial, PM Peak, Capacity 1370 VPHPL Used in Volume-Delay Functions) ............. 84

Figure 4-32: Reliability Measures on Freeways for AM Peak …………………………... 91

Figure 4-33: Reliability Measures on Freeways for Mid-Day ........................................... 91

Figure 4-34: Reliability Measures on Freeways for PM Peak........................................... 92

Figure 4-35: Reliability Measures on Arterial for AM Peak ............................................. 94

Figure 4-36: Reliability Measures on Arterial for Mid-Day.............................................. 94

Figure 4-37: Reliability Measures on Arterial for PM Peak............................................ 95 


\section{LIST OF ACRONYMS}

\begin{tabular}{|c|c|}
\hline FHWA & Federal Highway Administration \\
\hline FDOT & Florida Department of Transportation \\
\hline FSUTMS & Florida Standard Urban Transportation Model Structure \\
\hline ELToD & Express Lanes Time of Day \\
\hline TCRPM & Treasure Coast Regional Planning Model \\
\hline OUATS & Orlando Urban Area Transportation Study \\
\hline NERPM & North East Regional Planning Model \\
\hline SERPM & South East Regional Planning Model \\
\hline TBRPM & Tampa Bay Regional Planning Mode \\
\hline VDF & Volume Delay Function \\
\hline BPR & Bureau of Public Roads \\
\hline HSM & Highway Safety Manual \\
\hline MAP-21 & Moving Ahead for Progress in the 21st Century \\
\hline LOS & Level of Service \\
\hline MPO & Metropolitan Planning Organization \\
\hline $\mathrm{HCM}$ & Highway Capacity Manual \\
\hline DOT & Departments of Transportation \\
\hline $\mathrm{TPO}$ & Transportation Planning Organization \\
\hline FREEVAL & FREeway EVALuation \\
\hline STREETVAL & STREET EVALuation \\
\hline RITIS & Regional Integrated Transportation Information System \\
\hline MVDS & Microwave Vehicle Detection System \\
\hline
\end{tabular}




$\begin{array}{ll}\text { SHRP2 } & \text { Second Strategic Highway Research Program } \\ \text { HCS } & \text { Highway Capacity Software } \\ \text { TTI } & \text { Travel Time Index } \\ \text { MTTI } & \text { Mean Travel Time Index } \\ \text { NPMRDS } & \text { National Performance Management Research Data Set } \\ \text { TMC } & \text { Traffic Message Channel } \\ \text { LHL } & \text { Lane Hour Lost } \\ \text { NOAA } & \text { National Oceanic and Atmospheric Administration } \\ \text { ME } & \text { Mean Error } \\ \text { MAE } & \text { Mean Absolute Error } \\ \text { MAPE } & \text { Mean Absolute Percentage Error }\end{array}$




\section{Chapter 1 \\ INTRODUCTION}

\subsection{Background}

Transportation agencies are increasingly interested in measuring and estimating system performance and the impact of advanced technologies and strategies on existing and future year transportation system conditions. This interest increased with the MAP-21 (Moving Ahead for Progress in the $21^{\text {st }}$ Century) federal legislation emphasis on establishing performance goals focusing on seven areas: safety, infrastructure conditions, congestion reduction (mobility), system reliability, freight, environmental sustainability, and project delivery time (FHWA, 2012).

There has been significant application, development, and research on estimating mobility and reliability performance measures. The models used in demand forecasting tools, those developed and included in the Highway Capacity Manual (HCM), traffic flow theory-based models, and Second Strategic Highway Research Program (SHRP2) products are some of the examples. However, these models have not been sufficiently incorporated into and integrated with decision support tools for performance estimation that supports decision-making process of transportation agencies. There have been recent limited efforts toward such incorporation and integration, such as the post-processing tool to estimate Level of Service (LOS) interfaced with the North East Regional Planning Model (NFTPO, 2015), and the reliability estimation tool incorporated as part of the Tampa Bay Regional Planning Model (FDOT, 2015). However, current practices are not adequate.

Undoubtedly, there is a need for integrated tools and methods that allow transportation agencies such as metropolitan planning organizations (MPOs) and state 
departments of transportation (DOTs) to estimate performance measures (e.g., mobility, reliability, etc.) that are related to the goals of these agencies. Such methods and tools would be integrated with existing modeling and data collection techniques for better estimation of the impacts of advanced strategies on transportation system performance.

This study intends to focus exclusively on two major performance areas designated by the MAP-21 federal legislation: mobility and reliability. The results of this study will support forecasting system performance and impacts of conventional improvements and advanced strategies on performance by taking advantage of existing data and state-of-art models, methods, and parameters.

\subsection{Research Needs and Problem Statement}

Federal legislation requires states and MPOs to identify performance measures and associated targets to be included in state and MPO plans. For existing conditions, this estimation can be done based on data collected from multiple sources, such as statistics office detectors, traffic management system detectors, incident and crash databases, weather agencies, and other sources of data. For future conditions, there is a need to identify models and methods that can be used to support the estimation of system performance. These models will have to be supported by data from multiple sources to ensure their accuracy in estimating future conditions.

The goal of this study is to support forecasting system performance by taking advantage of state-of-art models, methods, and parameters, as well as the availability of data from multiple sources. The study hypothesizes that transportation agencies need to incorporate mobility and reliability performance measures while assessing transportation 
investment alternatives, and widely accepted and frequently used methods would be useful while measuring mobility and reliability estimates.

\subsection{Research Goal and Objectives}

The goal of this research is to determine the performance measures of mobility and reliability, and to investigate the predictive ability of different traffic flow models with respect to mobility and reliability. The specific objectives are:

1. To investigate the predictive ability of different traffic flow models in the presence of recurrent and non-recurrent congestion; and

2. To investigate the predictive ability of widely-accepted travel time reliability products, tools and methods.

\subsection{Thesis Organization}

This thesis is comprised of five chapters. The contents of the next four chapters are as follows. Chapter 2 presents a comprehensive literature review on the widely accepted estimation approaches for mobility and reliability measures. Chapter 3 describes the detailed study area, data sources, and data preparation efforts undertaken in this thesis. Chapter 3 also provides the general methodology adopted in this study to compare mobility and reliability estimation approaches against the real-world data. Chapter 4 presents the estimation of mobility and reliability measures and discusses the predictive ability of different traffic flow models. The most accurate predictive models for mobility and reliability measures are also discussed in this chapter. Chapter 5 concludes this dissertation 
by summarizing the contributions of this research and providing recommendations for future research. 


\section{Chapter 2 \\ LITERATURE REVIEW}

This chapter provides a comprehensive literature review on mobility and reliability estimation approaches. Section 2.1 focuses on different theories, methods, tools, and approaches associated with mobility estimation. Section 2.2 discusses similar theories, methods, tools, and approaches associated with reliability estimation.

\subsection{Mobility Estimation Approaches}

The first objective of this thesis was to investigate the predictive ability of widelyaccepted mobility estimation methodologies. This section presents a comprehensive review of the most popular and widely accepted mobility estimation approaches.

Mobility refers to the movement of people and goods. Mobility measurement and estimation are usually straightforward in uncongested traffic conditions but can become complicated in congested conditions. However, this is much more difficult in congested conditions, when traffic demand is much higher than the available capacity and/or there is a drop-in capacity due to incident, weather, or construction events.

"Volume" and "Demand" are two important traffic parameters often used as inputs to estimate traffic congestion and are critical to understanding mobility. In an uncongested free-flow traffic condition, these two parameters remain identical. But in a congested traffic condition, volume and demand are distinct, which complicates mobility estimation. By definition, volume represents the number of vehicles that pass a given point on the roadway in a specified period of time, and demand refers to the actual number of vehicles that desire 
to pass the point in that specific time period. When demand becomes higher than capacity, a portion of traffic referred to as "unmet demand" cannot travel through the roadway section due to queuing. Quantifying the unmet demand is always a challenge for traffic engineers and will be considered in this study.

As researchers have used several estimation approaches to estimate mobility in a congested condition, this sub-section is therefore organized according to the analytical methods found in the reviewed literature.

\section{BPR Curve}

As part of the 1965 Highway Capacity Manual (HCM), the Bureau of Public Roads (BPR) developed a relationship between speed and flow commonly referred to as the "BPR curve." The BPR curve has been widely used in travel demand models, including in Florida, as a link capacity-based Volume-Delay Function (VDF). The curve suggests that if volume (or flow) increases relative to the capacity, the speed would decrease (or the travel time would increase). By definition, the BPR curve defines delay as a function of link length instead of number of vehicles in the queue (NCHRP, 1999). Thus, the shorter the coded link with the high volume/capacity $(\mathrm{V} / \mathrm{C})$ ratio, the lower the delay, and no spillback of congestion is projected to upstream links.

In Florida, the BPR curve is widely used in the FSUTMS (Florida Standard Urban Transportation Model Structure) models to produce the congested time (or speed) in a capacity restraint route choice assignment (Arnold, 2015).

Although BPR curves are very popular in static route choice assignment as part of demand forecasting, it is often criticized for underperforming in congested traffic 
conditions where demand exceeds capacity. For instance, the Greater Treasure Coast Regional Planning Model (TCRPM) used the BPR curve to determine average travel speed (FDOT, 2014). Researchers and practitioners often raised questions on this kind of application as there are no situations where V/C is higher than 1.0 in the real world. Queue forms in the real world when demand exceeds capacity, while the passing volume on the congested link does not exceed the queue discharge rate, which is lower than capacity. This impracticality eventually leads researchers and practitioners to investigate other realistic traffic flow models to represent volume delay function, as described in the next section.

Equation 1 shows the expression of the BPR curve to calculate link travel time.

$$
t_{i}=t_{0}\left[1+\alpha\left(\frac{v}{c}\right)^{\beta}\right]
$$

where $t_{i}$ is congested travel time and $t_{0}$ is free-flow travel time for link $i$. $v$ refers to traffic volume on link i and $\mathrm{c}$ is link capacity. $\alpha$ and $\beta$ are the BPR coefficient and the BPR exponential coefficient, respectively, whose values vary with the functional class of links and are usually calibrated for local conditions. This study obtained $\alpha$ and $\beta$ estimates from a well-calibrated regional model (e.g., SERPM), which were 0.32 and 7.00, respectively, for the freeway corridor. The coefficients were different in the arterial corridor, which were 0.55 and 5.05, respectively. 


\section{Akcelik Function}

Akcelik function is another popular volume-delay function. This function was proposed to overcome the conceptual and calibration issues associated with Davidson's function, another previously utilized function that is described in the next section (Akcelik, 1991). The Akcelik function significantly improved the modeling of link travel speed as it has been reported that it can better capture intersection delays. Several studies confirmed the real-world application of the Akcelik function and found that it provided a better fit to the observed speed compared to the BPR functions (Skabardonis and Dowling, 1997, Singh, 1999). The expression for the Akcelik equation is shown in Equation 2.

$$
\begin{aligned}
& \text { Ratio of congested time to free flow time }=\left(\frac{1}{S}+\left(g _ { p b } * g _ { T } * \left(\left(\text { VoC }+g_{\text {Akcellikoffset }}-1\right)+\right.\right.\right. \\
& \left.\left.\left.\qquad\left(\left(\text { VoC }+g_{\text {Akcellikoffest }}-1\right)^{2}+\left(8 * g_{P} *\left(\frac{\text { VoC }+g_{\text {Akcellikoffest }}}{c * g_{T}}\right)\right)\right)^{0.5}\right)\right)\right)
\end{aligned} /\left(\frac{1}{S}\right)
$$

where $\mathrm{S}$ is free-flow speed in $\mathrm{mph} . \mathrm{g}_{\mathrm{pb}}$ and $\mathrm{g}_{\mathrm{pa}}$ are facility specific parameters. $\mathrm{g}_{\mathrm{T}}$ is the length of the time period in hours. $\mathrm{g}_{\text {AkcelikOffset }}$ is an Akcelik offset parameter, which contributes to the shape of the volume delay curve by shifting the base of the curve from a travel time ratio of 1.0. The Akcelik equation has been used in the Express Lanes Time of Day (ELToD) Model, a tool developed by the Florida's Turnpike Enterprise in 2012 to evaluate a tolled corridor at a sketch planning level.

In Florida, the ELToD Model (Express Lanes Time of Day Model) provides the user with the option to select either the BPR curve or Akcelik function as the VDF curve (FDOT, 2016 a). 


\section{Regression Models Developed by Florida State University (FSU)}

In 1978, Davidson developed a typical congestion function, where link travel time is expressed as a function of degree of saturation of the network element, environmental parameter (e.g., road type, design standard, land use, etc.), and absolute link capacity (Davidson, 1978). The Davidson function became very popular as a volume density function (VDF) in the early days of travel demand modeling because of its flexibility and accommodation of a wide range of traffic conditions. However, the function had an inherent weakness as it could not define the travel time in a situation where link volume exceeds link capacity (Taylor, 1997). Due to this limitation, computational problems arise, particularly when link volume is derived in an iterative manner and overload some links to find an intermediate solution. Tisato (1991) proposed a modification of the Davidson function by adding a linear extension term, which is known as a modified Davidson function.

As part of a Florida Department of Transportation (FDOT) research project conducted by Florida State University (FSU), Mtoi and Moses (2014) presented a piecewise modified Davidson volume-delay function, which is referred to in this study as "Regression Models Developed by FSU." First, the researchers, conducted a study to evaluate the predictive accuracy of various traffic models (e.g., Modified BPR, Modified Davidson, Akcelik, and Conical Functions) by testing model parameters against real-world data. The study tested these volume delay functions, which were then calibrated and implemented as part of the FSUTMS OUATS (Orlando Urban Area Transportation Study) modeling environment. The researchers found that only the modified BPR and modified 
Davidson provided a reasonable match between model-estimated counts and real-world counts.

Mtoi and Moses (2014) utilized the general BPR function (Equation 3) in their study and came up with a set of $\alpha$ and $\beta$ estimates by facility and area type, as presented in the Table 2-1. They applied the Akcelik function as a form of Equation 4, where $\mathrm{J}$ is a delay parameter. The estimates of $\mathbf{J}$ by facility and area type are also provided in Table 21. The Conical delay model was utilized, as shown in Equation 5, where $\beta$ corresponds to the exponent $\beta$ of the BPR function. The estimates of $\alpha$ and $\beta$ for the Conical delay model are also presented in Table 2-1. Mtoi and Moses also applied the modified Davidson function, as shown in Equation 6, where $\mathrm{S}$ is speed, $S_{0}$ is free-flow speed, $J_{D}$ is a delay parameter, and $\mu$ is saturation threshold parameter. The estimates of $J_{D}$ and $\mu$ by facility and area type are also presented in Table 2-1.

$$
\begin{aligned}
& U_{v}=\frac{U_{0}}{\left[1+\alpha(v / c)^{\beta}\right]} \\
& U_{v}=\frac{U_{0}}{\left(1+0.25 U_{0}\left[\left(\frac{v}{c}-1\right)+\sqrt{\left(\frac{v}{c}-1\right)^{2}+8 J \frac{\frac{v}{c}}{c T}}\right]\right)} \\
& U_{v}=\frac{U_{0}}{\left[2+\sqrt{\beta^{2}\left(1-\frac{v}{c}\right)^{2}+\alpha^{2}}-\beta\left(1-\frac{v}{c}\right)-\alpha\right]}
\end{aligned}
$$




$$
S= \begin{cases}\frac{S_{0}}{1+\frac{J_{D}\left(\frac{V}{C}\right)}{1-\frac{V}{C}}} & \text { for } \frac{V}{C} \leq \mu \\ \frac{S_{0}}{1+\frac{J_{D} \times \mu}{1-\mu}+\frac{J_{D}\left(\frac{V}{C}-\mu\right)}{(1-\mu)^{2}}} & \text { for } \frac{V}{C}>\mu\end{cases}
$$

Table 2-1: Estimated VDF Parameters (FSU Model)

\begin{tabular}{|c|c|c|c|c|c|c|c|c|}
\hline \multirow[t]{2}{*}{ Facility Type } & \multirow[t]{2}{*}{ Area Type } & \multicolumn{2}{|c|}{ Fitted BPR } & \multicolumn{2}{|c|}{ Conical } & \multicolumn{2}{|c|}{$\begin{array}{l}\text { Modified } \\
\text { Davidson }\end{array}$} & \multirow{2}{*}{$\begin{array}{c}\text { Akcelik } \\
\mathrm{J}\end{array}$} \\
\hline & & $\alpha$ & $\beta$ & $\beta$ & $\alpha$ & $\mathrm{J}$ & $\mu$ & \\
\hline \multirow[t]{3}{*}{ Freeway } & Urban & 0.263 & 6.869 & 18.390 & 1.029 & 0.009 & 0.950 & 0.100 \\
\hline & Residential & 0.286 & 5.091 & 18.390 & 1.029 & 0.009 & 0.949 & 0.101 \\
\hline & Rural & 0.150 & 5.610 & 15.064 & 1.036 & 0.010 & 0.951 & 0.099 \\
\hline \multirow[t]{3}{*}{ Toll Road } & Urban & 0.162 & 6.340 & 18.390 & 1.029 & 0.008 & 0.940 & 0.110 \\
\hline & Residential & 0.250 & 7.900 & 15.064 & 1.036 & 0.010 & 0.952 & 0.098 \\
\hline & Rural & 0.320 & 6.710 & 15.064 & 1.036 & 0.010 & 0.940 & 0.097 \\
\hline \multirow[t]{2}{*}{$\mathrm{HOV} / \mathrm{HOT}$} & Residential & 0.320 & 8.400 & 18.550 & 1.028 & 0.009 & 0.950 & 0.090 \\
\hline & Urban & 0.330 & 8.600 & 18.700 & 1.028 & 0.009 & 0.947 & 0.080 \\
\hline \multirow{2}{*}{$\begin{array}{c}\text { Divided } \\
\text { Arterial - } \\
\text { Signalized, <35 } \\
\text { MPH }\end{array}$} & Residential & 0.215 & 8.135 & 1.029 & 18.390 & 0.008 & 0.945 & 0.105 \\
\hline & Urban & 0.240 & 7.895 & 1.033 & 16.599 & 0.010 & 0.951 & 0.099 \\
\hline \multirow{2}{*}{$\begin{array}{c}\text { Divided } \\
\text { Arterial - } \\
\text { Signalized, } \\
>40 \mathrm{MPH}\end{array}$} & Residential & 0.250 & 8.460 & 1.028 & 18.550 & 0.009 & 0.950 & 0.090 \\
\hline & Urban & 0.260 & 8.650 & 1.028 & 18.700 & 0.009 & 0.947 & 0.080 \\
\hline \multirow{2}{*}{$\begin{array}{c}\text { Undivided } \\
\text { Arterial - } \\
\text { Signalized, }<35 \\
\text { MPH }\end{array}$} & Residential & 0.215 & 8.135 & 1.029 & 18.390 & 0.008 & 0.945 & 0.105 \\
\hline & Urban & 0.240 & 7.895 & 1.033 & 16.599 & 0.010 & 0.951 & 0.099 \\
\hline \multirow{2}{*}{$\begin{array}{l}\text { Undivided } \\
\text { Arterial - } \\
\text { Signalized, } \\
>40 \mathrm{MPH}\end{array}$} & Residential & 0.250 & 8.460 & 1.028 & 18.550 & 0.009 & 0.950 & 0.090 \\
\hline & Urban & 0.260 & 8.650 & 1.028 & 18.700 & 0.009 & 0.947 & 0.080 \\
\hline
\end{tabular}




\section{Queuing Theory}

Queuing occurred when the number of arriving vehicles (e.g., demand flow rate) became greater than the roadway segment capacity within a particular time period. Queuing measures such as queue lengths and associated delays can be estimated using analytical models such as the queuing theory, which is based on the cumulative volume and shockwave theory. When comparing queuing and shock wave analysis, queuing analysis is the more widely used method to identify congestion impacts. A study by Rakha and Zhang (2005) demonstrated the consistency in delay estimates based on queuing theory and shock-wave analyses and pointed out that the queuing theory provides a simple and accurate technique for estimating delay and queues at bottlenecks. Thus, this study will investigate the use of the queuing theory to calculate the delay at locations when the volume exceeds capacity.

The number of vehicles in queue can be estimated using Equation 7.

$$
N_{q i}=V_{a i}-V_{d i}+N_{q(i-1)}
$$

where $\mathrm{N}_{\mathrm{qi}}$ is the number of queued vehicles at the end of period i. $\mathrm{V}_{\mathrm{ai}}$ is the number

of arriving vehicles during period $\mathrm{i}$. $\mathrm{V}_{\mathrm{di}}$ is the roadway segment capacity, and $\mathrm{N}_{\mathrm{q}(\mathrm{i}-1)}$ is the number of vehicles queued at the end of period (i-1). 


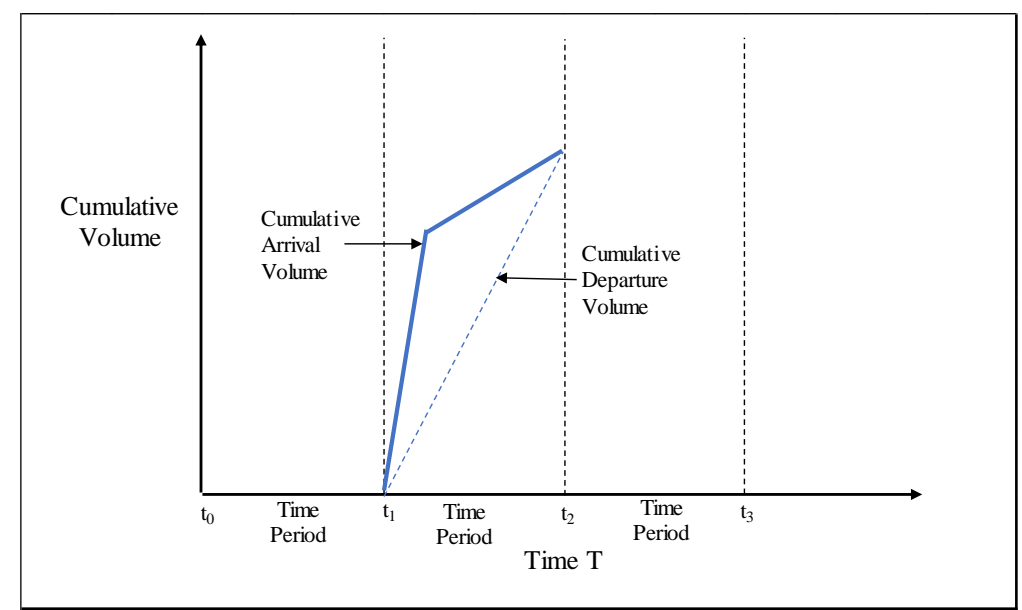

Figure 2-1: Queuing Delay Estimation Approach

To estimate the queuing delay, a study needs to estimate the difference between demand and capacity for each time period (e.g. $t_{0}, t_{1}, t_{2}, t_{3} \ldots$ ), where queue exists, as explained in Figure 2-1. Next, the average vehicle delay for each time period can be identified from the ratio between the area formed by cumulative demand vs. cumulative capacity curve and actual volume for that time period. Finally, the queuing delay can be accounted for to estimate actual travel time (or speed) for each time period (Hadi et al., 2014).

\section{HCM Freeway and Urban Arterial Facility Procedures}

The Highway Capacity Manual (HCM) procedure provides another more detailed method used to estimate mobility measures. The HCM procedure requires the input of traffic flow at the mainline entrance, as well as at on-ramps and off-ramps for freeway mobility measure estimation. For freeways, when the facility is undersaturated, the HCM speed-flow relationship for each type of segment is used to determine the segment speed. For oversaturated traffic conditions, the flow variables are adjusted to reflect the upstream 
and downstream effects of bottleneck with the utilization of shockwave analysis to determine the extent of the queue and spillbacks. In addition to the freeway facility procedure mentioned above, the HCM also includes a detailed signalized arterial facility procedure that involves the modeling of signal control plans, platooning, and spillback effects on arterial traffic operations.

A computational engine is needed to implement the methodology described in the HCM $6^{\text {th }}$ edition. Examples of these tools are the FREEVAL (FREeway EVALuation) tool for freeway facility procedures and the Highway Capacity Software (HCS) for both freeway and arterial facilities (Trask et al., 2015).

\subsection{Reliability Estimation Approaches}

Quantifying reliability is always a challenge, including defining reliability measures (variability of travel time or on-time arrival probability), measuring reliability performance (standard deviation of travel time, buffer index, travel time index, and planning time index), and identifying reliability measurement or estimation approach (different levels of modeling and analysis or based on real-world data).

The products of the second Strategic Highway Research Program (SHRP2) are the largest source of the reliability-related information. The SHRP2 program was created to identify strategic solutions to three national transportation challenges: improving highway safety, reducing congestion, and improving methods for renewing roads and bridges. The

four major focus areas of SHRP2 are safety, renewal, reliability, and capacity. From a traffic operational standpoint, the products of the "Reliability" and "Capacity" focus area 
address the assessment of system operation performance and identify the cause of problems and provide solutions.

Selective SHRP2 products (i.e., L03, L07, and C11) that are aligned with the goals and objectives of this thesis are reviewed and summarized in the following sections.

\section{The SHRP2 L03 Project (Analytical Procedures for Determining the Impacts of Reliability Mitigation Strategies)}

As a foundation study, the product of the SHRP2 L03 Project defines reliability, presents recommended reliability measures derived from travel time distributions, presents the causes of congestion, explains how to build a database for estimating reliability prediction models, conducts before and after studies of operations and capacity improvements, and develops two sets of prediction models based on empirical data from numerous metropolitan areas (Cambridge Systematics et al., 2013). The SHRP2 L03 gathered a year's worth of readily available real-world detector-based travel time data from transportation agencies/private sectors for different regions of the United States. The study adopted a before-after study approach to build the relationship between highway improvements and travel time reliability. The SHRP2 L03 developed two cross-sectional statistical predictive models (data poor model and data rich model) to capture the relationship in the context of highway improvements.

\section{$\underline{\text { Data-Poor Model }}$}

The SHRP2 L03 produced a highly practical set of relationships to predict reliability known as the "data-poor" model. The data-poor model is a simple model that 
can be applied in an environment with limited data for two conditions: if the mean TTI was less than 2 (Equations 8-13), and if the mean TTI was greater than 2 (Equations 1416).

Overall mean TTI $=1.0274 *$ RecurringMeanTTI ${ }^{1.2204}$

95th Percentile TTI $=$ mean TTI ${ }^{1.8834}$

90th Percentile TTI $=$ mean TTI ${ }^{1.6424}$

80th Percentile TTI $=$ mean TTI $^{1.365}$

Median TTI $=$ mean $\mathrm{TTI}^{0.8601}$

10th Percentile TTI $=$ mean $\mathrm{TTI}^{0.1524}$

95th percentile TTI $=1+3.6700 * \ln ($ Mean TTI $)$

90th percentile TTI $=1+2.7809 * \ln ($ Mean TTI $)$

80th percentile TTI $=1+2.1406 * \ln ($ Mean TTI $)$

\section{$\underline{\text { Data-Rich Model }}$}

The L03 Project quantifies the impact of incidents and work zones on reliability with respect to three key variables: a) lane hours lost, b) critical demand-to-capacity ratio, and c) hours of rainfall exceeding 0.05 inch. The relationship is provided below.

50th Precntile TTI $=e^{\left(0.09335 * d c_{c r i t}+0.00932 * L H L\right.}$

80th Precntile TTI $=e^{\left(0.13992 * d c_{c r i t}+0.01118 * L H L+0.01271 * R_{05}\right.}$

95th Precntile TTI $=e^{\left(0.23233 * d c_{c r i t}+0.01222 * L H L+0.01777 * R_{05}\right.}$

Where,

LHL = lane hours lost 
$\mathrm{dc}_{\mathrm{crit}}=$ critical demand-to-capacity ratio

$\mathrm{j}_{\mathrm{n}}, \mathrm{k}_{\mathrm{n}}, 1_{\mathrm{n}}=$ coefficients for $\mathrm{nth}$ percentile

\section{The SHRP 2 LO7 Project (Identification and Evaluation of the Cost-Effectiveness of Highway Design Features to Reduce Non-recurrent Congestion)}

The SHRP 2 L07 is a design guide, consisting of a compendium of design treatments likely to affect non-recurring congestion, plus an Excel-based tool that designers can use to evaluate the effects of such treatments on delay, safety, travel time reliability, and lifecycle benefits and costs (Potts et al., 2014). The SHRP2 L03 developed models for predicting a travel time index (TTI) at five percentiles (10th, 50th, 80th, 95th, and 99th) along the TTI distribution, but only for certain peak periods (e.g., AM Peak, PM Peak). The SHRP2 L07 research team adapted a modification to the SHRP2 L03 data-rich models, as shown in Equation 20, for use during one-hour time-slices, so that the TTI distribution could be predicted for each hour of the day. The coefficients corresponding to Equation 18 are shown in the Table 2-3.

$$
T T I_{n}=\left\{\begin{array}{c}
T T I_{N P, n} * e^{\left(c_{n} R_{05^{\prime \prime}}+d_{n} S_{01^{\prime \prime}}\right)} \quad \text { for } d / c \leq 0.8 \\
\frac{T T I_{N P, n}}{N_{\text {days }}} *\left[N_{N P}+V_{F F}\left(\frac{R_{05^{\prime \prime}}}{c 1_{n} V_{F F}+c 2_{n} T T I_{N P, n}}+\frac{s_{01^{\prime \prime}}}{d 1_{n} V_{F F}+d 2_{n} T T I_{N P, n}}\right)\right] \text { for } d / c>0.8
\end{array}\right.
$$

Where,

$\mathrm{TTI}_{\mathrm{n}}=$ predicted $\mathrm{nth}$ percentile TTI

$\operatorname{TTI}_{\mathrm{NP}, \mathrm{n}}=$ non-precipitation portion of $\operatorname{TTI}_{n}=e^{\left(a_{n} d / c+b_{n} L H L\right)}$

$\mathrm{LHL}=\mathrm{LHL}$ due to incidents and work zones

$\mathrm{d} / \mathrm{c}=$ demand-to-capacity ratio 
$\mathrm{R}_{05^{\prime \prime}}=$ number of hours in time-slice with rain exceeding 0.05 in.

$\mathrm{S}_{01 "}=$ number of hours in time-slice with snow exceeding $0.01 \mathrm{in}$.

$\mathrm{N}_{\text {days }}=$ number of hours in time-slice $(365)$

$\mathrm{N}_{\mathrm{NP}}=$ number of hours in time-slice with no precipitation

$\mathrm{V}_{\mathrm{FF}}=$ free-flow travel time on segment $(\mathrm{mph})$

$a_{n}, b_{n}=n t h$ percentile coefficients for non-precipitation components (d/c and LHL)

$c_{n}, d_{n}=n t h$ percentile coefficients for rain and snow components $(d / c<0.8)$

$\mathrm{c} 1_{\mathrm{n}}, \mathrm{c} 2_{\mathrm{n}}=\mathrm{nth}$ percentile coefficients for rain component $(\mathrm{d} / \mathrm{c}>0.8)$

$\mathrm{d} 1_{\mathrm{n}}, \mathrm{d} 2_{\mathrm{n}}=$ nth percentile coefficients for snow component $(\mathrm{d} / \mathrm{c}>0.8)$

Table 2-2: Default co-efficient for L07 data-rich model

\begin{tabular}{|c|c|c|c|c|c|c|c|c|c|c|}
\hline & \multicolumn{4}{|c|}{$\mathbf{d} / \mathbf{c}<\mathbf{0 . 8}$} & \multicolumn{6}{c|}{$\mathbf{d} / \mathbf{c}>\mathbf{0 . 8}$} \\
\hline $\begin{array}{c}\mathbf{N} \\
\text { percentile) }\end{array}$ & $\mathbf{a}_{\mathbf{n}}$ & $\mathbf{b}_{\mathbf{n}}$ & $\mathbf{c}_{\mathbf{n}}$ & $\mathbf{d}_{\mathbf{n}}$ & $\mathbf{a}_{\mathbf{n}}$ & $\mathbf{b}_{\mathbf{n}}$ & $\mathbf{c 1}_{\mathbf{n}}$ & $\mathbf{c 2}_{\mathbf{n}}$ & $\mathbf{d 1}_{\mathbf{n}}$ & $\mathbf{d} \mathbf{2}_{\mathbf{n}}$ \\
\hline 10 & 0.014 & 0.00099 & 0.00015 & 0.00037 & 0.07643 & 0.00405 & 1.364 & -28.34 & 0.178 & 15.55 \\
\hline 50 & 0.07 & 0.00495 & 0.00075 & 0.00184 & 0.29097 & 0.0138 & 0.966 & -6.74 & 0.345 & 3.27 \\
\hline 80 & 0.11214 & 0.00793 & 0.0012 & 0.0031 & 0.52013 & 0.01544 & 0.63 & 6.89 & 0.233 & 5.24 \\
\hline 95 & 0.19763 & 0.01557 & 0.00197 & 0.01056 & 0.63071 & 0.01219 & 0.639 & 5.04 & 0.286 & 1.67 \\
\hline 99 & 0.47282 & 0.0417 & 0.003 & 0.02293 & 1.13062 & 0.01242 & 0.607 & 5.27 & 0.341 & -0.55 \\
\hline
\end{tabular}

Hadi et. al. (2015) conducted a pilot study where the SHRP2 L07 TTI model did not produce a good estimation. Therefore, they derived the following TTI model (Equation 21) based on local conditions. The coefficients corresponding to Equation 21 are shown in the Table 2-4.

$$
T T I=e^{b 1 * d c+b 2 * L H L+b 3 * R a i n+b 4 * L e n g t h+b 5}+b 6
$$


Table 2-3: Calibrated co-efficient for data-rich model

\begin{tabular}{|c|c|c|c|c|c|c|c|}
\hline Percentile & $\boldsymbol{R 2}$ & $\boldsymbol{b 1}$ & $\boldsymbol{b 2}$ & $\boldsymbol{b 3}$ & $\boldsymbol{b 4}$ & $\boldsymbol{b 5}$ & $\boldsymbol{b 6}$ \\
\hline 10 & 0.581 & 0.5 & 0 & 0.013 & -0.075 & -1.555 & 0.749 \\
\hline 50 & 0.864 & 17.445 & 0 & 0 & -2.457 & -15.568 & 1.071 \\
\hline 80 & 0.825 & 14.865 & 0 & 0 & -0.658 & -13.912 & 1.072 \\
\hline 95 & 0.827 & 10.477 & 0.029 & 0 & -0.832 & -9.139 & 1.105 \\
\hline 99 & 0.814 & 5.481 & 0.049 & 0 & -0.894 & -3.758 & 1.105 \\
\hline Mean & 0.884 & 14.02 & 0 & 0 & -0.619 & -13.470 & 1.058 \\
\hline
\end{tabular}

The SHRP2 C11 (Development of Improved Economic Analysis Tools Based on Recommendations from Project C03 (2))

The SHRP2 C11 aimed to improve the state of the practice in assessing the wider economic benefits of transportation capacity projects. Three classes of project benefits were addressed in the $\mathrm{C} 11$ Project; a) travel time reliability benefits, b) intermodal connectivity benefits, and c) market access benefits (Economic Development Research Group (ERD Group) et al., 2013). It should be noted that SHRP2 C11 is a modification of the L03 data-poor model. However, the inferences of these two products (e.g., L03 and C11) are completely different.

The travel time reliability benefits were estimated in the SHRP2 C11 using the following steps:

Step 01: Free Flow Speed Estimation

For freeways and rural two-lane highways,

$$
\text { Free Flow Speed }=(0.88 * \text { Speed Limit })+14
$$

For signalized highways,

$$
\text { Free Flow Speed }=(0.79 * \text { Speed Limit })+12
$$


Step 02: Travel Time per Unit Distance (Travel Rate) for the Current and Forecast Years

$$
\left.t=\left\{\left(1+\left(0.1225 *(v / c)^{8}\right)\right)\right)\right\} / \text { Free Flow Speed, }, \text { for } v / c \leq 1.40
$$

where

$\mathrm{t}=$ travel rate (hours per mile);

$\mathrm{v}=$ hourly volume; and

$\mathrm{c}=$ capacity

Step 03: Delay Due to Incidents (Incident Delay Rate) in Hours per Mile

$$
D_{a}-D_{u} *\left(1-R_{f}\right) *\left(1-R_{d}\right)^{2}
$$

where

$D_{a}=$ Adjusted delay (hours of delay per mile);

$D_{u}=$ Unadjusted (base) delay (hours of delay per mile,

from the incident rate tables);

$R_{\mathrm{f}}=$ Reduction in incident frequency expressed as a fraction (with $R_{\mathrm{f}}=0$ meaning no reduction, and $\mathrm{R}_{\mathrm{f}}=0.30$ meaning a $30 \%$ reduction in incident frequency)

$R_{d}=$ Reduction in incident duration expressed as a fraction (with $R_{d}=0$ meaning no reduction, and $R_{d}=0.30$ meaning a $30 \%$ reduction in incident duration)

Step 04: Compute the Overall Mean Travel Time Index $\left(T T I_{m}\right)$

$$
\begin{aligned}
& \operatorname{TTI}_{m}=1+F F S *(\text { Recurring Delay Rate }+ \text { Incident Delay Rate }) \\
& \operatorname{TTI}_{95}=1+3.6700 * \ln \left(T T I_{m}\right) \\
& \operatorname{TTI}_{50}=4.01224 /\left\{\left(1+e^{\left(1.7417-0.93677 * T T I_{m}\right)}\right)^{(1 / 0.82741)}\right\}
\end{aligned}
$$




$$
\operatorname{TTI}_{80}=5.3746 /\left\{\left(1+e^{\left(-1.5782-0.85867 * T T I_{m}\right)}\right)^{(1 / 0.04953)}\right\}
$$

The SHRP2 C11 Project reliability models predict reliability measures as a function of the mean travel time index (MTTI) for a segment. A SHRP2 C11 Post-Processor tool was developed under a Florida Department of Transportation (FDOT) contract, in conjunction with the Hillsborough County MPO in Tampa, Florida (FDOT, 2016 b). To develop reliability prediction equations for Florida, the C11 Post-Processor tool mentioned above obtained travel data for the Tampa region from the National Performance Management Research Data Set (NPMRDS) for 2014 and 2015. In the analysis, the segments were defined based on the Traffic Message Channels (TMCs) location referencing scheme, which is the basic geographic reporting unit (link) in the NPMRDS data.

The following equations were derived for the travel time index (TTI) for freeways:

$$
\begin{aligned}
\operatorname{TTI}_{50} & =10.4910-9.5867 \times e^{\left(-0.0142 \times X^{2.2367)}\right.} \text { for } X>1.07 \\
& =0.963 X+0.037 \text { otherwise } \\
\operatorname{TTI}_{80} & =7.3567-6.9965 \times e^{\left(-0.0910 \times X^{2.0185)}\right.} \text { for } X>1.03 \\
& =1.0 \text { otherwise } \\
\operatorname{TTI}_{95} & =11.7933-16.2178 \times e^{\left(-0.3855 \times X^{1.0336)}\right.} \text { for } X>1.08 \\
& =1.3737 X-0.3737 \text { otherwise }
\end{aligned}
$$

where

$\mathrm{X}=$ Mean Travel Time Index (TTI)

$\mathrm{TTI}_{50}=50$ th percentile TTI 
$\mathrm{TTI}_{80}=80$ th percentile TTI

TTI $_{95}=95$ th percentile TTI

The following equations were used to derive the travel time index (TTI) for signalized arterials:

$$
\begin{aligned}
\operatorname{TTI}_{50} & =\frac{0.9333 \times 101.7049+12.887 \times X^{2.403}}{101.7049+X^{2.403}} \text { for } X<1.07 \\
& =X \text { otherwise } \\
\operatorname{TTI}_{80} & =\frac{0.7266 \times 26.26+9.6702 \times X^{2.5698}}{26.26+X^{2.5698}} \\
\operatorname{TTI}_{95} & =21.1669 \times e^{-\frac{2.9506}{X}}
\end{aligned}
$$

The following steps were used to calculate the mean travel time index (MTTI):

Step 01: Assign Free Flow Speed (FFS)

$=60$ when HWY_TYPE $=$ 'Freeway'

$=45$ when HWY_TYPE $=$ 'Arterial'

$=35$ when HWY_TYPE $=$ 'Collector'

$=30$ when HWY_TYPE $=$ 'Other'

Step 02: Calculate the Recurring Delay Rate (hours per vehicle-mile)

Recurring Delay Rate $=(1 /$ Speed $)-(1 /$ FFS $)$

Step 03: Calculate the Base Incident-Related Delay Rate (hours per vehicle-mile)

Number of lanes $<=2$ :

$$
\mathrm{Du}=-0.0111 /\left(1-1471 * \exp ^{(-6.8498 * \mathrm{v} / \mathrm{c})}\right)
$$


Number of lanes $=3$ :

$$
\mathrm{Du}=-0.0085 /\left(1-1872 * \exp ^{(-7.1381 * \mathrm{v} / \mathrm{c})}\right)
$$

Number of lanes $>=4$ :

$$
\mathrm{Du}=-0.0068 /\left(1-1827 * \exp ^{(-7.1090 * \mathrm{v} / \mathrm{c})}\right)
$$

Where,

$\mathrm{Du}=$ Base incident delay rate

v/c = volume-to-capacity ratio

\section{Step 04: Calculate the Mean Travel Time Index (MTTI)}

$$
\text { MTTI }=1+(\text { FFS * }(\text { Recurring Delay Rate }+ \text { Du }))
$$

Table 2-5 below provides a summary of the travel time reliability estimation methodology, in relation to reliability definition, reliability measures, recommendations of reliability measures, and reliability measurement approach based on the following SHRP 2 Projects:

- L02

- L03

- L04

- L05
- L08

- L11

- $\mathrm{C} 04$

- $\mathrm{C} 05$ 
Table 2-4: Travel Time Reliability Estimation Methodology in SHRP 2 Projects

\begin{tabular}{|c|c|c|c|c|}
\hline $\begin{array}{l}\text { SHRP } 2 \\
\text { Product }\end{array}$ & Reliability Definition & Reliability Measures & $\begin{array}{c}\text { Recommendations } \\
\text { on Reliability } \\
\text { Measures }\end{array}$ & Reliability Measurement Approach \\
\hline $\begin{array}{l}\text { L02 } \\
\text { (Establishing } \\
\text { Monitoring } \\
\text { Programs for } \\
\text { Travel Time } \\
\text { Reliability) }\end{array}$ & $\begin{array}{l}\text { Reliability is } \\
\text { expressed as the } \\
\text { probability density } \\
\text { functions (PDF)/ } \\
\text { cumulative density } \\
\text { functions (CDF) } \\
\text { to portray the } \\
\text { variation in travel } \\
\text { time. }\end{array}$ & $\begin{array}{l}\text { PDF and CDF of travel } \\
\text { time rate (in } \\
\text { second/mile) was used } \\
\text { as a primary reliability } \\
\text { measure. } \\
\text { Semi-variance was also } \\
\text { used as a secondary } \\
\text { measure to determine } \\
\text { the unreliability } \\
\text { contribution factor (e.g., } \\
\text { high demand, bad } \\
\text { weather, and incidents). }\end{array}$ & $\begin{array}{l}\text { For any } \\
\text { facility/trip, } \\
\text { L02 recommends } \\
\text { deriving the } \\
\text { reliability measure } \\
\text { from the } \\
\text { distribution of } \\
\text { travel time. }\end{array}$ & $\begin{array}{l}\text { Four types of raw travel time } \\
\text { information (single loop, double } \\
\text { loop, automated vehicle } \\
\text { identification, automated vehicle } \\
\text { location) were analyzed by Monte } \\
\text { Carlo Simulation and Queuing } \\
\text { Analysis to obtain travel time } \\
\text { distributions. To obtain reliability, a } \\
\text { comparison was made between actual } \\
\text { percentile travel time for a given } \\
\text { route and the travel time obtained by } \\
\text { summing the individual segment } \\
\text { travel times for the same percentile. }\end{array}$ \\
\hline
\end{tabular}




\begin{tabular}{|c|c|c|c|c|}
\hline $\begin{array}{l}\text { SHRP } 2 \\
\text { Product }\end{array}$ & Reliability Definition & Reliability Measures & $\begin{array}{c}\text { Recommendations } \\
\text { on Reliability } \\
\text { Measures }\end{array}$ & Reliability Measurement Approach \\
\hline $\begin{array}{l}\text { L03 } \\
\text { (Analytical } \\
\text { Procedures for } \\
\text { Determining } \\
\text { the } \\
\text { Impacts of } \\
\text { Reliability } \\
\text { Mitigation } \\
\text { Strategies) }\end{array}$ & $\begin{array}{l}\text { Two major } \\
\text { perspectives were } \\
\text { considered while } \\
\text { defining Reliability: } \\
\text { i) Variability } \\
\text { Perspectives } \\
\text { (deviation from } \\
\text { average travel time) } \\
\text { ii) Failure } \\
\text { Perspectives (being } \\
\text { on time) }\end{array}$ & $\begin{array}{l}\text { Six measures were } \\
\text { considered: } \\
\text { i) Buffer Index } \\
\text { ii) On-time } \\
\text { Performance } \\
\text { iii) 95th Percentile PTI } \\
\text { iv) 80th Percentile TTI } \\
\text { v) Skew Statistics } \\
\text { Index } \\
\text { vi) Misery Index }\end{array}$ & $\begin{array}{l}\text { In the context of } \\
\text { highway } \\
\text { improvement: } \\
\text { The 80th } \\
\text { Percentile TTI is } \\
\text { more appropriate } \\
\text { for investigating } \\
\text { the reliability } \\
\text { impacts, while the } \\
\text { 95th Percentile PTI } \\
\text { is too sensitive } \\
\text { (not } \\
\text { recommended). }\end{array}$ & $\begin{array}{l}\text { A year's worth of readily available } \\
\text { real-world detector-based travel time } \\
\text { data were gathered from } \\
\text { transportation agencies/private } \\
\text { sectors for different regions of the } \\
\text { USA. The before-after study } \\
\text { approach was adopted to build the } \\
\text { relationship between highway } \\
\text { improvements and travel time } \\
\text { reliability. Two cross-sectional } \\
\text { statistical predictive models were } \\
\text { developed to capture the relationship } \\
\text { in the context of highway } \\
\text { improvements. }\end{array}$ \\
\hline
\end{tabular}




\begin{tabular}{|c|c|c|c|c|}
\hline $\begin{array}{l}\text { SHRP } 2 \\
\text { Product }\end{array}$ & Reliability Definition & Reliability Measures & $\begin{array}{c}\text { Recommendations } \\
\text { on Reliability } \\
\text { Measures }\end{array}$ & Reliability Measurement Approach \\
\hline $\begin{array}{l}\text { L04 } \\
\text { (Incorporating } \\
\text { Reliability } \\
\text { Performance } \\
\text { Measures in } \\
\text { Operations } \\
\text { and Planning } \\
\text { Modeling } \\
\text { Tools) }\end{array}$ & $\begin{array}{l}\text { Reliability is defined } \\
\text { as a variation in } \\
\text { experienced travel } \\
\text { times for a given } \\
\text { facility with the } \\
\text { ability to distinguish } \\
\text { between systematic } \\
\text { and random } \\
\text { variability. }\end{array}$ & $\begin{array}{l}\text { A framework was } \\
\text { proposed to address } \\
\text { reliability in } \\
\text { microsimulation and } \\
\text { mesosimulation models. } \\
\text { The framework has } 3 \\
\text { components (Scenario } \\
\text { manager, reliability- } \\
\text { integrated simulation } \\
\text { model, and vehicle } \\
\text { trajectory processor) to } \\
\text { portray reliability in a } \\
\text { network. }\end{array}$ & $\begin{array}{l}\text { Reliability } \\
\text { measures are } \\
\text { usually derived } \\
\text { from travel time } \\
\text { distribution, which } \\
\text { is heavily } \\
\text { dependent on } \\
\text { supply and demand } \\
\text { factors. Therefore, } \\
\text { travel time } \\
\text { reliability must be } \\
\text { characterized in } \\
\text { the context of } \\
\text { travel demand } \\
\text { models. }\end{array}$ & $\begin{array}{l}\text { Simulation-based derived data were } \\
\text { utilized in this study to obtain travel } \\
\text { time distribution: } \\
\text { - The Scenario Manager } \\
\text { component can generate } \\
\text { hypothetical scenarios, as well as } \\
\text { actual scenarios, and enables the } \\
\text { execution of experimental designs } \\
\text { that entail simulation over } \\
\text { multiple days, thus reflecting } \\
\text { daily fluctuations in demand, both } \\
\text { systematic and random. } \\
\text { The simulation models produce } \\
\text { individual vehicle trajectories. } \\
\text { The vehicle trajectory processor } \\
\text { produces the scenario-specific } \\
\text { travel time distribution from each } \\
\text { simulation run. }\end{array}$ \\
\hline
\end{tabular}




\begin{tabular}{|c|c|c|c|c|}
\hline $\begin{array}{l}\text { SHRP } 2 \\
\text { Product }\end{array}$ & Reliability Definition & Reliability Measures & $\begin{array}{c}\text { Recommendations } \\
\text { on Reliability } \\
\text { Measures }\end{array}$ & Reliability Measurement Approach \\
\hline $\begin{array}{l}\text { L05 } \\
\text { (Incorporating } \\
\text { Reliability } \\
\text { Performance } \\
\text { Measures into } \\
\text { the } \\
\text { Transportation } \\
\text { Planning and } \\
\text { Programming } \\
\text { Process) }\end{array}$ & $\begin{array}{l}\text { Reliability is defined } \\
\text { as the variability of } \\
\text { travel time. }\end{array}$ & $\begin{array}{l}\text { Several travel time } \\
\text { distribution-based } \\
\text { measures were } \\
\text { mentioned in the study: } \\
\text { i) Planning Time Index } \\
\text { ii) Buffer Time Index } \\
\text { iii) Standard Deviation } \\
\text { iv) Semi-Standard } \\
\text { v) Failure Measure } \\
\text { vi) Misery Index }\end{array}$ & $\begin{array}{l}\text { L05 emphasized } \\
\text { the estimation of } \\
\text { multiple reliability } \\
\text { performance } \\
\text { measures as } \\
\text { different measures } \\
\text { capture different } \\
\text { aspects of the } \\
\text { travel time } \\
\text { distribution. }\end{array}$ & $\begin{array}{l}\text { This study did not estimate specific } \\
\text { reliability measures. Rather, the study } \\
\text { provided a guideline for agencies to } \\
\text { address fluctuations in travel time } \\
\text { resulting from systematic and } \\
\text { stochastic events and incorporated } \\
\text { into planning and programming. }\end{array}$ \\
\hline
\end{tabular}




\begin{tabular}{|c|c|c|c|c|}
\hline $\begin{array}{l}\text { SHRP } 2 \\
\text { Product }\end{array}$ & Reliability Definition & Reliability Measures & $\begin{array}{l}\text { Recommendations } \\
\text { on Reliability } \\
\text { Measures }\end{array}$ & Reliability Measurement Approach \\
\hline $\begin{array}{l}\text { L08 } \\
\text { (Incorporating } \\
\text { Travel Time } \\
\text { Reliability } \\
\text { into the } \\
\text { Highway } \\
\text { Capacity } \\
\text { Manual) }\end{array}$ & $\begin{array}{l}\text { Similar to L03, } \\
\text { reliability is defined } \\
\text { by information from } \\
\text { both variability } \\
\text { perspectives and } \\
\text { failure perspectives. }\end{array}$ & $\begin{array}{l}\text { Several reliability } \\
\text { measures were used: } \\
\text { i) Standard statistical } \\
\text { measures (e.g., standard } \\
\text { deviation, kurtosis) } \\
\text { ii) Percentile-based } \\
\text { measures (e.g., 80th and } \\
\text { 95th percentile travel } \\
\text { times, buffer } \\
\text { index) } \\
\text { iii) On-time measures } \\
\text { (e.g., percentage of trips } \\
\text { completed within a } \\
\text { travel time threshold) } \\
\text { iv) Failure measures } \\
\text { (e.g., percentage of trips } \\
\text { that exceed a travel time } \\
\text { threshold) }\end{array}$ & $\begin{array}{l}\text { According to L08, } \\
\text { a specific } \\
\text { reliability measure } \\
\text { cannot be } \\
\text { recommended for } \\
\text { use in all cases. A } \\
\text { reliability measure } \\
\text { may work } \\
\text { appropriately for a } \\
\text { context, but not for } \\
\text { another project } \\
\text { where other } \\
\text { measures are better } \\
\text { suited. Therefore, } \\
\text { depending on the } \\
\text { specific } \\
\text { application, } \\
\text { reliability } \\
\text { measures need to } \\
\text { be carefully } \\
\text { selected. }\end{array}$ & $\begin{array}{l}\text { Two distinct scenario generators } \\
\text { (freeway and urban street) utilized } \\
\text { simulation-based derived data in L08 } \\
\text { to incorporate travel time reliability } \\
\text { into the Highway Capacity Manual. }\end{array}$ \\
\hline
\end{tabular}




\begin{tabular}{|c|c|c|c|c|}
\hline $\begin{array}{l}\text { SHRP } 2 \\
\text { Product }\end{array}$ & Reliability Definition & Reliability Measures & $\begin{array}{c}\text { Recommendations } \\
\text { on Reliability } \\
\text { Measures }\end{array}$ & Reliability Measurement Approach \\
\hline $\begin{array}{l}\text { L11 } \\
\text { (Evaluating } \\
\text { Alternative } \\
\text { Operations } \\
\text { Strategies to } \\
\text { Improve } \\
\text { Travel Time } \\
\text { Reliability) }\end{array}$ & $\begin{array}{l}\text { Defined reliability as } \\
\text { the variation in travel } \\
\text { time for the same trip } \\
\text { from day to day. }\end{array}$ & $\begin{array}{l}\text { L11 mentioned the } \\
\text { following items as the } \\
\text { primary reliability } \\
\text { measures: } \\
\text { i) 95th Percentile Travel } \\
\text { Time (Planning Time) } \\
\text { ii) Buffer Index } \\
\text { iii) Planning Time Index }\end{array}$ & $\begin{array}{l}\text { L11 recommends } \\
\text { estimation of } \\
\text { reliability measures } \\
\text { from a travel time } \\
\text { distribution, where } \\
\text { travel time data is } \\
\text { collected from an } \\
\text { extended period of } \\
\text { time (at least } 6 \\
\text { months). }\end{array}$ & $\begin{array}{l}\text { No reliability measures were } \\
\text { estimated in this study. L11 } \\
\text { examines the cost-effectiveness of } \\
\text { different approaches to improve } \\
\text { travel time reliability. Three } \\
\text { alternative scenarios (optimistic, } \\
\text { mediocre, and pessimistic) were } \\
\text { analyzed to capture the influence of } \\
\text { climate change, economic growth, } \\
\text { energy price, technological } \\
\text { advancements, and demographics on } \\
\text { travel time reliability. }\end{array}$ \\
\hline $\begin{array}{l}\text { C04 } \\
\text { (Improving } \\
\text { Our } \\
\text { Understanding } \\
\text { of How } \\
\text { Highway } \\
\text { Congestion } \\
\text { and Pricing } \\
\text { Affect Travel } \\
\text { Demand) }\end{array}$ & $\begin{array}{l}\text { Defined reliability as } \\
\text { the level of } \\
\text { uncertainty with } \\
\text { respect to the travel } \\
\text { time and congestion } \\
\text { levels. }\end{array}$ & $\begin{array}{l}\text { Standard deviation of } \\
\text { travel time was used as } \\
\text { the primary reliability } \\
\text { measure. }\end{array}$ & $\begin{array}{l}\text { Similar to L04, this } \\
\text { study also } \\
\text { emphasized that } \\
\text { reliability measure } \\
\text { must be included in } \\
\text { the travel demand } \\
\text { models. }\end{array}$ & \\
\hline
\end{tabular}




\begin{tabular}{|c|c|c|c|c|}
\hline $\begin{array}{l}\text { SHRP } 2 \\
\text { Product }\end{array}$ & Reliability Definition & Reliability Measures & $\begin{array}{l}\text { Recommendations } \\
\text { on Reliability } \\
\text { Measures }\end{array}$ & Reliability Measurement Approach \\
\hline $\begin{array}{l}\text { C05 } \\
\text { (Understanding } \\
\text { the } \\
\text { Contributions } \\
\text { of Operations, } \\
\text { Technology, } \\
\text { and Design to } \\
\text { Meeting } \\
\text { Highway } \\
\text { Capacity } \\
\text { Needs) }\end{array}$ & $\begin{array}{l}\text { Defined reliability as } \\
\text { follows: } \\
\text { The reliability of the } \\
\text { performance is } \\
\text { represented by the } \\
\text { variability that occurs } \\
\text { across multiple days. }\end{array}$ & $\begin{array}{l}\text { The following reliability } \\
\text { measures were } \\
\text { considered as a Measure } \\
\text { of Effectiveness (MOE): } \\
\text { i) Mean Travel Time } \\
\text { ii) 95th Percentile } \\
\text { Travel Time } \\
\text { iii) Travel Time Index } \\
\text { iv) Buffer Index }\end{array}$ & $\begin{array}{l}\text { C05 emphasized } \\
\text { the inclusion of } \\
\text { reliability } \\
\text { measures in a cost- } \\
\text { benefit analysis of } \\
\text { potential strategies } \\
\text { and showed a } \\
\text { method to include } \\
\text { reliability } \\
\text { measures in a } \\
\text { Dynamic Traffic } \\
\text { Assignment } \\
\text { (DTA). }\end{array}$ & \\
\hline
\end{tabular}




\subsection{Summary}

This chapter presented a literature review on mobility and reliability estimation approaches, i.e., the measures and methods to quantify mobility and reliability.

Mobility is a relatively mature concept in the traffic engineering field. Therefore, many mobility measure methods are already available and widely accepted among practitioners and researchers. However, each method has their inherent weakness, particularly when they are applied and compared with the real-world data. For instance, BPR curves are very popular in route choice assignment, but it is often criticized for underperforming in congested traffic conditions where demand exceeds capacity. The Davidson function is another example, which was very popular as a volume density function (VDF) in the early days of travel demand modeling because of its flexibility and accommodation of a wide range of traffic conditions. However, the function had an inherent weakness as it could not define the travel time in a situation where link volume exceeds link capacity. Rahmi Akcelik proposed a function to overcome the conceptual and calibration issues associated with the Davidson function (Akcelik, 1991). Mtoi and Moses also came up with another modification and developed a piecewise modified Davidson volume-delay function that was able to provide a reasonable match between model estimated counts and real-world counts (Mtoi and Moses, 2014).

In contrast, reliability is a novel concept to transportation agencies. Historically, only travel time benefits were accounted for while assessing highway improvement projects. Upon understanding the importance of precisely estimated reliability measures, the SHRP2 program was initiated to identify strategic solutions to major national transportation challenges, where 'Reliability' became one of the four major focus areas. 
Subsequently, several SHRP2 reliability products were developed. Among the SHRP2 reliability products, the study selected L03, L07, and C11 to investigate the applicability of these methods with real-world data. In addition, this study also summarized reliability definition, reliability measures, and reliability measurement approaches for selected SHRP2 products. 


\section{Chapter 3 \\ DATA PREPARATION AND METHODOLOGY}

Traffic characteristics on freeways and arterials are influenced by different sets of factors. For instance, the volume/capacity ratio plays a vital role in measuring mobility and reliability on freeways, whereas traffic signal timing is crucial for measuring mobility and reliability on arterials. Therefore, mobility and reliability estimation techniques need to be applied distinctively by facilities (e.g., freeways or arterials) to consider their governing factors.

Even on a similar type of facility, data preparation and application are different for mobility and reliability estimation and measurement. For instance, traffic indents and weather events are extremely important parameters used to estimate reliability measures and need to be included in the dataset, whereas incidents and weather events are considered outliers, and depending on the purpose, are sometimes excluded from the dataset used for mobility estimation.

The following sections elaborate on the data-related efforts that were undertaken for this research.

- Study area (freeway and arterials),

- data sources (freeway and arterials), and

- data preparation for volume, speed, weather condition, traffic incident, traffic signal timing, and roadway capacity. 


\subsection{Study Area}

This study applied mobility and reliability estimation techniques on freeways and arterials. The following corridors were selected as case studies for freeways and urban arterials, respectively.

- I-95 NB between NW $32^{\text {nd }}$ Street and NW $103^{\text {rd }}$ Street

- Sunrise Boulevard between US 441 and US 1

\subsubsection{Freeway Study Area}

A 4.73-mile (24977 ft) long freeway roadway segment along I-95 northbound (NB) was selected for use as a freeway case study. This segment includes six microwave point detection stations, starting from NW $32^{\text {nd }}$ Street to NW $103^{\text {rd }}$ Street. Prior studies suggest that the NW $103^{\text {rd }}$ Street on-ramp merge is a bottleneck to I-95 NB traffic. For that reason, this study picked NW $103^{\text {rd }}$ Street as the congested location. The study corridor was selected such that the detector on the other end remains uncongested during the study period. The detectors were considered uncongested, if the detected traffic speed on a detector is greater than $40 \mathrm{mph}$.

The figure below shows the detector number (green color) and the distance covered by each detector. As shown in the figure, detector No. 2876 is located near NW 103rd Street, and detector No. 3016 is located near NW 32nd Street. The traffic flow direction is from NW 32nd Street (e.g., detector no. 3016) to NW 103rd Street (e.g., detector no. 2876). 


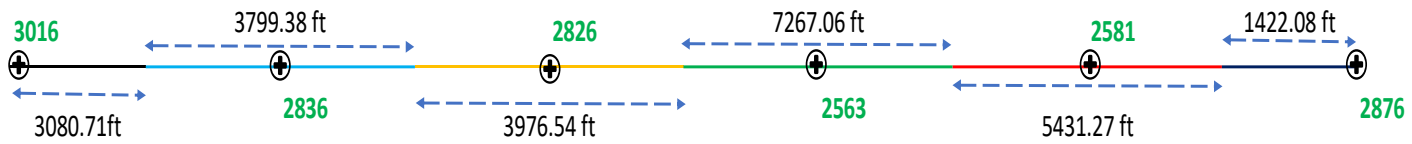

Figure 3-1: Detector location and coverage along the I-95 NB (Freeway Corridor)

\subsubsection{Arterial Study Area}

Sunrise Boulevard from US 441 up to US 1 in the East-Bound (EB) corridor was selected as the arterial case study. The length of this segment is around 5.3 miles and includes seven detection stations that provide volume and speed measurements.

Figure 3-2 shows the detector number (green color) and the distance covered by each detector. As shown in the figure, detector No. 9 is located near US 441, and detector No. 15 is located near US 1. The traffic flow direction is Eastbound (EB), from US 441 to US 1 .

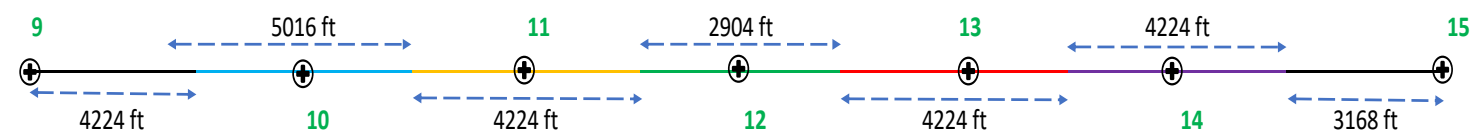

Figure 3-2: Detector location and coverage along Sunrise Blvd EB (Arterial Corridor)

\subsection{Data Sources}

A series of data from a variety of sources was required for this study. Some of the data had to be processed in this study, while other data were already processed as obtained. 


\subsubsection{Freeway Data}

Three important freeway parameters were required for this study to estimate mobility and reliability measures, as follows:

- Traffic Parameters (Volume and Speed Data),

- Weather Data, and

- Incident Data.

Volume data was needed for this study to measure demand, while speed data was required to estimate travel time. This study gathered volume and speed data from the RITIS (Regional Integrated Transportation Information System) website.

Weather data (e.g., rainfall intensity) was used in this study to estimate reliability, as per the requirement of SHRP2 L03 data-rich environment and L07 models. The rainfall intensity information was collected from NOAA (National Oceanic and Atmospheric Administration) to obtain the number of hours during the time slice exceeding 0.05 in rainfall.

This study also utilized incident data to estimate reliability. Detail incident data were collected from FDOT District Six to calculate the number of incidents during a time slice, average number of lane blockages per incident and average duration of each incident. Eventually, these incident data were used to estimate lane hours lost (LHL), which is an input parameter that measures reliability in the SHRP2 L03 data-rich model and the SHRP2 L07 model. 


\subsubsection{Arterial Data}

To estimate mobility and reliability measures, the following traffic measurements were obtained in this study:

- Volume and Speed Data

- Traffic Signal Timing Data

- Incident Data

Similar to the freeway facility, volume data was needed on the arterial facility to measure demand, and speed data was required to estimate travel time. This study gathered volume and speed data from the RITIS (Regional Integrated Transportation Information System) website. The volume data was collected using Microwave Vehicle Detection System (MVDS) data for the Sunrise Boulevard EB segment between US 441 and US 1. Real-world travel time data, which was used to compare the model estimated travel times, was collected based on Bluetooth, HERE and INRIX data.

This study obtained turning movement data, as well as traffic signal timing data from a VISSIM network. The VISSIM network was previously calibrated for Sunrise Boulevard. The VISSIM network with turning movement traffic is provided in Figure 3-3. 


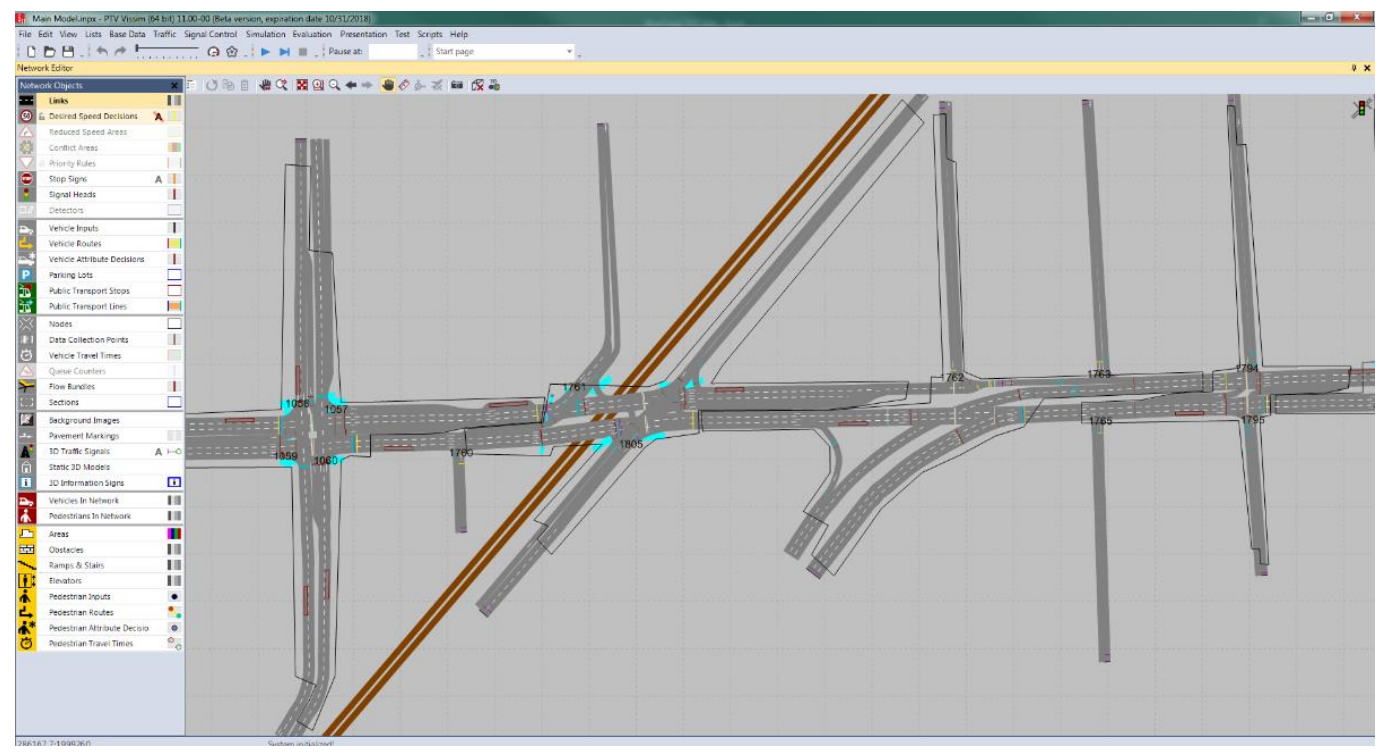

Figure 3-3: VISSIM Network for Arterial Roadways (Sunrise Boulevard)

Similar to the freeway, this study also estimated reliability utilizing incident data. Detailed incident data were collected from the FDOT District 4 SunGuide system to determine the number of incidents during a time slice, average number of lane blockages per incident, and average duration of each incident. The incident data was used to estimate lane hours lost (LHL), which is an input parameter that estimates reliability in the SHRP2 L07 Project.

\subsection{Data Preparation}

This study performed extensive data analysis to measure mobility and reliability. To accomplish this, one year's worth of volume and speed/travel time data were processed (or gathered) for both freeway and arterial roadways. Traffic incident and weather condition data for the corresponding year were also obtained for both corridors. Traffic 
signal timing information were gathered for use in estimating mobility and reliability on arterial roadways.

\subsubsection{Volume and Speed Data}

Volume and Speed/travel time data were extracted from the RITIS website for the selected freeway study corridor detectors. Along with the detectors, this study also gathered probe data (e.g., HERE data) from RITIS. The detector and probe data were obtained only from the general-purpose lanes on freeways. However, probe data may include managed lanes data, and in some instances, probe data is GPS data by nature. RITIS data provides information on volume, speed, and occupancy collected using point detectors. For the arterial segment, travel time data were obtained from Bluetooth readers and two private sector data vendors (HERE and INRIX).

For the mobility estimation, this study utilized a full year of volume and speed data. From the full year of data, only weekdays were used for mobility estimation as the traffic conditions of weekdays and weekends differed significantly. Incident days data were also collected from the RITIS website and removed from the database while estimating mobility. The main comparison to ground truth data was done to investigate how accurately the models could predict mobility compared to real-world data for regular days without the impact of incidents. For analysis purposes, this study aggregated the downloaded 15minute data into three-time periods. For freeways, the time periods were defined as AM Peak (07:00AM - 09:30 AM), Mid-Day (12:00 PM - 02:30 PM), and PM Peak (02:30 PM - 04:30 PM). The PM peak was defined to avoid the spillback effect as the focus of this study was exclusively to capture the rush hour congestion on freeways. For arterials, the 
time periods were defined as AM Peak (07:00 AM - 09:00 AM), Mid-Day (11:00 AM 01:00 PM), and PM Peak (04:00 PM - 06:00 PM). To precisely understand the prediction of mobility, volume and speed data were processed for ten randomly selected days, instead of averaging them over the full year.

For reliability estimation, speed and volume data were also gathered for the same freeway and arterial corridors. Like mobility, only weekday data was considered for reliability estimation, but incident days data were also included in the reliability analysis, as incident is a key contributing factor in reliability studies. The time period was defined similarly to the mobility analysis for freeway and arterial reliability analysis.

\subsubsection{Weather Condition Data}

This study requires weather condition data (e.g., rainfall intensity) to measure reliability. Rainfall intensity information were obtained from NOAA for the corresponding year. The following steps were followed to process weather condition data.

- NOAA data provides hourly level rainfall intensity information for every day of a year.

- From NOAA data, the number of hours that represented rainfall intensity greater than 0.05 inch were counted.

- Then, the number of hours were divided by the number of days in the year to obtain the average number of hours per day, as required by the SHRP2 L07. 
- Since this study analyzed data in 3 specific time slices (AM, Mid-Day, and $\mathrm{PM})$, rainfall intensity measure was also estimated separately for each time period.

\subsubsection{Traffic Incident Data}

Traffic incident data are also required in this study to estimate reliability. Since this study measured reliability for both freeway and arterial segments, incident data were collected for both facilities.

Traffic incident data for the I-95 NB facility was collected from the FDOT District Six and RITIS website. The traffic incident data for Sunrise Boulevard was collected from the SunGuide system. Incident data were also gathered during the same periods when the traffic and weather data were collected. The FDOT traffic incident data provides detailed incident information for every incident that occurred in the year 2012 in the study area. The following information was extracted from the incident database and utilized in this study.

- Number of incidents

- Average number of lanes blocked per incident

- Average duration of incident

Since this study analyzed data in 3 specific time slices (AM, Mid-Day, and PM), the above information was estimated for each time slice. 


\subsubsection{Traffic Signal and Capacity Data}

This study estimated mobility and reliability on arterials where traffic signal timing and capacity data were needed. Through traffic volume data on Sunrise Boulevard was collected using MVDS (Microwave Vehicle Detection System) detectors from the SunGuide database.

As mentioned earlier, a previously well-calibrated VISSIM network for Sunrise Boulevard was utilized in this study to obtain turning-movement volume and traffic signal timing information (e.g., effective green time, cycle length). Traffic signal timing information for each of the intersections along the EB Sunrise Boulevard corridor was extracted from the VISSIM network. The cycle length was found to be consistent for all intersections, which was 180 seconds. The effective green times for the EB main street through movement on individual intersections vary from intersection to intersection, between 93 seconds and 145 seconds.

Effective green time and cycle length information were utilized to derive the arterial roadway capacity using the following equation:

$$
\text { Capacity }=\frac{\text { Effectice Green Time }}{\text { Cycle Length }} \times 1700
$$

Four different capacities were used in delay-volume functions, such as the BPR curve and Akcelik equation, as follows:

- 900 vehicles per hour per lane: This is the value used in the SERPM demand model for Sunrise Boulevard. 
- 880 vehicles per hour per lane: Obtained from Equation (39) by taking the minimum value for the effective green time and cycle length ratio across all of the intersections along EB Sunrise Boulevard.

- 1,120 vehicles per hour per lane: Obtained from Equation (39) by taking the average value for the effective green time and cycle length ratio over all of the intersections along EB Sunrise Boulevard.

- 1,370 vehicles per hour per lane: Obtained from Equation (39) by taking the maximum value for the effective green time and cycle length ratio across all of the intersections along EB Sunrise Boulevard.

\subsection{Methodology}

This section provides the methodology adopted in this study to assess different mobility and reliability estimation methods for freeway and arterial segments. The study investigated the predictive ability of the different methods with respect to real-world measures. The following mobility estimation methods were comparted against real-world data (e.g., Detector data, HERE data, Bluetooth data, INRIX data):

- BPR curve

- Akcelik function

- FSU BPR Curve

- FSU Akcelik

- FSU Conical Delay

- FSU Davidson

- FREEVAL (for freeways) 
- HCS (for arterials)

- Queuing Theory

The following reliability estimation methods were comparted against real-world data (e.g., Detector data, HERE data, Bluetooth data, INRIX data):

- SHRP 2 L03 Data Poor Model

- SHRP 2 L03 Data Rich Model

- SHRP 2 L07 Original Model

- SHRP 2 L07 Calibrated Model

- SHRP 2 C11 Original Model

- SHRP 2 C11 Calibrated Model

The prediction accuracy of these estimation methods was determined with respect to the real-world measurements utilizing the following goodness-of-fit measures:

- Mean Error (ME)

- Mean Absolute Error (MAE)

- Mean Absolute Percentage Error (MAPE)

For this study, ME refers to the mean error between any specific model-predicted measure and the real-world measure and MAE refers to the average absolute difference between any specific model-predicted measure and the real-world measure. This study also estimated MAPE to expresses the accuracy of the predictive models in terms of the percentage error. 


\subsection{Summary}

This chapter provided information on the study area, data sources, data preparation efforts, in addition to the methodology utilized in this study to assess various approaches to estimate mobility and reliability measures. This study considered I-95 NB between NW 32nd Street and NW 103rd Street as the freeway study corridor, and Sunrise Boulevard between US 441 and US 1 as the arterial study corridor. Several databases were used in this research, including the Regional Integrated Transportation Information System (RITIS) for speed/travel time and volume data on both freeways and arterials, National Oceanic and Atmospheric Administration (NOAA) data to estimate rainfall intensity hours, FDOT District Six incident data, FDOT District Four incident data, MVDS point detector data, and Bluetooth data. In addition, this study also obtained traffic parameters from calibrated travel demand models (e.g., $\alpha$ and $\beta$ estimates for BPR curve from the SERPM Model) and turning movement counts and signal control parameters from an existing traffic simulation model. 


\section{Chapter 4}

\section{ANALYSIS AND RESULTS}

This chapter is divided into two major sections. The first section presents the analyses, results, and discussion of the utilization of the BPR curve, Akcelik function, Regression Models developed by FSU (BPR curve, Akcelik, Conical delay, and Modified Davidson), Queuing Theory, and HCM-based models to estimate mobility measures (i.e., travel time, speed). The second section focuses on assessing the utilization of the products of the SHRP2 projects (L03, L07, C11) to estimate reliability measures (i.e., travel time indices).

\subsection{Mobility Analysis}

This section provides the assessment of the application of different mobility estimation methods for freeway and arterial segments.

\subsubsection{Freeway Mobility}

For the study purpose, the volume data collected from the RITIS website were divided into the following three time periods:

- $\quad$ AM Peak (07:00 AM - 09:30 AM)

- Mid-Day (12:00 PM- 02:30 PM)

- PM Peak (02:30 PM - 04:30 PM) 


\section{$\underline{\text { AM Peak }}$}

On the 10 randomly selected days studied, the volume (v) detected in the AM Peak (07:00 AM - 09:30 AM) was always found to be less than the roadway capacity (c). The v/c ratio of AM Peak was found as less than 1 for all selected ten days, and this study determined that there was no congestion on the I-95 NB roadway segment during the AM Peak.

Figures 4-1 to 4-6 show the mobility estimates (e.g., speed and travel time) for the AM Peak period. The figures also provide information on the predictive ability of different mobility estimation methods. For discussion purposes, this section highlighted only 3 days from the selected 10 days to avoid repetitive discussion. The days were selected to represent the different seasons of the year 2017: early year (February 7, 20170), mid-year (June 22, 2017), and the end of the year (December 12, 2017).

Day 01: February 7, 2017

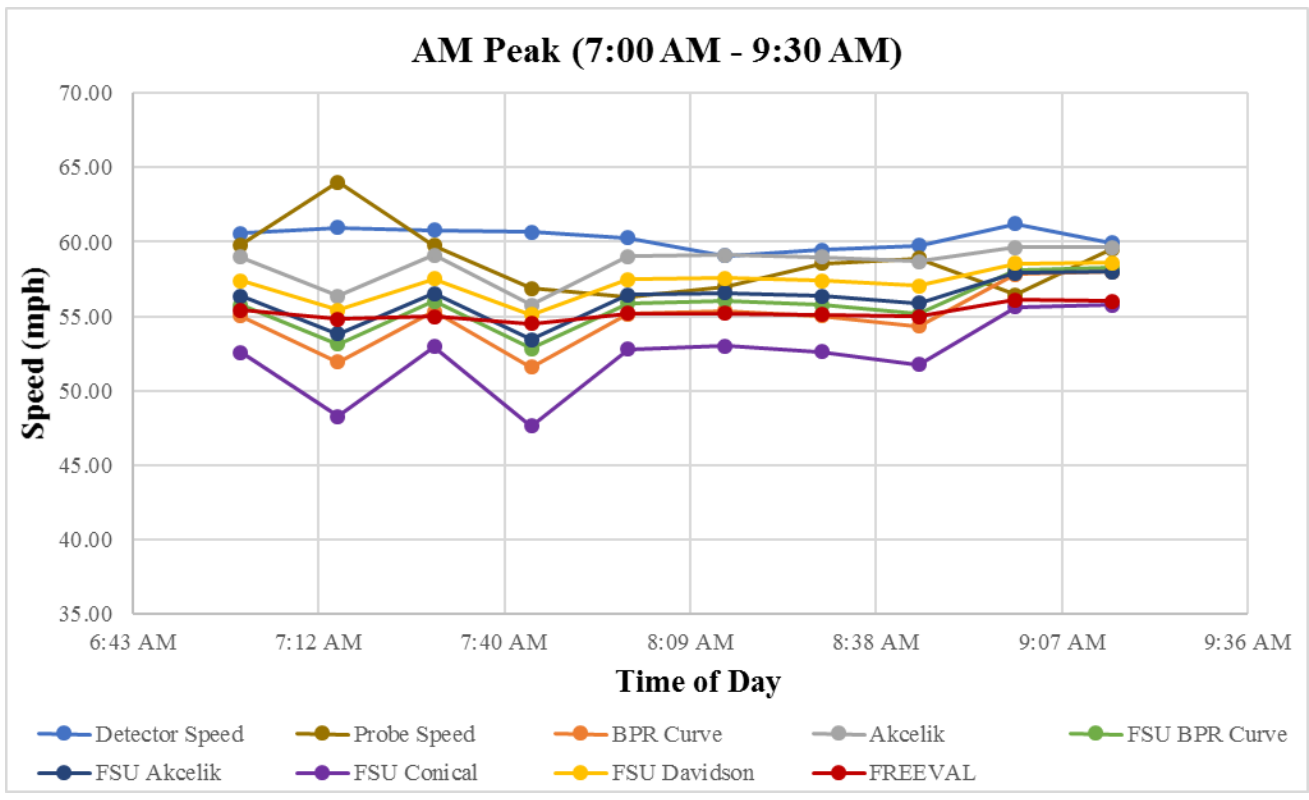

Figure 4-1: Predictive ability of different mobility estimation methods - 


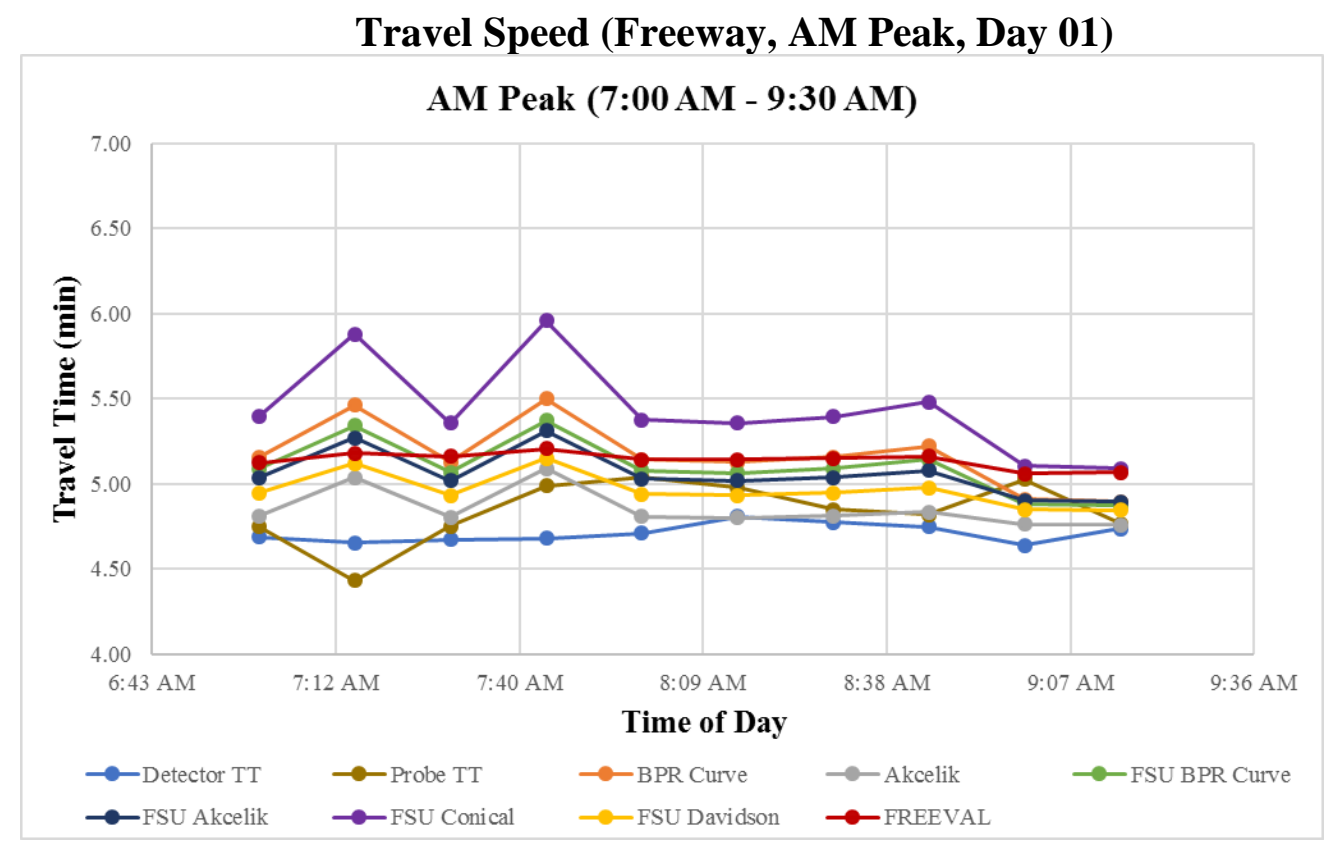

Figure 4-2: Predictive ability of different mobility estimation methods Travel Time (Freeway, AM Peak, Day 01)

Day 02: June 22, 2017

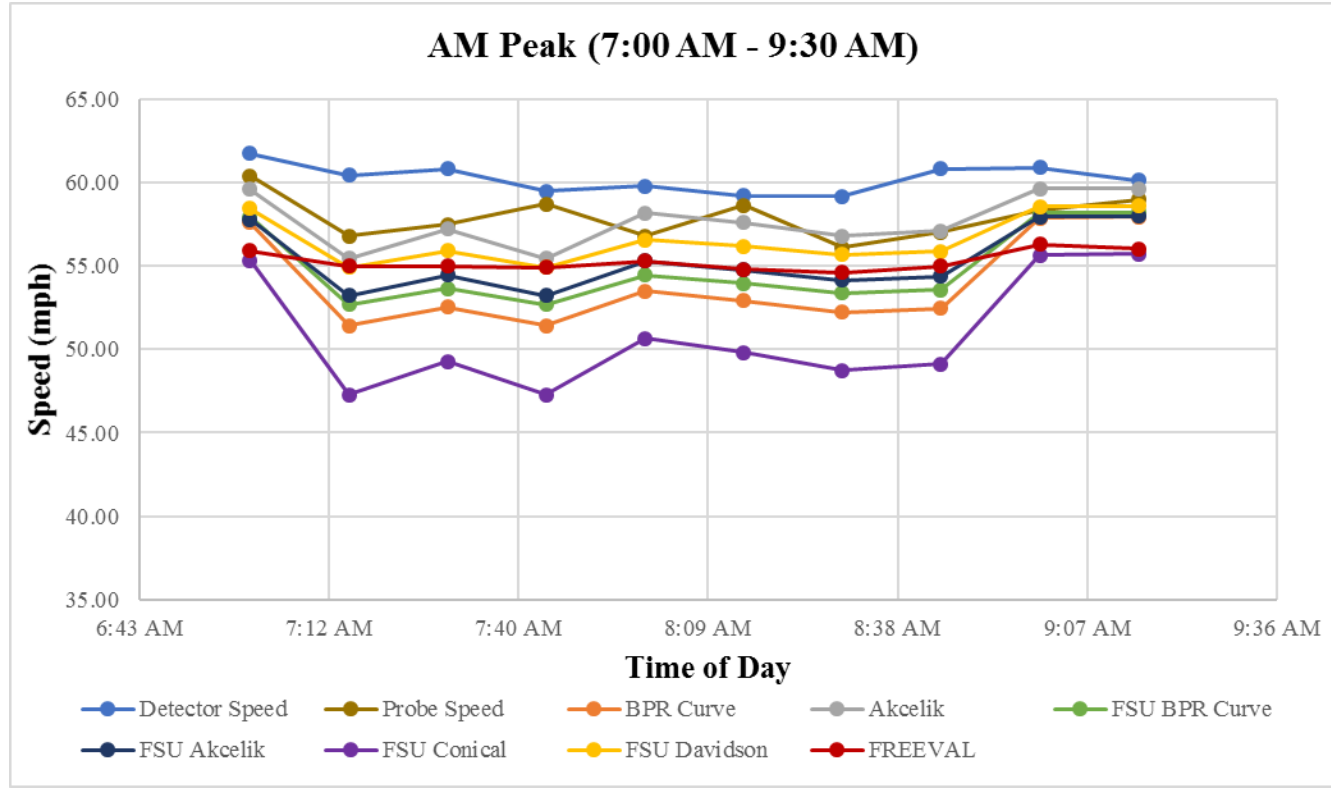

Figure 4-3: Predictive ability of different mobility estimation methods Travel Speed (Freeway, AM Peak, Day 02) 


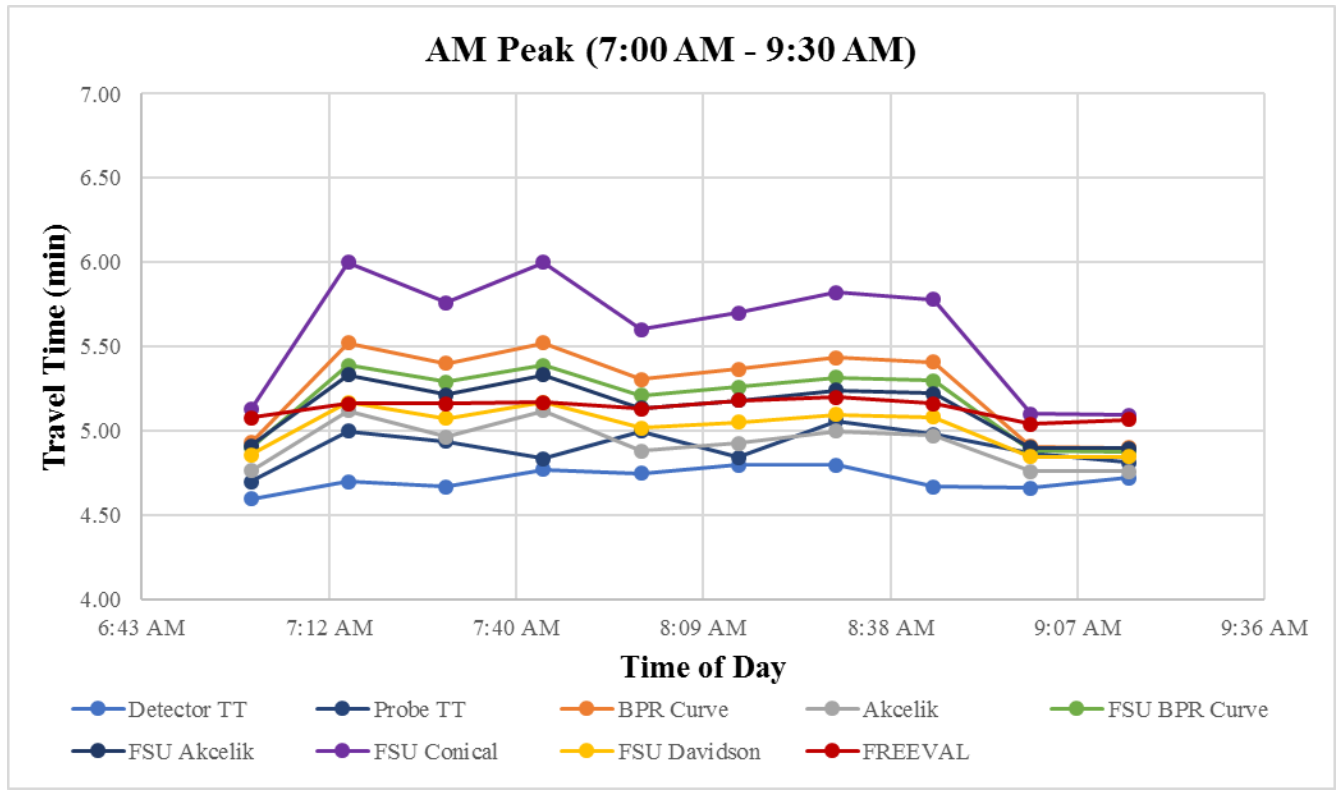

Figure 4-4: Predictive ability of different mobility estimation methods Travel Time (Freeway, AM Peak, Day 02)

Day 03: December 12, 2017

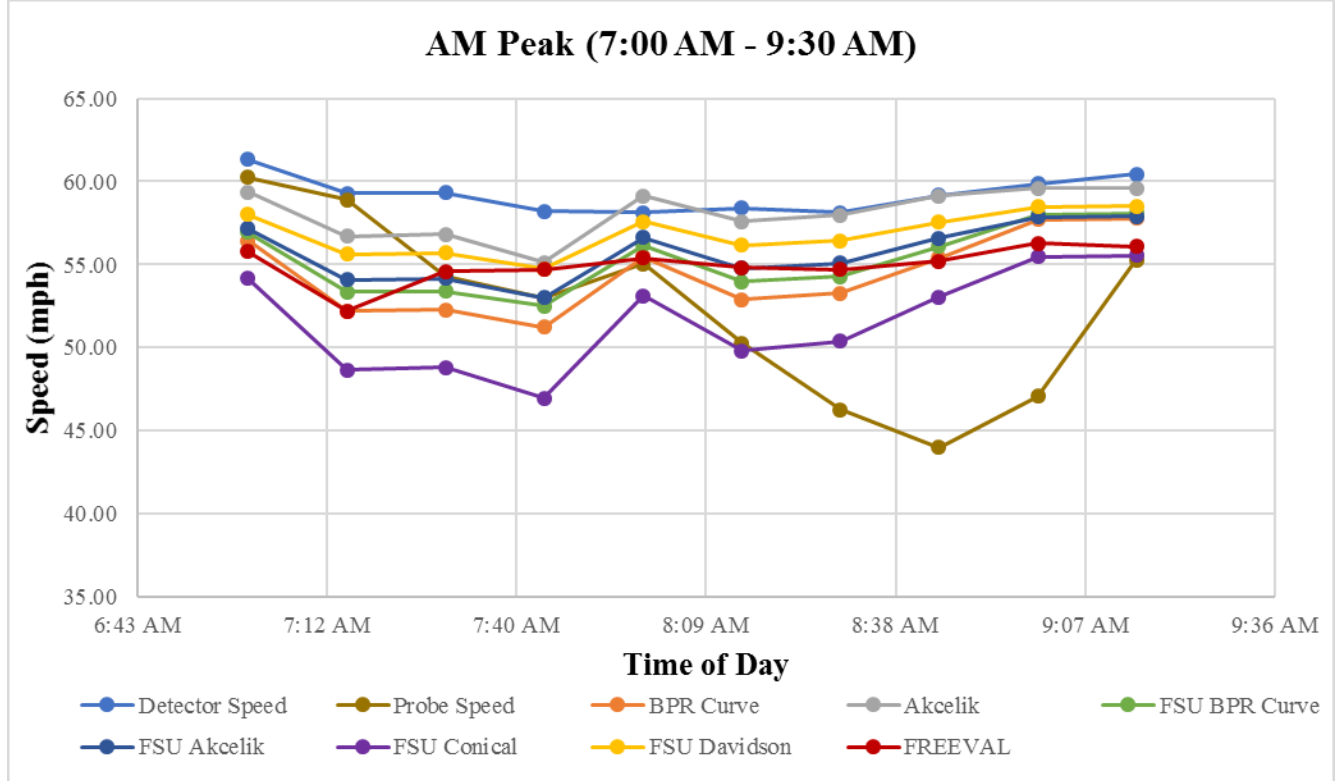

Figure 4-5: Predictive ability of different mobility estimation methods Travel Speed (Freeway, AM Peak, Day 03) 


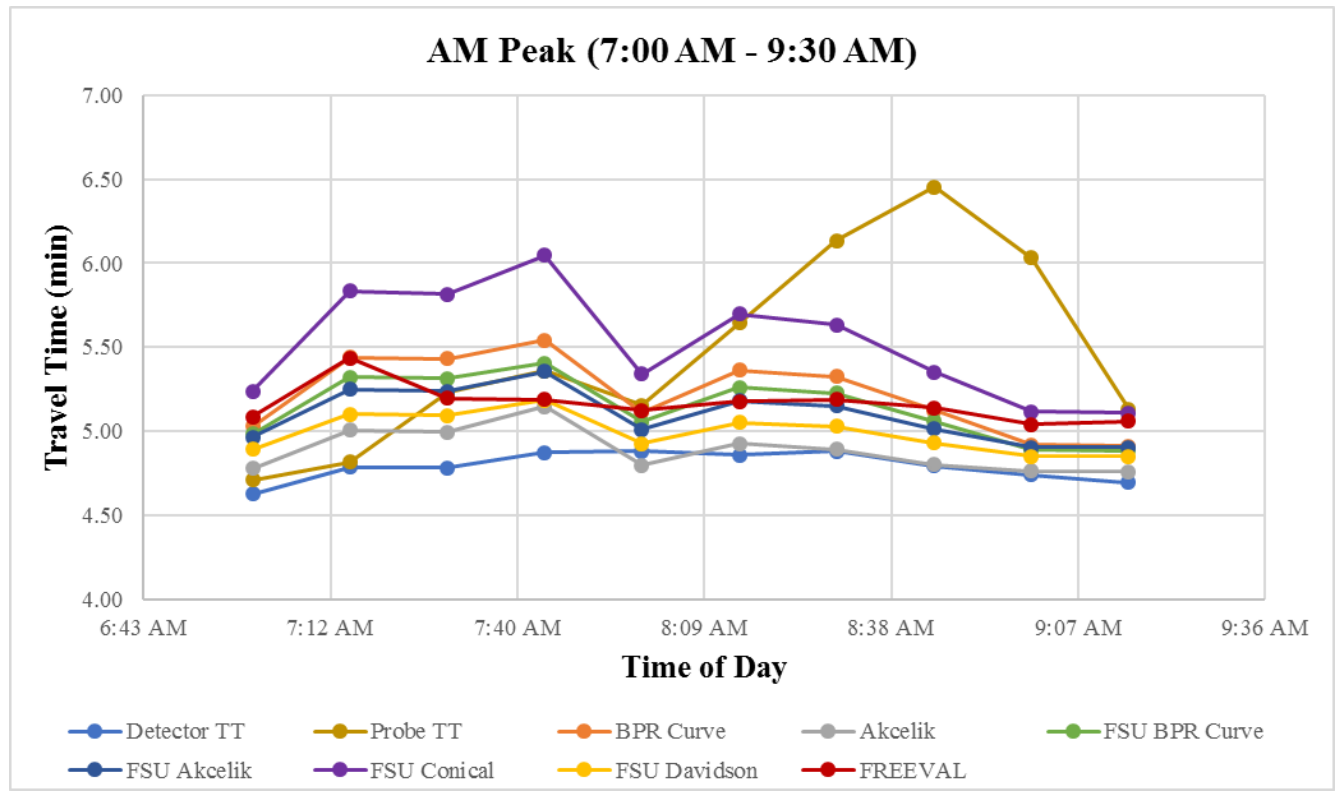

Figure 4-6: Predictive ability of different mobility estimation methods Travel Time (Freeway, AM Peak, Day 03)

Tables 4-1 and 4-2 present a performance summary of different mobility estimation methods in terms of the mean error (ME), mean absolute error (MAE), and mean absolute percentage error (MAPE) for the AM Peak period. This study found that the predicted mobility measures (e.g., travel time, speed) were similar to real-world mobility measures for all mobility estimation methods during the AM Peak period, except for the FSU Conical Delay model (which showed a higher percentage of errors). 
Table 4-1: Performance Summary of Mobility Methods (Freeway, AM Peak, Speed) for Detector Data

\begin{tabular}{|c|c|c|c|c|c|c|c|c|c|c|c|c|c|c|c|c|c|c|c|c|c|}
\hline & \multicolumn{7}{|c|}{ ME } & \multicolumn{7}{|c|}{ MAE } & \multicolumn{7}{|c|}{ MAPE } \\
\hline & 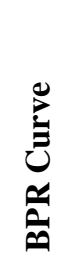 & 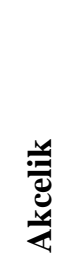 & 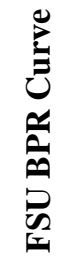 & 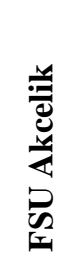 & 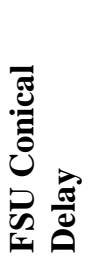 & 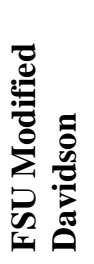 & $\frac{2}{\frac{\pi}{a}}$ & 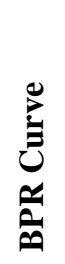 & 资 & 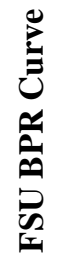 & 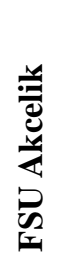 & 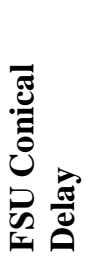 & 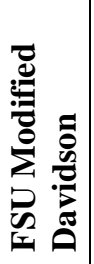 & 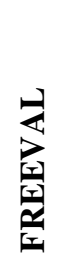 & 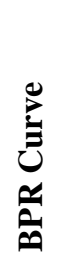 & 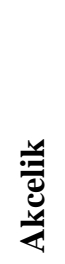 & 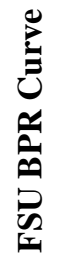 & 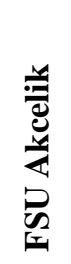 & 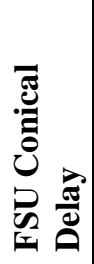 & 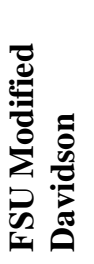 & $\underset{\frac{\pi}{x}}{\frac{1}{x}}$ \\
\hline January $19^{\text {th }}$ & 0.2 & -3.3 & -0.8 & -1.1 & 4.0 & -2.4 & -1.8 & 4.3 & 5.3 & 4.3 & 4.4 & 5.5 & 4.8 & 4.5 & 8 & 10 & 8 & 8 & 10 & 9 & 9 \\
\hline February $7^{\text {th }}$ & 3.8 & 0.2 & 3.0 & 2.6 & 6.4 & 1.5 & 3.5 & 4.0 & 1.9 & 3.4 & 2.9 & 6.4 & 2.3 & 3.5 & 7 & 3 & 6 & 5 & 11 & 4 & 6 \\
\hline March 30 ${ }^{\text {th }}$ & 3.8 & 5.4 & 7.6 & 7.5 & 12.4 & 6.1 & 6.9 & 3.8 & 5.4 & 7.6 & 7.5 & 12.4 & 6.1 & 6.9 & 6 & 9 & 12 & 12 & 20 & 10 & 11 \\
\hline April 10 ${ }^{\text {th }}$ & 4.1 & 4.0 & 6.8 & 6.4 & 10.2 & 5.3 & 7.2 & 4.1 & 4.0 & 6.8 & 6.4 & 10.2 & 5.3 & 7.2 & 7 & 6 & 11 & 10 & 16 & 8 & 12 \\
\hline May $9^{\text {th }}$ & 3.0 & -0.6 & 2.0 & 1.7 & 6.5 & 0.4 & 1.3 & 3.0 & 1.8 & 2.1 & 1.9 & 6.5 & 1.3 & 1.4 & 5 & 3 & 4 & 3 & 12 & 2 & 2 \\
\hline June 22 ${ }^{\text {nd }}$ & 3.9 & 0.3 & 3.0 & 2.6 & 7.0 & 1.4 & 2.6 & 3.9 & 1.1 & 3.0 & 2.6 & 7.0 & 1.4 & 2.6 & 7 & 2 & 5 & 4 & 12 & 2 & 5 \\
\hline July 20 & 3.0 & -0.7 & 2.2 & 1.7 & 5.9 & 0.5 & 2.0 & 3.0 & 1.0 & 2.2 & 1.7 & 5.9 & 0.7 & 2.1 & 5 & 2 & 4 & 3 & 10 & 1 & 4 \\
\hline August 17 ${ }^{\text {th }}$ & 1.7 & -1.7 & 0.9 & 0.6 & 4.5 & -0.5 & 1.0 & 2.7 & 2.8 & 2.3 & 2.3 & 4.5 & 2.1 & 1.9 & 5 & 5 & 4 & 4 & 8 & 4 & 3 \\
\hline December $^{\text {th }}$ & 2.4 & -1.3 & 1.6 & 1.2 & 5.2 & 0.0 & 1.7 & 3.3 & 2.8 & 2.7 & 2.2 & 5.4 & 1.9 & 2.1 & 6 & 5 & 5 & 4 & 9 & 3 & 4 \\
\hline December $12^{\text {th }}$ & -2.0 & -5.7 & -2.8 & -3.3 & 0.8 & -4.4 & -2.5 & 4.9 & 6.3 & 4.9 & 4.9 & 5.2 & 5.6 & 4.8 & 10 & 13 & 10 & 10 & 10 & 11 & 10 \\
\hline Average & 2.4 & -0.3 & 2.4 & 2.0 & 6.3 & 0.8 & 2.2 & 3.7 & 3.2 & 3.9 & 3.7 & 6.9 & 3.1 & 3.7 & 6.5 & 5.8 & 6.8 & 6.4 & 11.9 & 5.6 & 6.4 \\
\hline
\end{tabular}


Table 4-2: Performance Summary of Mobility Methods (Freeway, AM Peak, Speed) for Probe Data

\begin{tabular}{|c|c|c|c|c|c|c|c|c|c|c|c|c|c|c|c|c|c|c|c|c|c|}
\hline & \multicolumn{7}{|c|}{ ME } & \multicolumn{7}{|c|}{ MAE } & \multicolumn{7}{|c|}{ MAPE } \\
\hline & 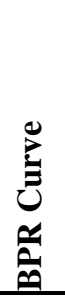 & 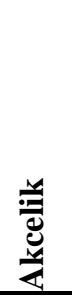 & 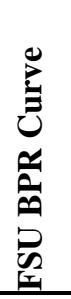 & 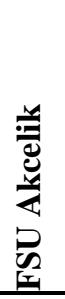 & 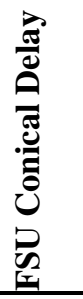 & 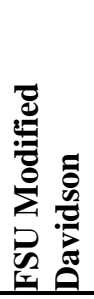 & 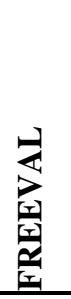 & 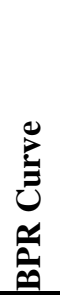 & 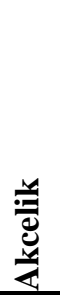 & 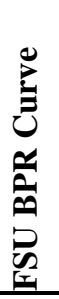 & 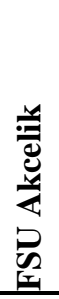 & 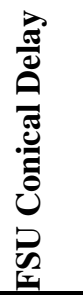 & 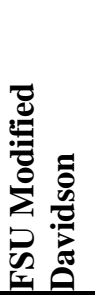 & $\sum_{2}^{2}$ & 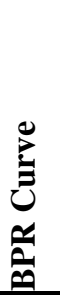 & 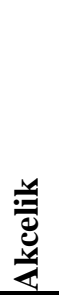 & 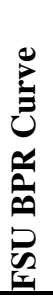 & 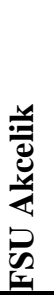 & 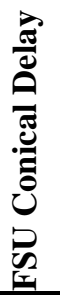 & 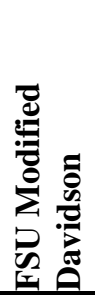 & 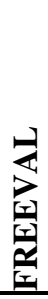 \\
\hline January $19^{\text {th }}$ & 2.2 & -1.3 & 1.2 & 0.9 & 6.0 & -0.4 & 0.2 & 3.4 & 3.4 & 3.1 & 3.0 & 6.2 & 3.2 & 3.6 & 6 & 7 & 6 & 6 & 11 & 6 & 7 \\
\hline February $7^{\text {th }}$ & 5.3 & 1.7 & 4.6 & 4.1 & 8.0 & 3.1 & 5.0 & 5.3 & 1.7 & 4.6 & 4.1 & 8.0 & 3.1 & 5.0 & 9 & 3 & 8 & 7 & 13 & 5 & 8 \\
\hline March 30 ${ }^{\text {th }}$ & 8.6 & 5.4 & 7.6 & 7.5 & 12.4 & 6.1 & 6.9 & 8.6 & 5.4 & 7.6 & 7.5 & 12.4 & 6.1 & 6.9 & 14 & 9 & 12 & 12 & 20 & 10 & 11 \\
\hline April 10 ${ }^{\text {th }}$ & 7.5 & 4.0 & 6.8 & 6.4 & 10.2 & 5.3 & 7.2 & 7.5 & 4.0 & 6.8 & 6.4 & 10.2 & 5.3 & 7.2 & 12 & 6 & 11 & 10 & 16 & 8 & 12 \\
\hline May $9^{\text {th }}$ & 6.6 & 3.1 & 5.6 & 5.3 & 10.1 & 4.0 & 4.9 & 6.6 & 3.1 & 5.6 & 5.3 & 10.1 & 4.0 & 4.9 & 11 & 5 & 9 & 9 & 17 & 7 & 8 \\
\hline June $22^{\text {nd }}$ & 6.3 & 2.6 & 5.4 & 4.9 & 9.3 & 3.7 & 5.0 & 6.3 & 2.6 & 5.4 & 4.9 & 9.3 & 3.7 & 5.0 & 10 & 4 & 9 & 8 & 16 & 6 & 8 \\
\hline July $20^{\text {th }}$ & 5.4 & 1.7 & 4.5 & 4.1 & 8.3 & 2.9 & 4.4 & 5.4 & 1.7 & 4.5 & 4.1 & 8.3 & 2.9 & 4.4 & 9 & 3 & 8 & 7 & 14 & 5 & 7 \\
\hline August $17^{\text {th }}$ & 4.3 & 0.9 & 3.5 & 3.2 & 7.1 & 2.1 & 3.6 & 4.3 & 1.6 & 3.5 & 3.2 & 7.1 & 2.3 & 3.6 & 7 & 3 & 6 & 5 & 12 & 4 & 6 \\
\hline December $^{\text {th }}$ & 5.0 & 1.3 & 4.2 & 3.7 & 7.8 & 2.6 & 4.2 & 5.0 & 1.3 & 4.2 & 3.7 & 7.8 & 2.6 & 4.2 & 8 & 2 & 7 & 6 & 13 & 4 & 7 \\
\hline December $12^{\text {th }}$ & 4.8 & 1.1 & 4.0 & 3.5 & 7.6 & 2.4 & 4.3 & 4.8 & 1.3 & 4.0 & 3.5 & 7.6 & 2.4 & 4.3 & 8 & 2 & 7 & 6 & 13 & 4 & 7 \\
\hline Average & 5.6 & 2.1 & 4.7 & 4.4 & 8.7 & 3.2 & 4.6 & 5.7 & 2.6 & 4.9 & 4.6 & 8.7 & 3.5 & 4.9 & 10 & 4 & 8 & 8 & 15 & 6 & 8 \\
\hline
\end{tabular}




\section{Mid-Day}

This study defined the Mid-Day period between 12:00 PM and 02:30 PM. The study observed that recurrent congestion on I-9 NB started to build up at the end of the Mid-Day time period.

Figures 4-7 to 4-12 show the mobility estimates (e.g., speed and travel time) for the Mid-Day period. The figures also provide information on the predictive ability of different mobility estimation methods. Similar to AM Peak, this section highlighted only 3 days from the selected 10 days to avoid repetitive discussion. The days were selected to represent the different seasons of 2017: early year (February 7, 2017), mid-year (June 22, 2017), and end of the year (December 12, 2017).

Day 01: February 7, 2017

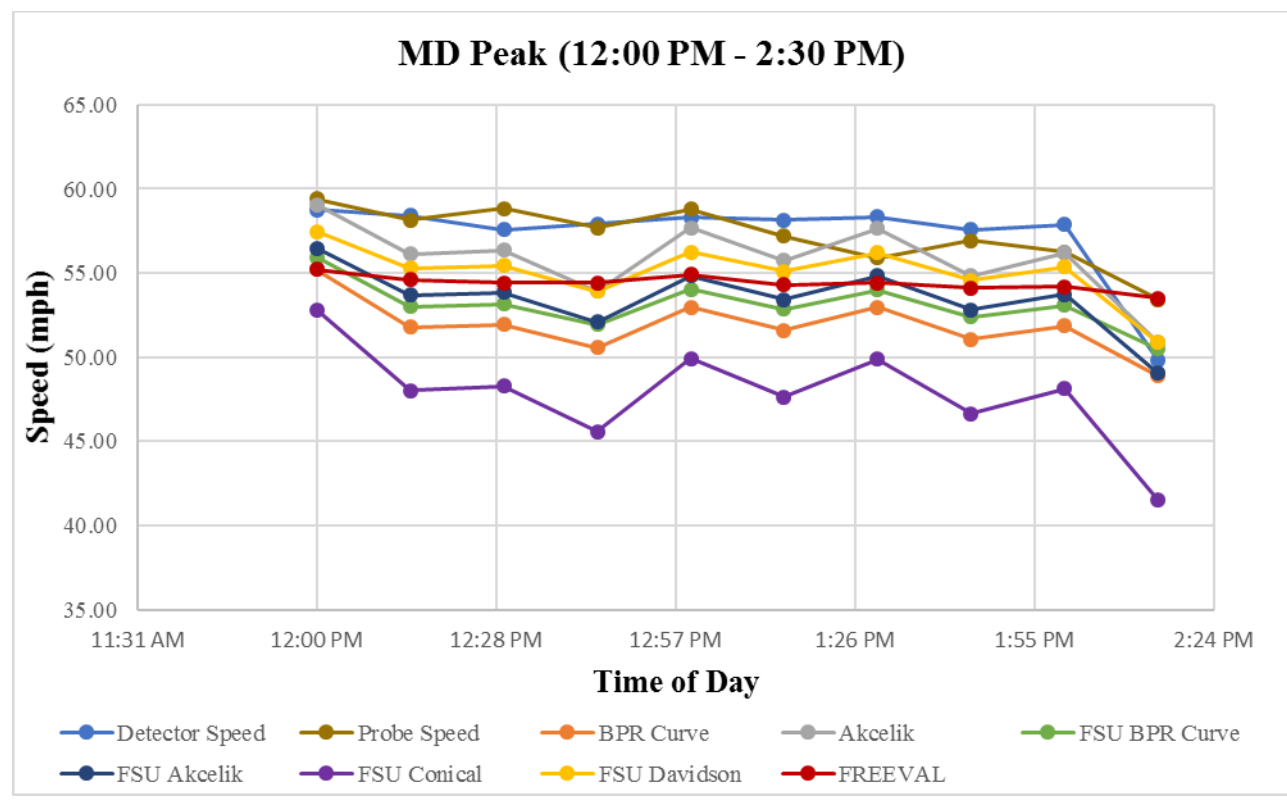

Figure 4-7: Predictive ability of different mobility estimation methods Travel Speed (Freeway, Mid-Day, Day 01) 


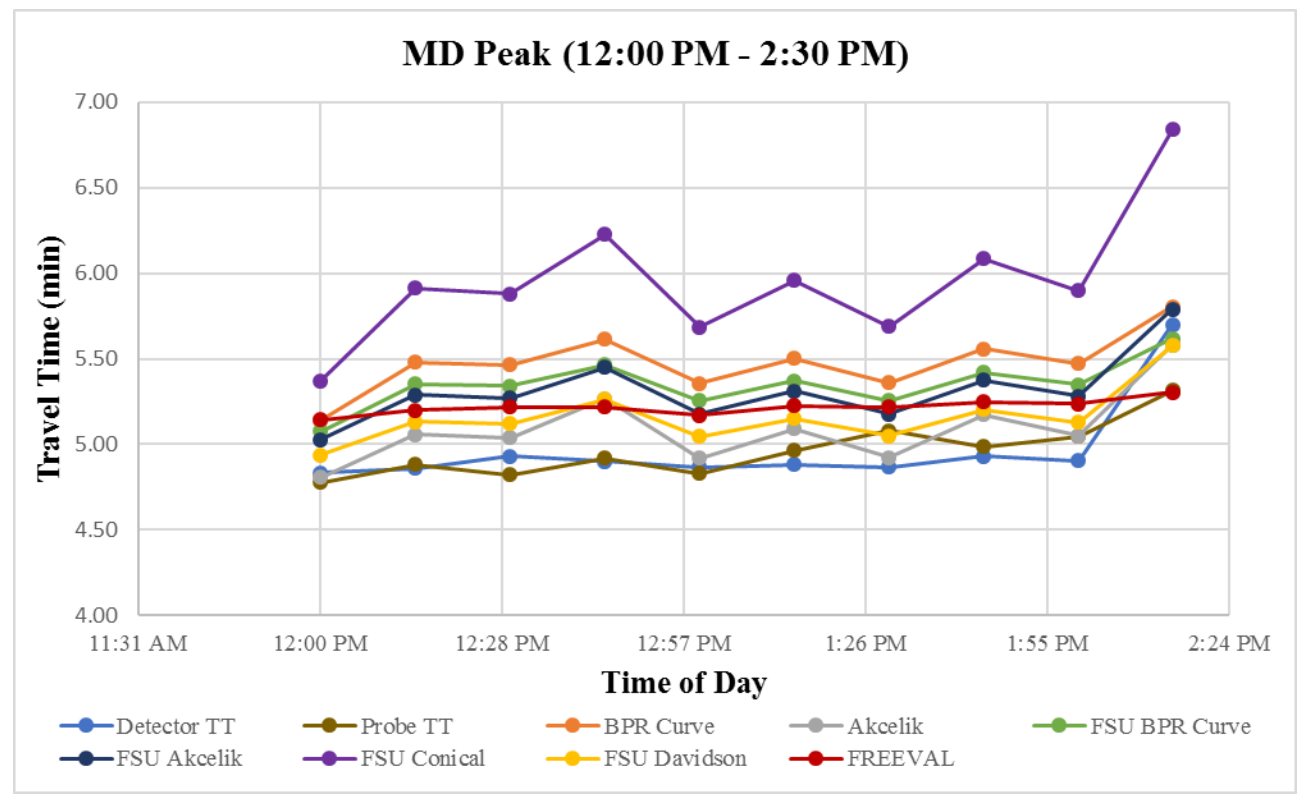

Figure 4-8: Predictive ability of different mobility estimation methods Travel Time (Freeway, Mid-Day, Day 01)

Day 02: June 22, 2017

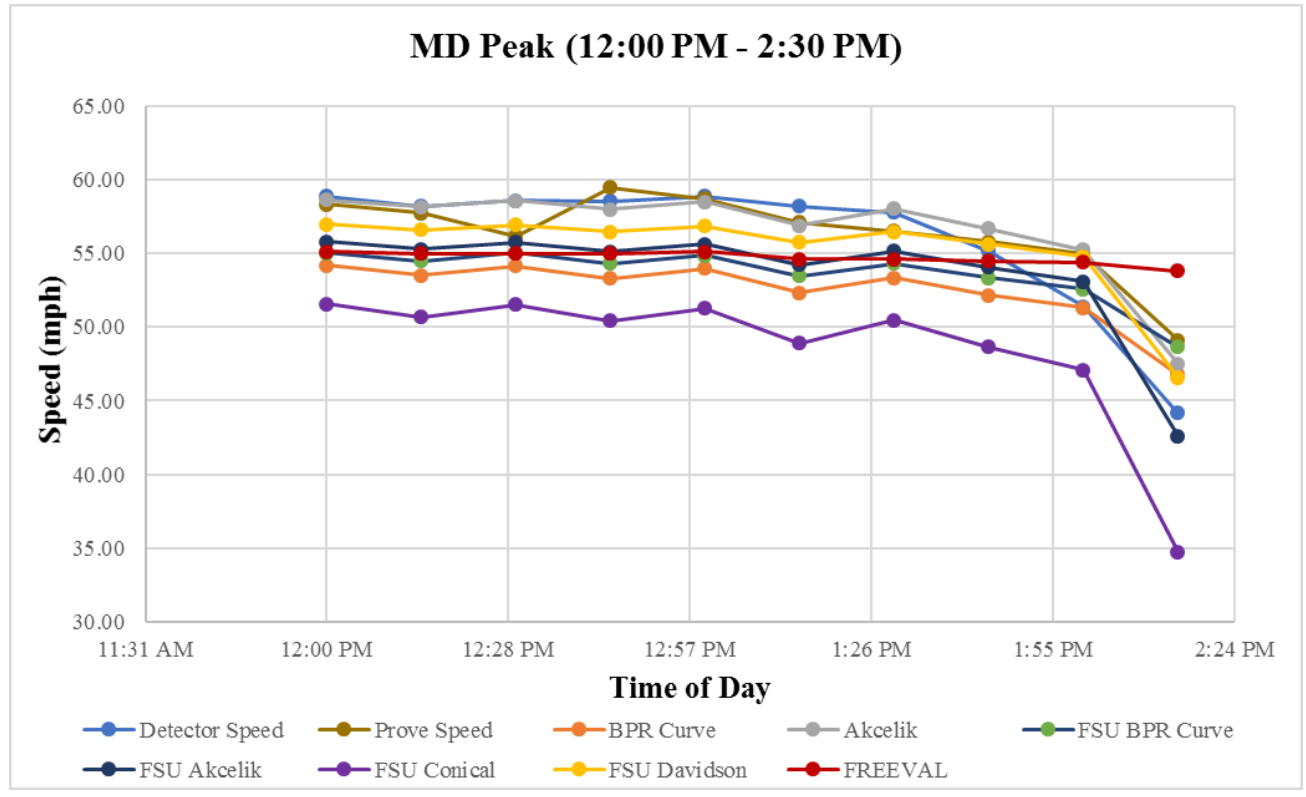

Figure 4-9: Predictive ability of different mobility estimation methods Travel Time (Freeway, Mid-Day, Day 02) 


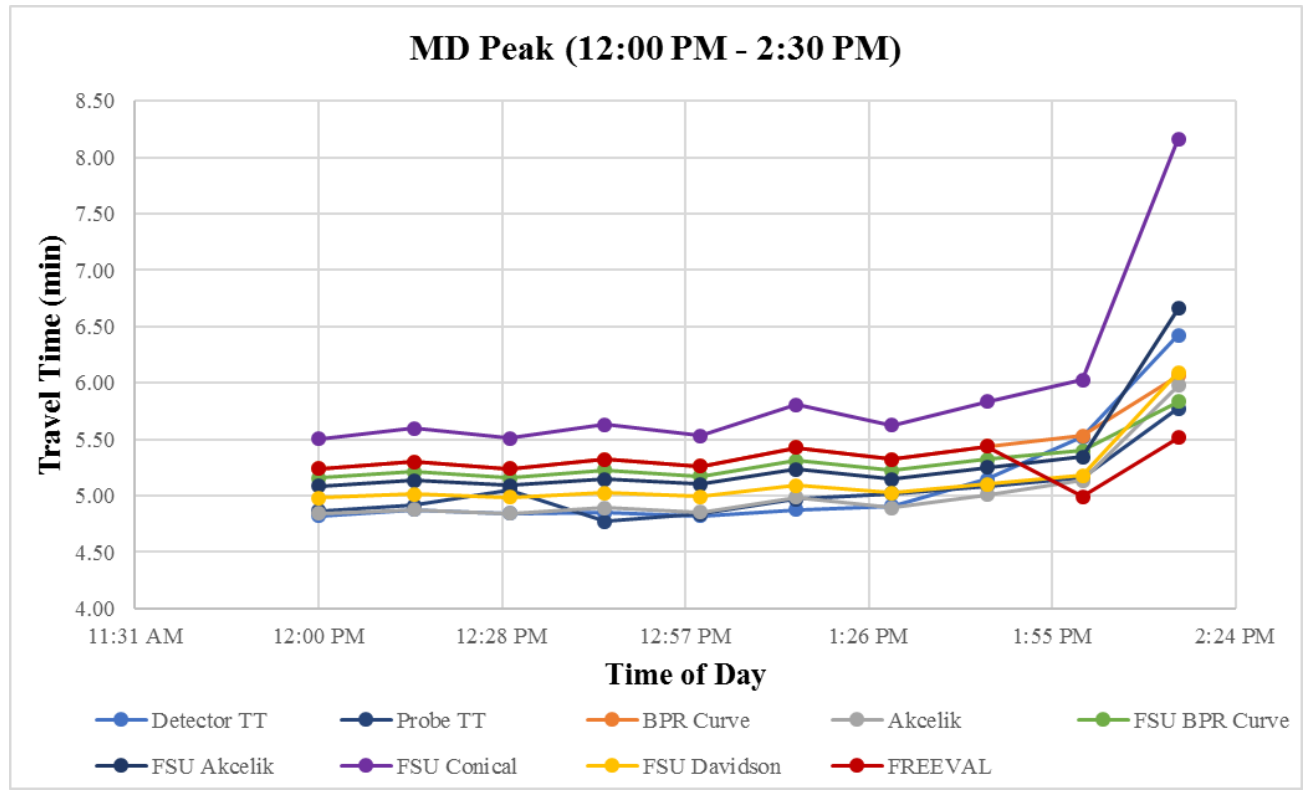

Figure 4-10: Predictive ability of different mobility estimation methods Travel Time (Freeway, Mid-Day, Day 02)

Day 03: December 12, 2017

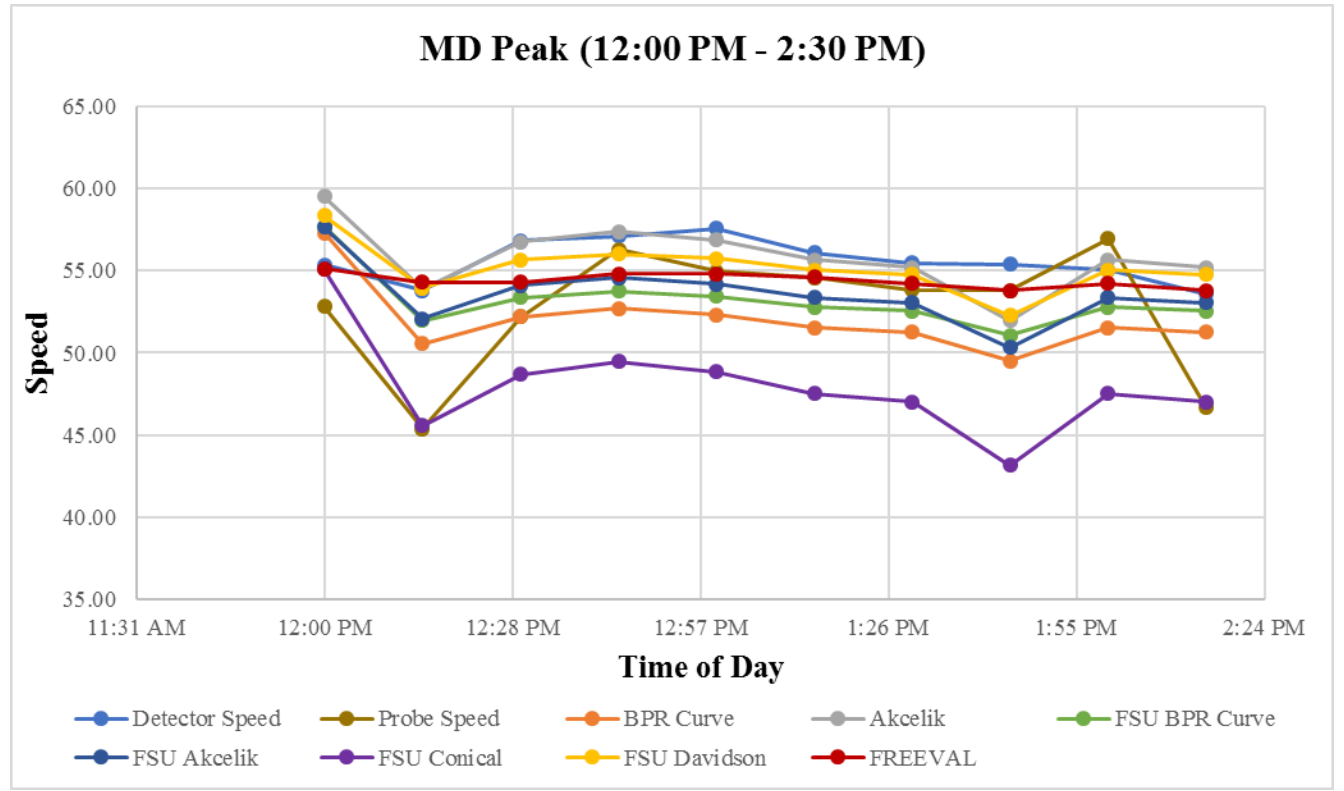

Figure 4-11: Predictive ability of different mobility estimation methods Travel Speed (Freeway, Mid-Day, Day 03) 


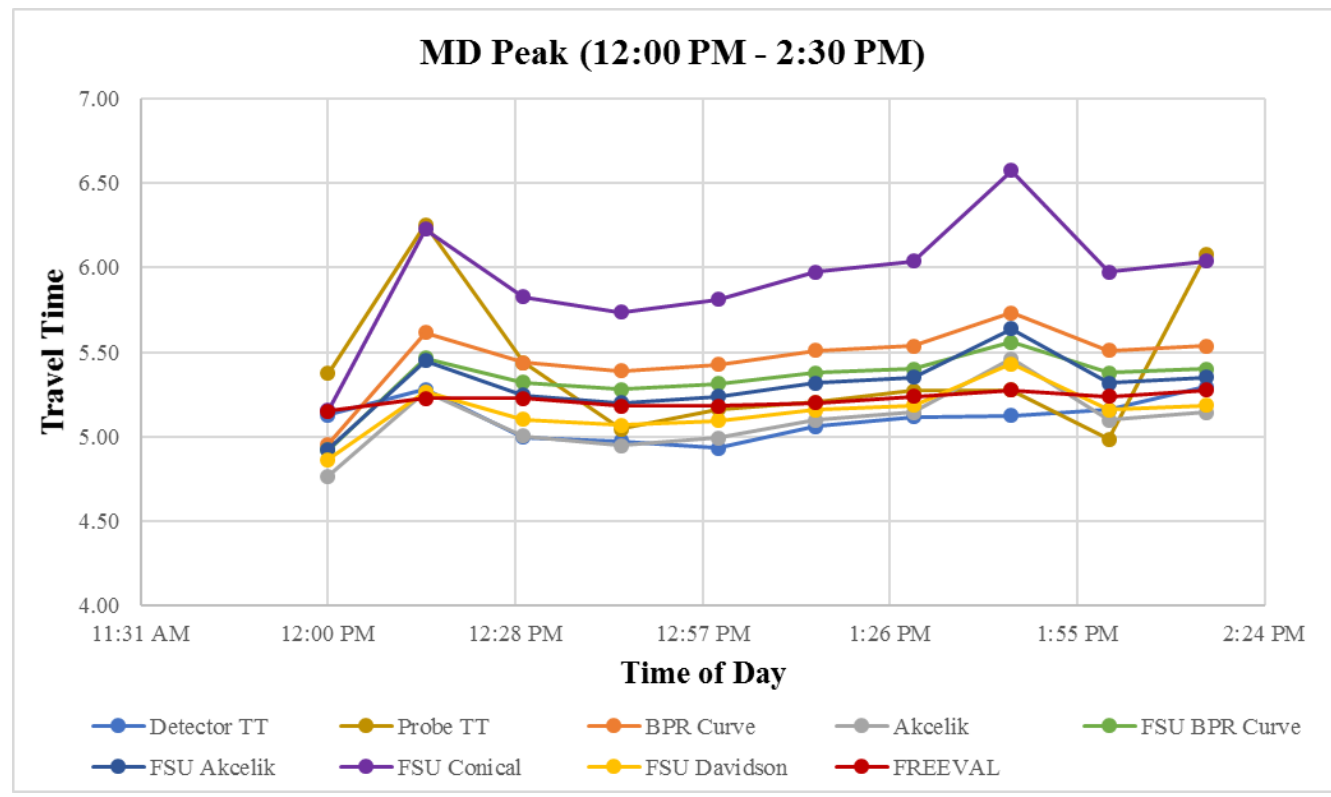

Figure 4-12: Predictive ability of different mobility estimation methods Travel Time (Freeway, Mid-Day, Day 03)

Tables 4-3 and 4-4 below present a performance summary of different mobility predictive methods in terms of mean error (ME), mean absolute error (MAE), and mean absolute percentage error (MAPE) for the Mid-Day period.

For the selected ten days, the demand remained to be less than the capacity during the Mid-Day time period. The comparison of speed and travel time measures suggests that the prediction accuracy is almost identical in AM Peak and Mid-Day periods. This finding confirms that mobility estimation methods, except for the FSU Conical Delay model (showing a higher percentage of errors), predicted reasonably well during the noncongested period $(\mathrm{v} / \mathrm{c}<1)$. 
Table 4-3: Performance Summary of Mobility Methods (Freeway, Mid-Day, Speed) for Detector Data

\begin{tabular}{|c|c|c|c|c|c|c|c|c|c|c|c|c|c|c|c|c|c|c|c|c|c|}
\hline & \multicolumn{7}{|c|}{ ME } & \multicolumn{7}{|c|}{ MAE } & \multicolumn{7}{|c|}{ MAPE } \\
\hline & 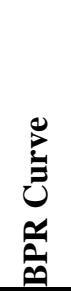 & 龸 & 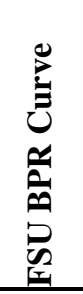 & 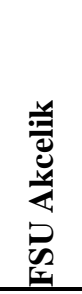 & 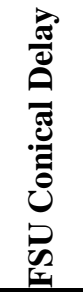 & 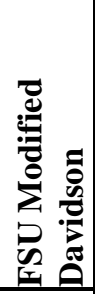 & $\frac{2}{2}$ & 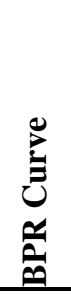 & 产 & 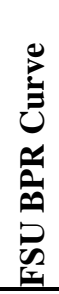 & 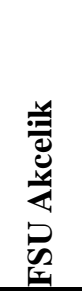 & 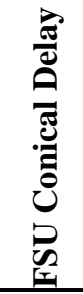 & 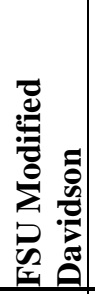 & $\frac{2}{2}$ & 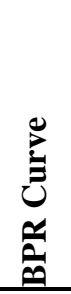 & 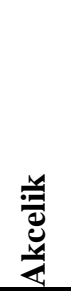 & 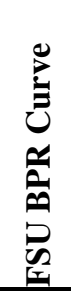 & 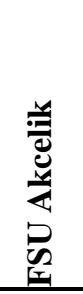 & 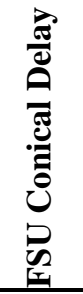 & 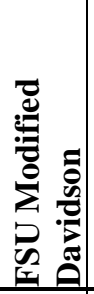 & $\begin{array}{l}2 \\
2 \\
\frac{1}{2} \\
\frac{1}{2} \\
\end{array}$ \\
\hline January $19^{\text {th }}$ & 5.8 & 2.3 & 4.5 & 4.4 & 10.7 & 2.7 & 2.5 & 5.8 & 2.4 & 4.5 & 4.4 & 10.7 & 2.7 & 2.7 & 10 & 4 & 8 & 8 & 19 & 5 & 5 \\
\hline February $7^{\text {th }}$ & 5.4 & 1.4 & 4.2 & 3.8 & 9.4 & 2.2 & 2.9 & 5.4 & 1.8 & 4.2 & 3.8 & 9.4 & 2.3 & 2.9 & 9 & 3 & 7 & 7 & 16 & 4 & 5 \\
\hline March 30 th & -0.4 & -5.2 & -4.2 & 5.4 & 9.3 & -3.6 & -1.1 & 1.6 & 5.9 & 4.6 & 12.5 & 11.2 & 5.3 & 6.3 & 4 & 13 & 11 & 32 & 30 & 12 & 15 \\
\hline April 10 ${ }^{\text {th }}$ & 2.7 & 4.5 & 6.6 & 8.1 & 13.7 & 5.2 & 4.8 & 3.0 & 4.5 & 6.6 & 8.1 & 13.7 & 5.2 & 4.8 & 5 & 8 & 11 & 14 & 24 & 9 & 8 \\
\hline May $9^{\text {th }}$ & 7.2 & 3.3 & 5.8 & 7.9 & 13.1 & 4.4 & 3.8 & 7.2 & 4.7 & 5.8 & 7.9 & 13.1 & 4.8 & 3.8 & 13 & 9 & 11 & 15 & 24 & 9 & 7 \\
\hline June $22^{\text {nd }}$ & 3.9 & -0.2 & 2.8 & 2.7 & 7.9 & 1.1 & 1.7 & 3.9 & 0.9 & 2.8 & 2.7 & 7.9 & 1.3 & 2.6 & 7 & 2 & 5 & 5 & 14 & 2 & 5 \\
\hline July $20^{\text {th }}$ & 0.6 & -1.9 & -1.3 & 10.4 & 14.2 & -0.1 & 17.1 & 2.6 & 4.7 & 2.8 & 13.0 & 14.4 & 4.4 & 18.7 & 6 & 10 & 7 & 32 & 35 & 10 & 39 \\
\hline August $17^{\text {th }}$ & 3.3 & -0.6 & 1.9 & 3.9 & 9.2 & 0.4 & -0.1 & 4.0 & 2.9 & 3.1 & 5.4 & 9.2 & 2.8 & 2.1 & 8 & 6 & 6 & 11 & 18 & 6 & 4 \\
\hline December $6^{\text {th }}$ & 3.3 & -0.7 & 2.0 & 3.7 & 8.8 & 0.5 & 1.3 & 3.3 & 2.3 & 2.3 & 4.3 & 8.8 & 2.1 & 1.9 & 6 & 4 & 4 & 9 & 17 & 4 & 3 \\
\hline December $12^{\text {th }}$ & 0.7 & -3.1 & -0.4 & -0.8 & 4.8 & -2.4 & -1.6 & 3.6 & 3.7 & 3.2 & 3.1 & 5.3 & 3.1 & 2.5 & 7 & 7 & 6 & 6 & 10 & 6 & 5 \\
\hline Average & 3.3 & 0.0 & 2.2 & 5.0 & 10.1 & 1.0 & 3.1 & 4.0 & 3.4 & 4.0 & 6.5 & 10.4 & 3.4 & 4.8 & 7.5 & 6.6 & 7.6 & 13.9 & 20.7 & 6.6 & 9.7 \\
\hline
\end{tabular}


Table 4-4: Performance Summary of Mobility Methods (Freeway, Mid-Day, Speed) for Probe Data

\begin{tabular}{|c|c|c|c|c|c|c|c|c|c|c|c|c|c|c|c|c|c|c|c|c|c|}
\hline & \multicolumn{7}{|c|}{ ME } & \multicolumn{7}{|c|}{ MAE } & \multicolumn{7}{|c|}{ MAPE } \\
\hline & 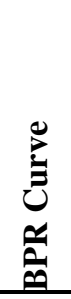 & 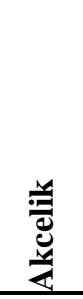 & 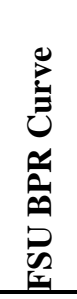 & 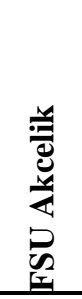 & 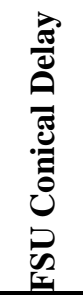 & 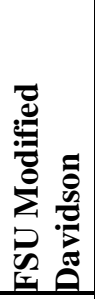 & $\frac{2}{2}$ & 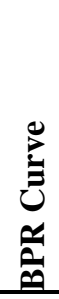 & $\begin{array}{l}y \\
y \\
y\end{array}$ & 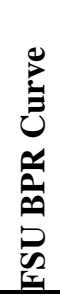 & 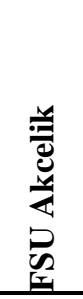 & 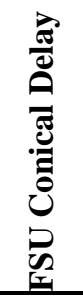 & 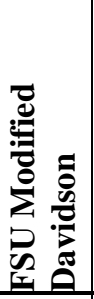 & 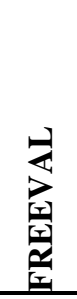 & 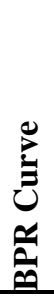 & 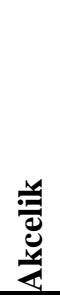 & 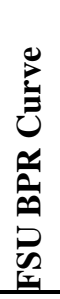 & 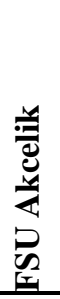 & 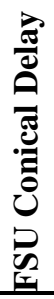 & 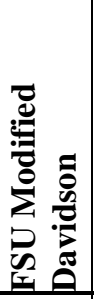 & 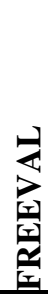 \\
\hline January $19^{\text {th }}$ & 5.7 & 2.2 & 4.3 & 4.3 & 10.6 & 2.6 & 2.4 & 5.7 & 2.2 & 4.3 & 4.3 & 10.6 & 2.6 & 3.0 & 10 & 4 & 8 & 8 & 19 & 4 & 5 \\
\hline February $7^{\text {th }}$ & 5.4 & 1.4 & 4.2 & 3.8 & 9.4 & 2.2 & 2.9 & 5.4 & 1.7 & 4.3 & 3.8 & 9.4 & 2.4 & 3.6 & 9 & 3 & 7 & 7 & 16 & 4 & 6 \\
\hline March 30 th & -2.4 & -5.2 & -4.2 & 5.4 & 9.3 & -3.6 & -1.1 & 3.9 & 5.9 & 4.6 & 12.5 & 11.2 & 5.3 & 6.3 & 9 & 13 & 11 & 32 & 30 & 12 & 15 \\
\hline April 10 ${ }^{\text {th }}$ & 7.9 & 4.5 & 6.6 & 8.1 & 13.7 & 5.2 & 4.8 & 7.9 & 4.5 & 6.6 & 8.1 & 13.7 & 5.2 & 4.8 & 13 & 8 & 11 & 14 & 24 & 9 & 8 \\
\hline May $9^{\text {th }}$ & 4.4 & 0.5 & 3.0 & 5.1 & 10.3 & 1.6 & 1.0 & 4.9 & 2.7 & 4.0 & 5.3 & 10.3 & 2.8 & 2.9 & 10 & 6 & 8 & 12 & 22 & 6 & 6 \\
\hline June $22^{\text {nd }}$ & 3.5 & -0.6 & 2.4 & 2.3 & 7.4 & 0.7 & 1.3 & 4.0 & 1.2 & 3.5 & 2.6 & 7.4 & 1.9 & 3.8 & 7 & 2 & 6 & 5 & 13 & 4 & 7 \\
\hline July $20^{\text {th }}$ & 0.9 & -1.6 & -1.0 & 10.7 & 14.5 & 0.2 & 17.3 & 2.8 & 4.2 & 3.1 & 12.8 & 14.6 & 3.8 & 17.7 & 6 & 9 & 7 & 32 & 36 & 8 & 36 \\
\hline August $17^{\text {th }}$ & 2.7 & -1.1 & 1.3 & 3.3 & 8.6 & -0.2 & -0.7 & 4.9 & 3.2 & 4.0 & 6.2 & 9.2 & 3.5 & 3.9 & 9 & 7 & 8 & 14 & 19 & 7 & 8 \\
\hline December $^{\text {th }}$ & 1.5 & -2.4 & 0.3 & 2.0 & 7.0 & -1.2 & -0.4 & 4.1 & 2.5 & 3.8 & 4.4 & 7.4 & 2.3 & 3.8 & 8 & 6 & 8 & 10 & 15 & 5 & 8 \\
\hline December $12^{\text {th }}$ & 3.6 & -0.2 & 2.4 & 2.0 & 7.6 & 0.5 & 1.2 & 4.0 & 1.2 & 2.9 & 2.5 & 7.6 & 1.3 & 1.4 & 7 & 2 & 5 & 4 & 14 & 2 & 2 \\
\hline Average & 3.3 & -0.3 & 1.9 & 4.7 & 9.9 & 0.5 & 2.9 & 4.8 & 2.9 & 4.1 & 6.3 & 10.2 & 3.2 & 5.1 & 9 & 6 & 8 & 14 & 21 & 7 & 10 \\
\hline
\end{tabular}




\section{$\underline{\text { PM Peak }}$}

This study found that congestion on I-95 NB started to form after 02:30 PM, which falls under the PM Peak period (02:30 - 04:30 PM). Although congestion persisted far beyond 04:30 PM, the study considered only the period up to 04:30 PM to avoid the congestion due to backup from bottlenecks downstream of the analysis segment. In comparison to the AM Peak and Mid-Day periods, mobility measures were found to be completely different during the PM Peak due to the congestion. Since the V/C became greater than 1, the predictive models also acted differently in response to the congestion.

Figures 4-13 to 4-18 present the mobility estimates (e.g., speed and travel time) for the PM Peak period. The figures also provide information on the predictive ability of different mobility estimation methods. Similar to AM Peak and Mid-Day periods, this section highlighted only 3 days from the selected 10 days to avoid repetitive discussion. The days were selected to represent the different seasons of 2017: early year (February 7, 20170), mid-year (June 22, 2017), and end of the year (December 12, 2017). 
Day 01: February 7, 2017

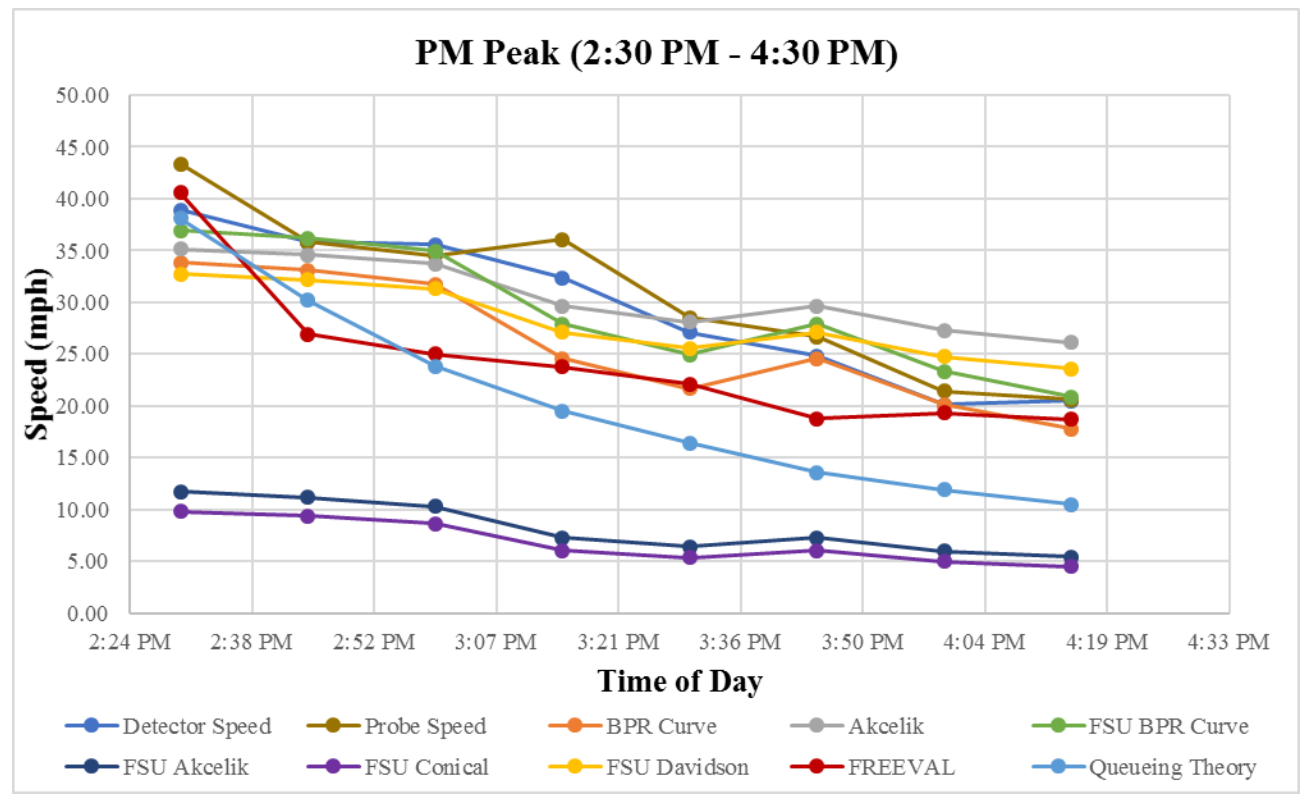

Figure 4-13: Predictive ability of different mobility estimation methods Travel Speed (Freeway, PM Peak, Day 01)

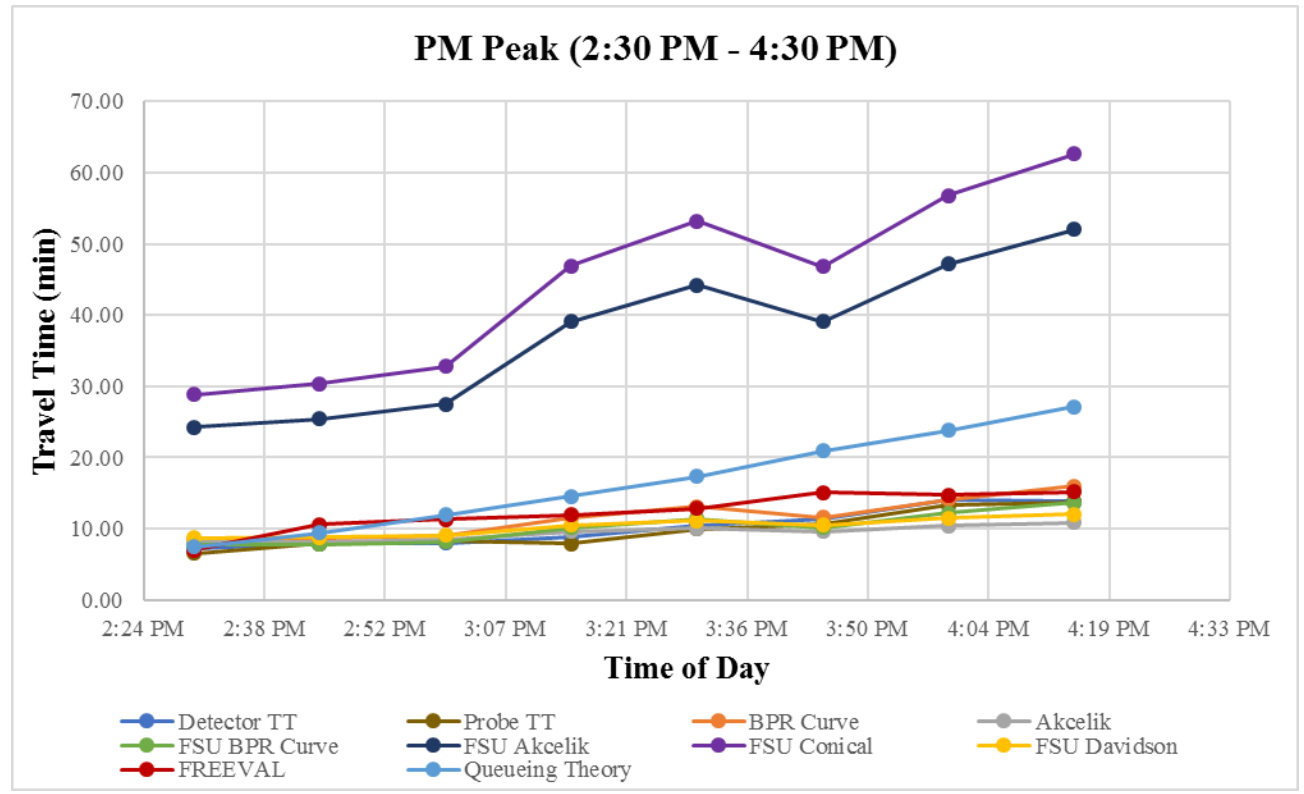

Figure 4-14: Predictive ability of different mobility estimation methods Travel Time (Freeway, PM Peak, Day 01) 
Day 02: June 22, 2017

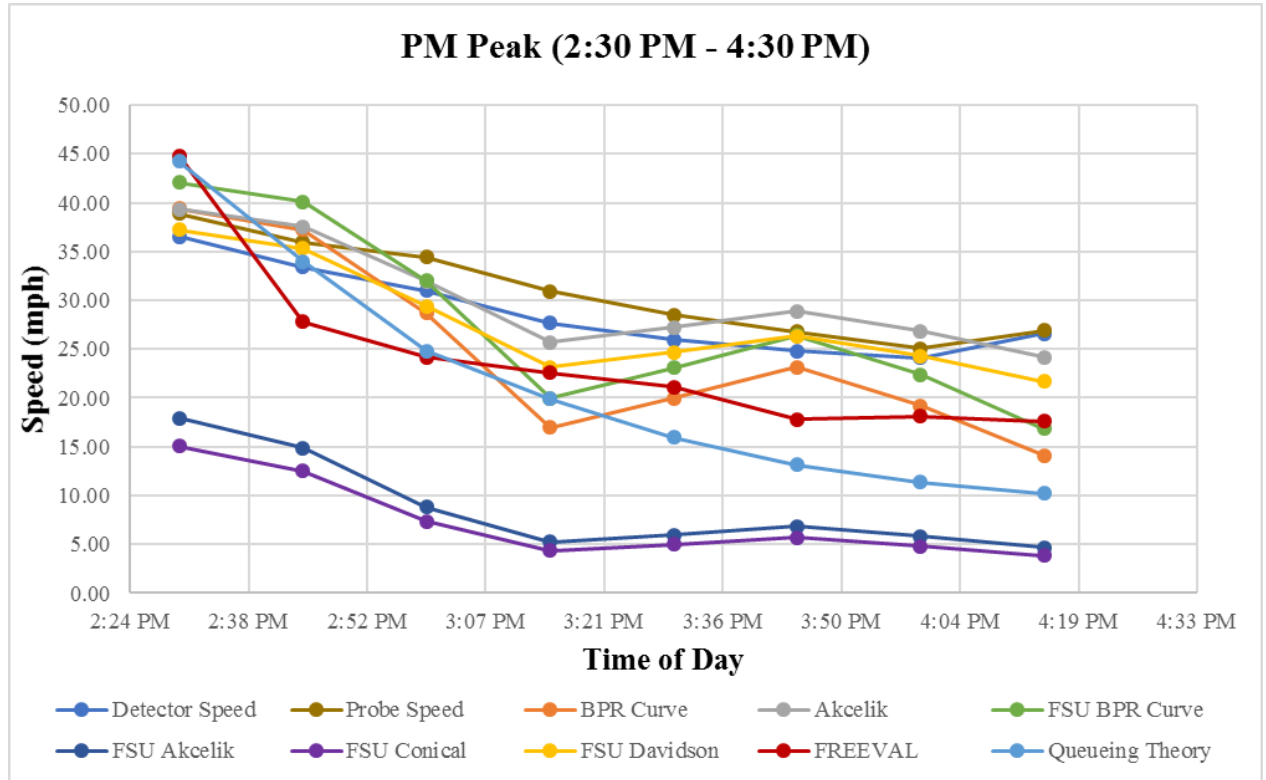

Figure 4-15: Predictive ability of different mobility estimation methods Travel Speed (Freeway, PM Peak, Day 02)

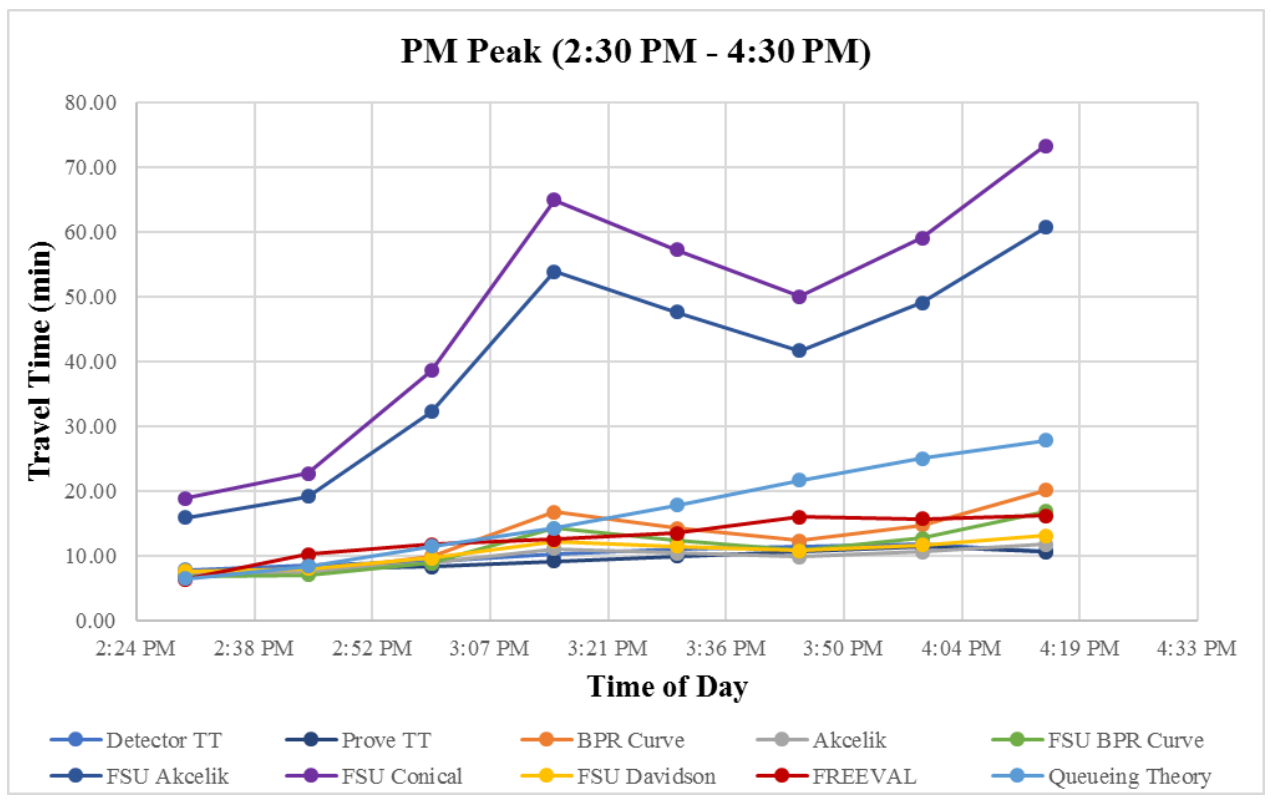

Figure 4-16: Predictive ability of different mobility estimation methods Travel Time (Freeway, PM Peak, Day 02) 
Day 03: December 12, 2017

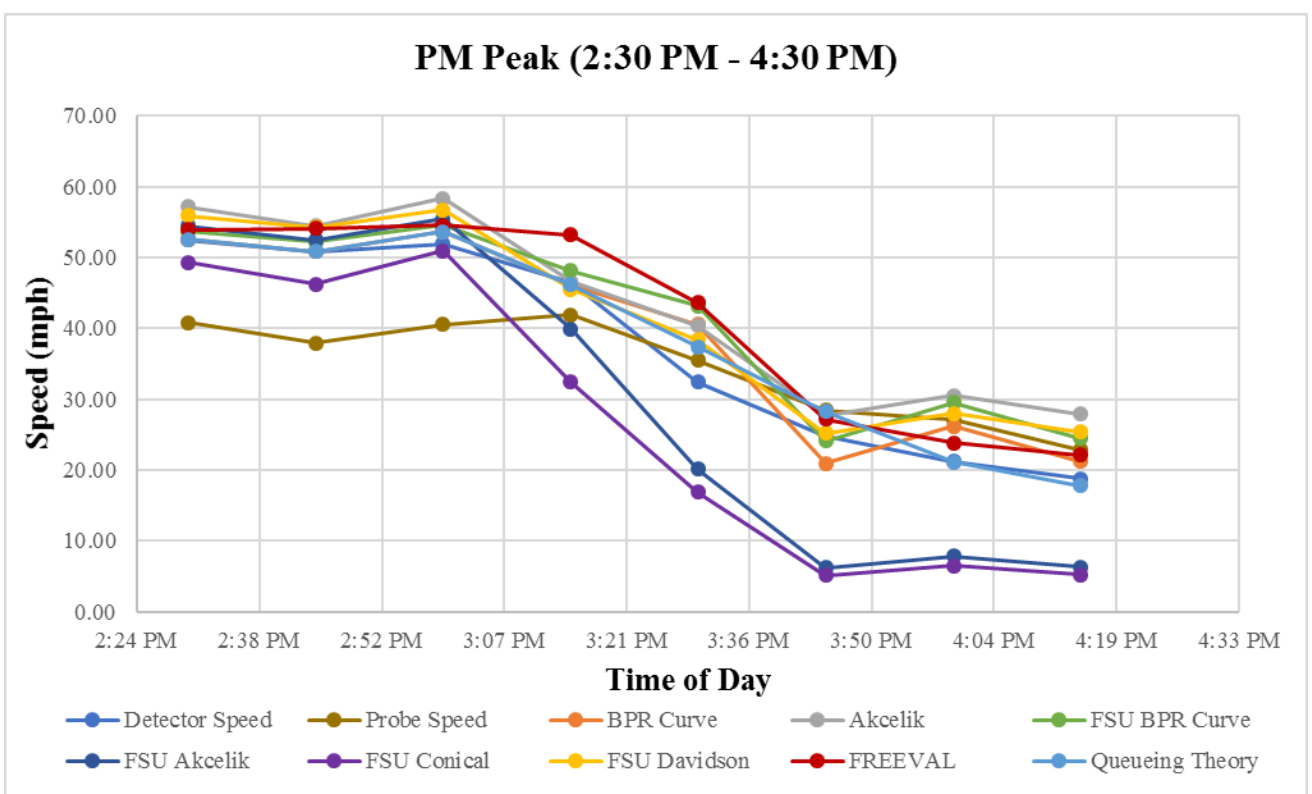

Figure 4-17: Predictive ability of different mobility estimation methods Travel Speed (Freeway, PM Peak, Day 03)

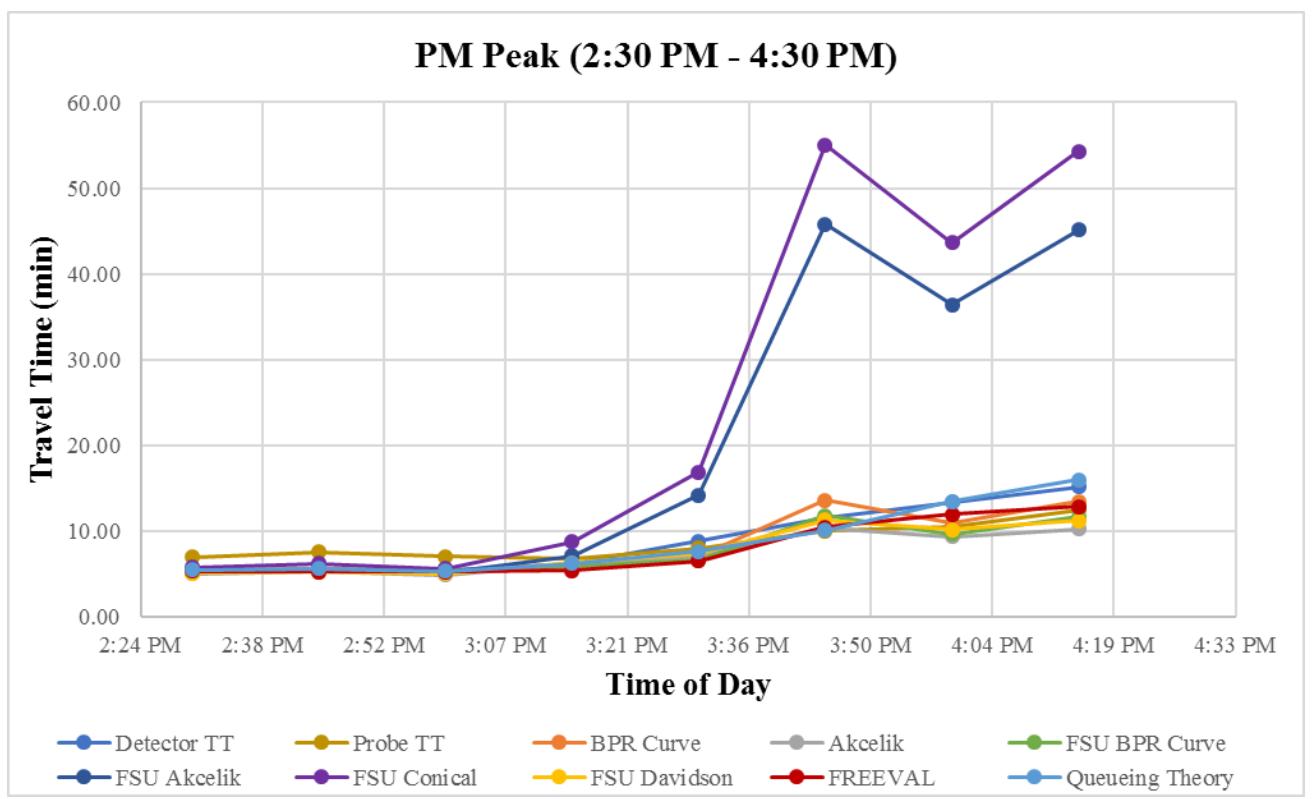

Figure 4-18: Predictive ability of different mobility estimation methods Travel Time (Freeway, PM Peak, Day 03) 
Tables 4-5 and 4-6 below present a performance summary of different mobility predictive methods in terms of mean error (ME), mean absolute error (MAE), and mean absolute percentage error (MAPE) for the PM Peak period.

As shown in Tables 4-5 and 4-6, the HCM facility procedure (e.g., FREEVAL) was able to predict mobility measures more precisely and was compared with the other prediction models according to the prediction error statistics of ME, MAE, and MAPE. The BPR curve, Akcelik function, FSU BPR curve, FSU Davidson, and Queuing theory also estimated mobility measures closer to the real world. However, estimation from the FSU Conical Delay model and FSU Akcelik model were not closer to real-world measures during the PM peak. 
Table 4-5: Performance Summary of Mobility Methods (Freeway, PM Peak, Speed) for Detector Data

\begin{tabular}{|c|c|c|c|c|c|c|c|c|c|c|c|c|c|c|c|c|c|c|c|c|c|c|c|c|}
\hline & \multicolumn{8}{|c|}{ ME } & \multicolumn{8}{|c|}{ MAE } & \multicolumn{8}{|c|}{ MAPE } \\
\hline & 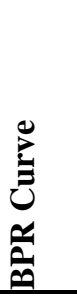 & 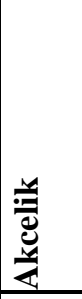 & 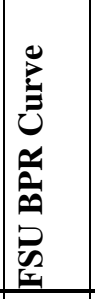 & 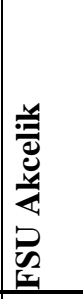 & 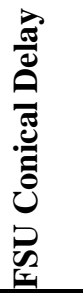 & 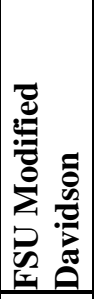 & 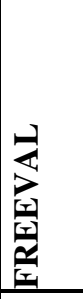 & 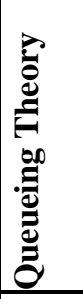 & 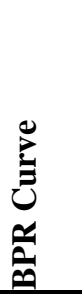 & 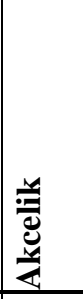 & 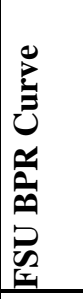 & 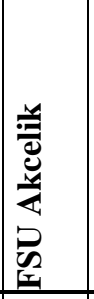 & 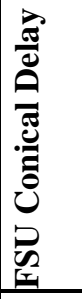 & 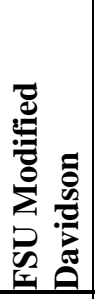 & 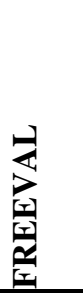 & 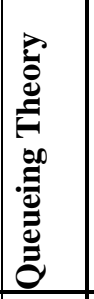 & 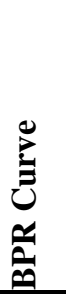 & 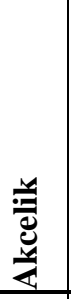 & 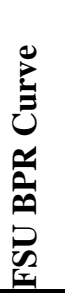 & 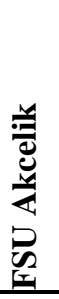 & 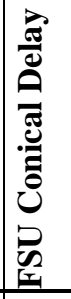 & 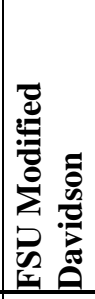 & 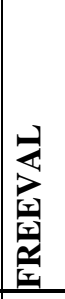 & 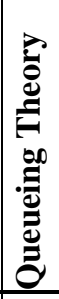 \\
\hline January $19^{\text {th }}$ & 0.9 & -4.9 & -1.5 & 9.4 & 12.1 & -3.0 & -2.1 & 2.4 & 5.2 & 6.9 & 5.5 & 11.7 & 12.9 & 5.6 & 3.4 & 4.3 & 18 & 28 & 22 & 47 & 51 & 22 & 12 & 16 \\
\hline February $7^{\text {th }}$ & 4.9 & 0.3 & 1.8 & 22.7 & 24.0 & 2.8 & 6.5 & 10.4 & 4.9 & 3.9 & 2.8 & 22.7 & 24.0 & 4.5 & 6.5 & 10.4 & 15 & 14 & 8 & 73 & 78 & 14 & 21 & 36 \\
\hline March 30 ${ }^{\text {th }}$ & 0.7 & -10.0 & -10.5 & 12.8 & 14.5 & -7.6 & 1.0 & 1.5 & 2.2 & 10.0 & 10.5 & 12.8 & 14.5 & 7.6 & 3.3 & 6.8 & 9 & 46 & 49 & 53 & 61 & 36 & 14 & 29 \\
\hline April 10 ${ }^{\text {th }}$ & -0.1 & 0.0 & 2.3 & 20.1 & 22.0 & 2.3 & 5.6 & 7.2 & 2.0 & 2.4 & 3.6 & 20.1 & 22.0 & 3.3 & 7.1 & 7.8 & 8 & 8 & 14 & 68 & 73 & 10 & 23 & 30 \\
\hline May $9^{\text {th }}$ & 9.0 & 2.7 & 6.1 & 23.7 & 25.0 & 5.1 & 11.1 & 12.9 & 9.9 & 7.7 & 8.3 & 23.7 & 25.0 & 8.2 & 11.1 & 12.9 & 30 & 26 & 26 & 75 & 79 & 25 & 31 & 45 \\
\hline June 22 $2^{\text {nd }}$ & 6.1 & 0.8 & 3.1 & 22.2 & 23.6 & 3.2 & 6.7 & 9.3 & 6.6 & 2.2 & 4.9 & 22.2 & 23.6 & 3.2 & 8.2 & 10.6 & 23 & 7 & 16 & 73 & 77 & 10 & 27 & 37 \\
\hline July 20 ${ }^{\text {th }}$ & 11.3 & 4.1 & 8.7 & 22.5 & 24.1 & 6.4 & 7.9 & 13.9 & 12.6 & 7.2 & 10.2 & 24.2 & 24.4 & 8.6 & 9.6 & 14.0 & 38 & 20 & 31 & 73 & 74 & 24 & 29 & 45 \\
\hline August $17^{\text {th }}$ & 5.8 & -0.8 & 2.8 & 20.5 & 21.6 & 1.7 & 6.7 & 11.3 & 9.5 & 6.5 & 9.0 & 20.5 & 21.6 & 7.1 & 6.7 & 11.3 & 35 & 27 & 36 & 74 & 78 & 28 & 22 & 45 \\
\hline December $6^{\text {th }}$ & 10.7 & 4.9 & 7.5 & 26.8 & 28.0 & 7.4 & 12.1 & 19.2 & 12.6 & 8.9 & 11.1 & 26.8 & 28.0 & 10.1 & 12.1 & 19.2 & 34 & 26 & 32 & 77 & 81 & 29 & 34 & 57 \\
\hline December $12^{\text {th }}$ & -4.6 & -8.5 & -6.9 & 4.0 & 7.8 & -6.8 & -7.2 & -4.1 & 7.2 & 8.7 & 7.9 & 14.8 & 14.6 & 7.6 & 8.5 & 6.9 & 20 & 24 & 21 & 47 & 47 & 20 & 22 & 19 \\
\hline Average & 4.5 & -1.2 & 1.3 & 18.5 & 20.3 & 1.1 & 4.8 & 8.4 & 7.3 & 6.4 & 7.4 & 19.9 & 21.0 & 6.6 & 7.7 & 10.4 & 23 & 23 & 25 & 66 & 70 & 22 & 24 & 36 \\
\hline
\end{tabular}


Table 4-6: Performance Summary of Mobility Methods (Freeway, PM Peak, Speed) for Probe Data

\begin{tabular}{|c|c|c|c|c|c|c|c|c|c|c|c|c|c|c|c|c|c|c|c|c|c|c|c|c|}
\hline & \multicolumn{8}{|c|}{ ME } & \multicolumn{8}{|c|}{ MAE } & \multicolumn{8}{|c|}{ MAPE } \\
\hline & 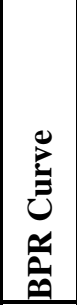 & 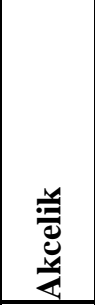 & 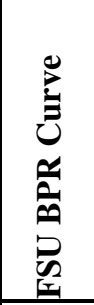 & 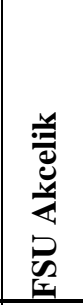 & 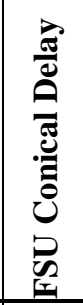 & 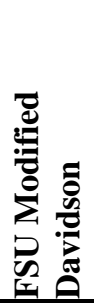 & $\frac{2}{2}$ & 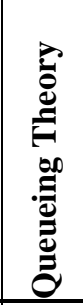 & 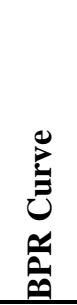 & 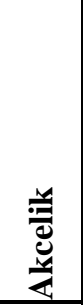 & 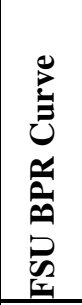 & 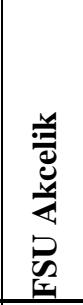 & 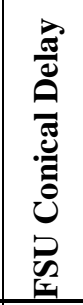 & 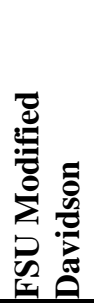 & 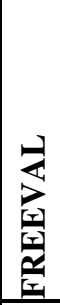 & 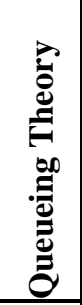 & 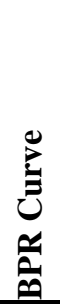 & 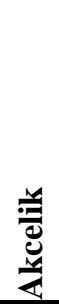 & 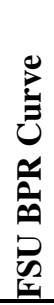 & 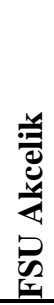 & 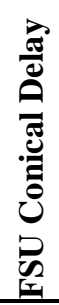 & 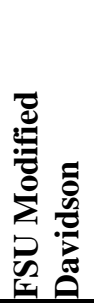 & 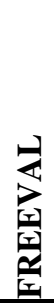 & 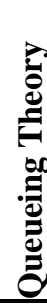 \\
\hline January $19^{\text {th }}$ & 1.4 & -4.5 & -1.1 & 9.8 & 12.6 & -2.6 & -1.6 & 2.9 & 4.8 & 5.3 & 4.4 & 12.3 & 13.5 & 42 & 2.6 & 4.9 & 16 & 20 & 15 & 49 & 52 & 15 & 8 & 18 \\
\hline February $7^{\text {th }}$ & 3.5 & -1.1 & 0.3 & 21.2 & 22.6 & 1.4 & 5.0 & 8.9 & 3.5 & 3.5 & 2.0 & 21.2 & 22.6 & 3.9 & 5.4 & 8.9 & 11 & 14 & 7 & 72 & 77 & 15 & 18 & 33 \\
\hline March 30 ${ }^{\text {th }}$ & -7.4 & -10.0 & -10.5 & 12.8 & 14.5 & -7.6 & 1.0 & 1.5 & 8.1 & 10.0 & 10.5 & 12.8 & 14.5 & 7.6 & 3.3 & 6.8 & 38 & 46 & 49 & 53 & 61 & 36 & 14 & 29 \\
\hline Apr & 5.2 & 0.0 & 2.3 & 20.1 & 22.0 & 2.3 & 5.6 & 7.2 & 5.4 & 2.4 & 3.6 & 20.1 & 22.0 & 3.3 & 7.1 & 7.8 & 20 & 8 & 14 & 68 & 73 & 10 & 23 & 30 \\
\hline May $9^{\text {th }}$ & 6.1 & -0.3 & 3.2 & 20.7 & 22.0 & 2.2 & 8.2 & 9.9 & 6.7 & 4.8 & 5.2 & 20.7 & 22.0 & 4.7 & 8.2 & 10.4 & 24 & 18 & 18 & 74 & 78 & 16 & 26 & 40 \\
\hline June 22 $2^{\text {nd }}$ & 3.9 & -1.4 & 0.9 & 20.0 & 21.4 & 1.0 & 4.5 & 7.1 & 5.6 & 2.5 & 4.6 & 20.0 & 21.4 & 2.1 & 6.6 & 9.1 & 20 & 9 & 16 & 71 & 76 & 7 & 23 & 34 \\
\hline August $17^{\text {th }}$ & 4.5 & -2.1 & 1.5 & 19.2 & 20.3 & 0.4 & 5.4 & 10.1 & 8.5 & 5.5 & 8.5 & 19.2 & 20.3 & 6.0 & 5.4 & 10.1 & 33 & 25 & 35 & 73 & 77 & 25 & 20 & 42 \\
\hline December $6^{\text {th }}$ & 0.1 & -5.7 & -3.1 & 16.2 & 17.4 & -3.2 & 1.5 & 8.6 & 7.4 & 8.3 & 9.1 & 16.2 & 17.4 & 7.0 & 2.6 & 8.6 & 31 & 40 & 41 & 68 & 73 & 33 & 10 & 38 \\
\hline December $12^{\text {th }}$ & -1.7 & -5.5 & -3.9 & 7.0 & 10.8 & -3.8 & -4.2 & -1.1 & 2.7 & 5.5 & 4.0 & 8.8 & 10.8 & 4.0 & 4.2 & 1.4 & 10 & 20 & 15 & 34 & 40 & 14 & 13 & 5 \\
\hline Average & 2.4 & -2.9 & -0.4 & 16.7 & 18.5 & -4.3 & 6.6 & 6.6 & 6.3 & 5.4 & 6.0 & 17.3 & 18.7 & 8.0 & 8.0 & 8.0 & 24 & 22 & 24 & 63 & 68 & 31 & 31 & 31 \\
\hline
\end{tabular}




\section{Impact of Incident Analysis:}

This study further investigated the predictive ability of these mobility estimation methods in the presence of an incident during the AM peak period (uncongested freeway study segment).

For investigation purposes, an incident day was selected that occurred during the AM peak period. Next, from the previously selected 10 days, a day was picked such that the incident day and the selected day were in the same month. The real-world incident happened in March between 08:00 AM to 08:30 AM near NW 103rd Street. Due to the incident, the capacity was adjusted accordingly based on the HCM procedure. Table 4-7 presents the performance summary of mobility estimation methods during the incident.

Table 4-7: Performance Summary of Mobility Methods During Incident

\begin{tabular}{|l|c|c|c|}
\hline & ME & MAE & MAPE \\
\hline BPR Curve & 7.73 & 8.86 & 21.89 \\
\hline Akcelik & 3.25 & 5.06 & 12.23 \\
\hline FSU BPR Curve & 6.79 & 8.04 & 19.98 \\
\hline FSU Akcelik & 7.91 & 9.08 & 23.17 \\
\hline FSU Conical & 11.81 & 12.50 & 29.29 \\
\hline FSU Davidson & 4.44 & 5.74 & 13.96 \\
\hline FREEVAL & 8.01 & 8.72 & 17.00 \\
\hline Queueing Theory & 11.52 & 12.65 & 25.74 \\
\hline
\end{tabular}

This investigation found that the error magnitude of mobility estimation methods during an incident were larger compared to the non-incident estimation. This was due to the lime lag between the actual incident time and the reported time. According to Table 47, the lowest error was observed for the Akcelik model, followed by FSU Davidson, FSU BPR curve and BPR curve models. Only the HCM procedure predicted a higher travel time when compared with the real-world measures. This occurred because the HCM-based 
procedure takes a longer time to recover from congestion caused by the incident. Other models, except for the Queueing Analysis and FREEVAL, do not take into consideration the time required for the queue to be removed. The predictions are made based on the $\mathrm{d} / \mathrm{c}$ ratio.

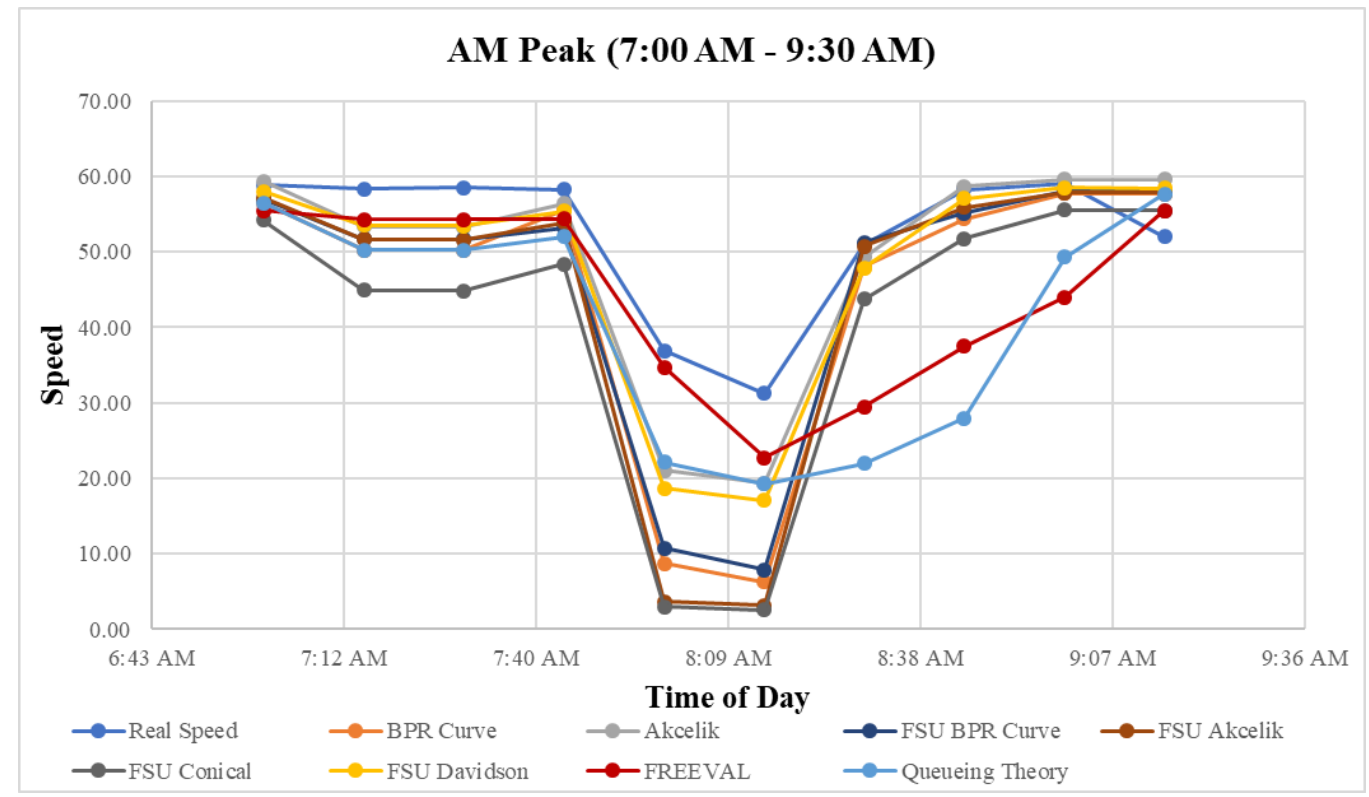

Figure 4-19 : Incident impact on predictive ability of different mobility estimation methods (Near 103rd Street)

\subsubsection{Arterial Mobility}

This study utilized Sunrise Boulevard between US 441 and US 1 as the arterial study area. Three methods (BPR curve, Akcelik function, and FSU Model) were applied to the arterial segment. For the study purpose, the volume data collected from the Broward County MVDS was divided into the three time periods. However, the definition of time periods is different in arterials since the congestion occurs at different times at the two studied corridors.

- AM Peak (07:00 AM - 09:00 AM) 
- Mid-Day (11:00 AM - 01:00 PM)

- PM Peak (04:00 PM - 06:00 PM)

Regarding the capacity used as input to the volume-delay functions, this study utilized four different possible capacities, which was discussed earlier in Section 3.3.4. In order to avoid repetitive discussion, arterial mobility measures corresponding only to June 22, 2017 were presented in the following section for all four capacity assumptions.

\section{$\underline{\text { AM Peak }}$}

Figures 4-21 to 4-24 presented the mobility measures (e.g., speed and travel time) for the arterial study corridor during the AM Peak period. The figures also provide information on the predictive ability of different mobility estimation methods.

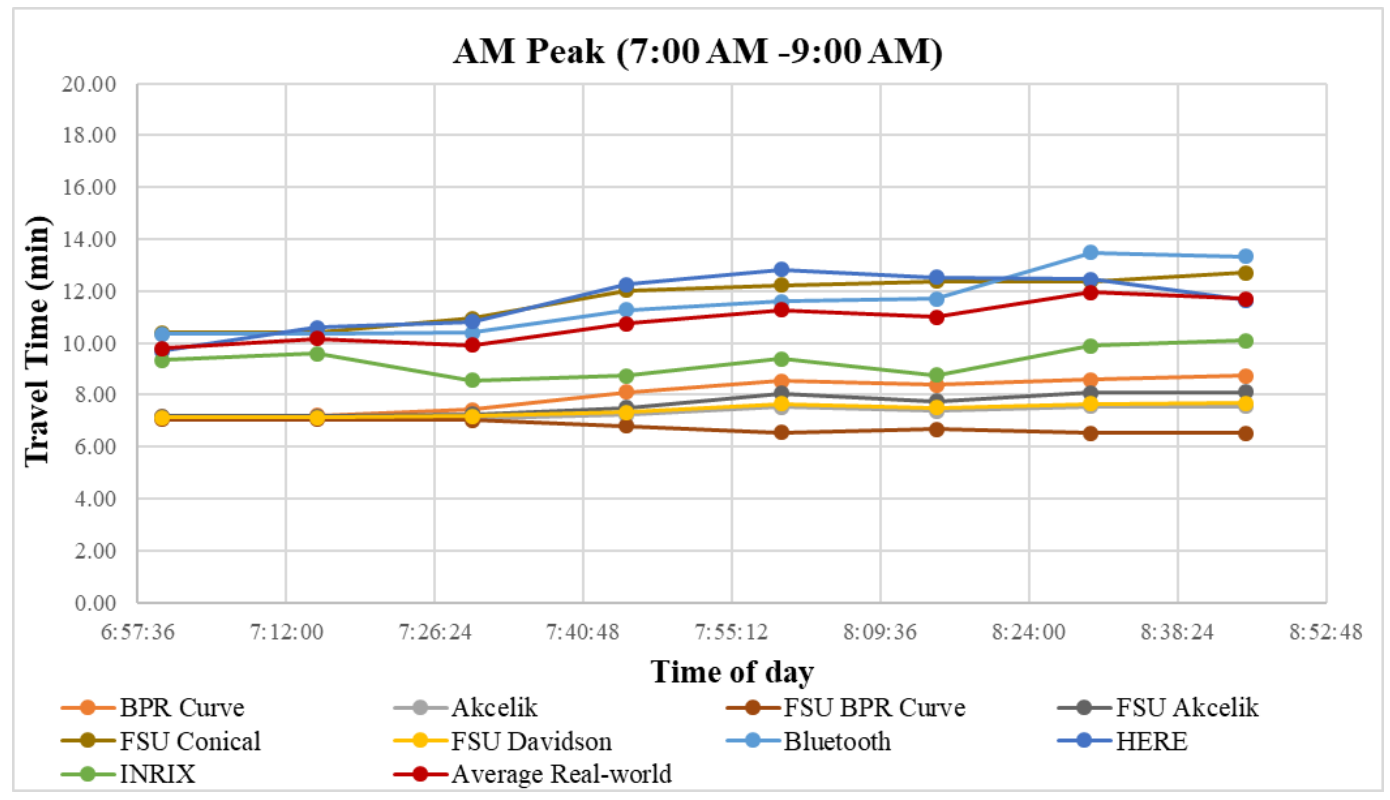

Figure 4-20: Predictive ability of different mobility estimation methods Travel Time (Arterial, AM Peak, Capacity 880 VPHPL Used in Volume-Delay Functions) 


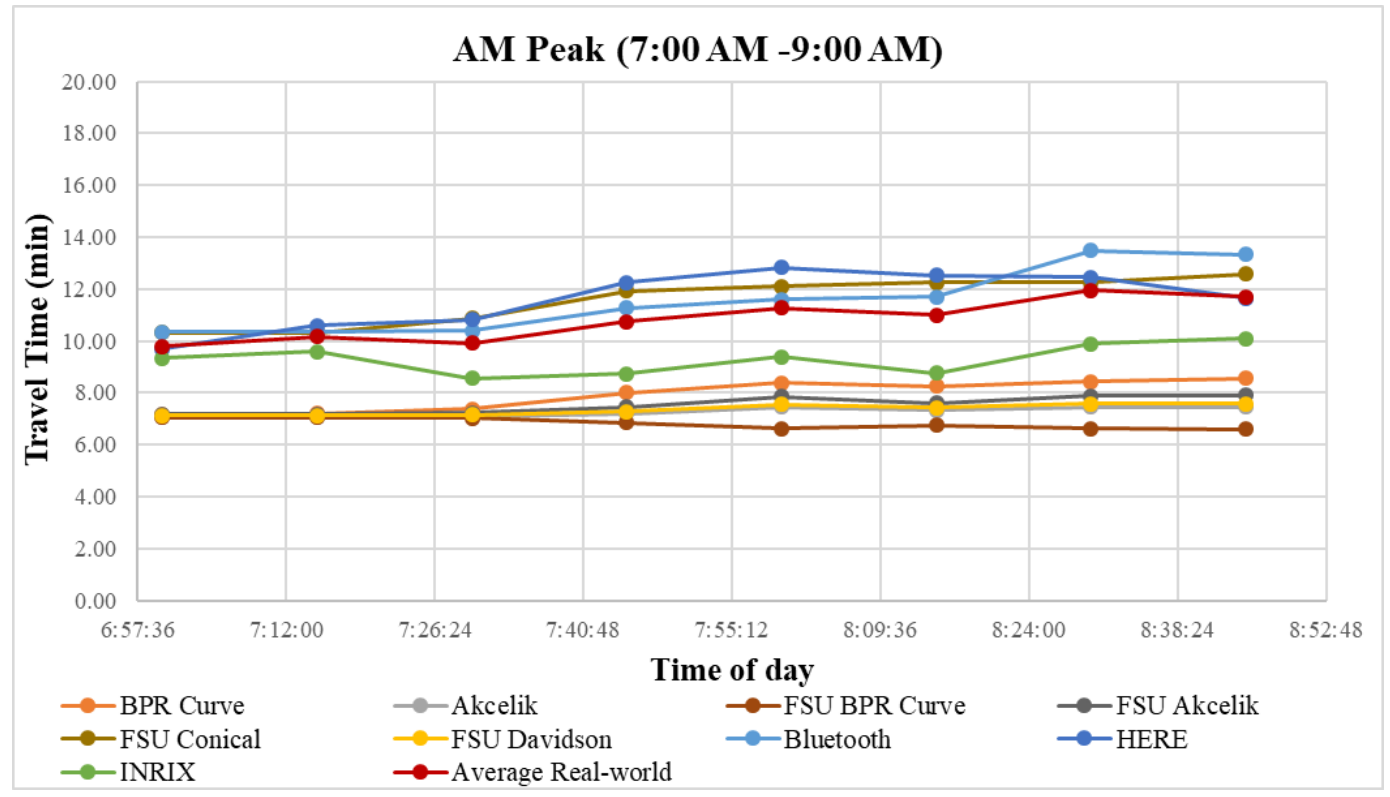

Figure 4-21: Predictive ability of different mobility estimation methods -

Travel Time (Arterial, AM Peak, Capacity 900 VPHPL Used in Volume-Delay Functions)

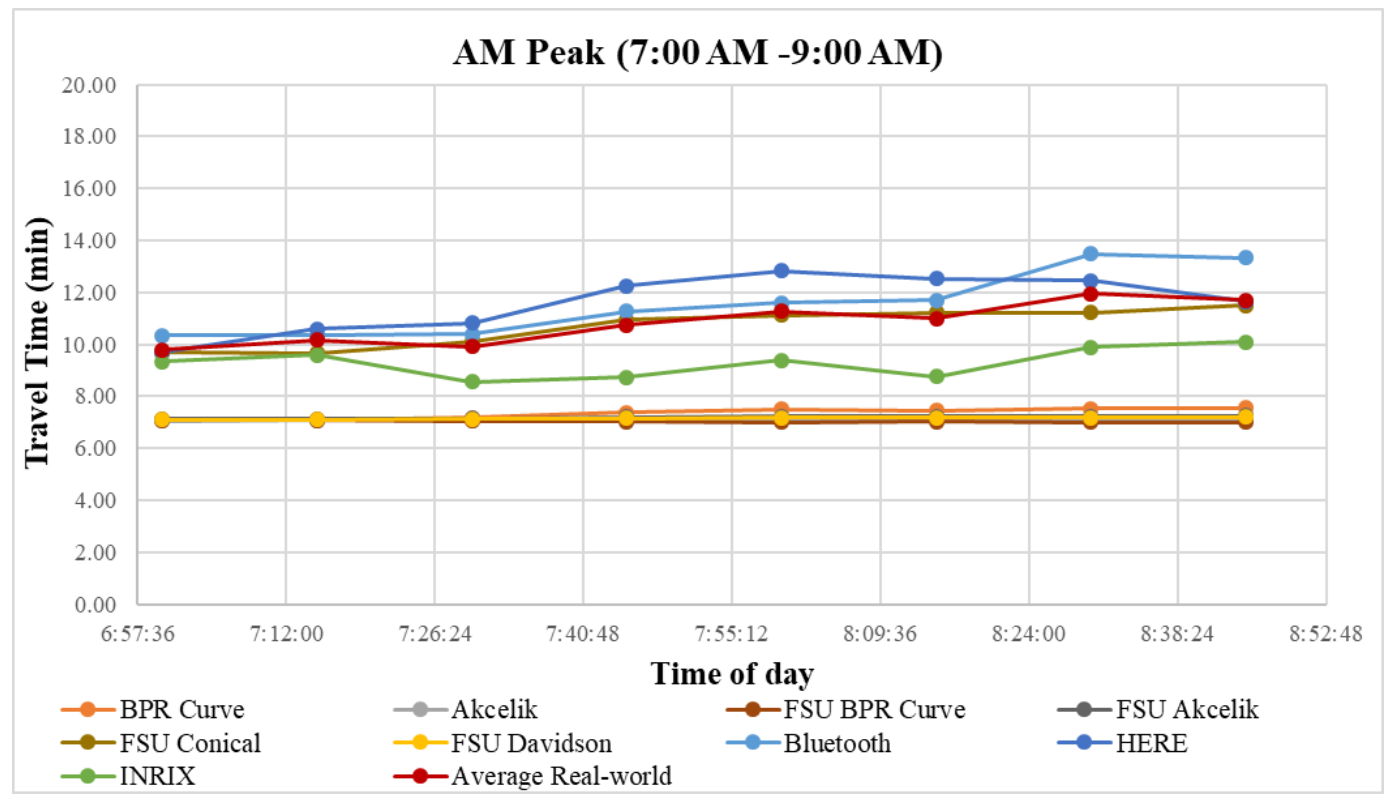

Figure 4-22: Predictive ability of different mobility estimation methods Travel Time (Arterial, AM Peak, Capacity 1120 VPHPL Used in Volume-Delay Functions) 


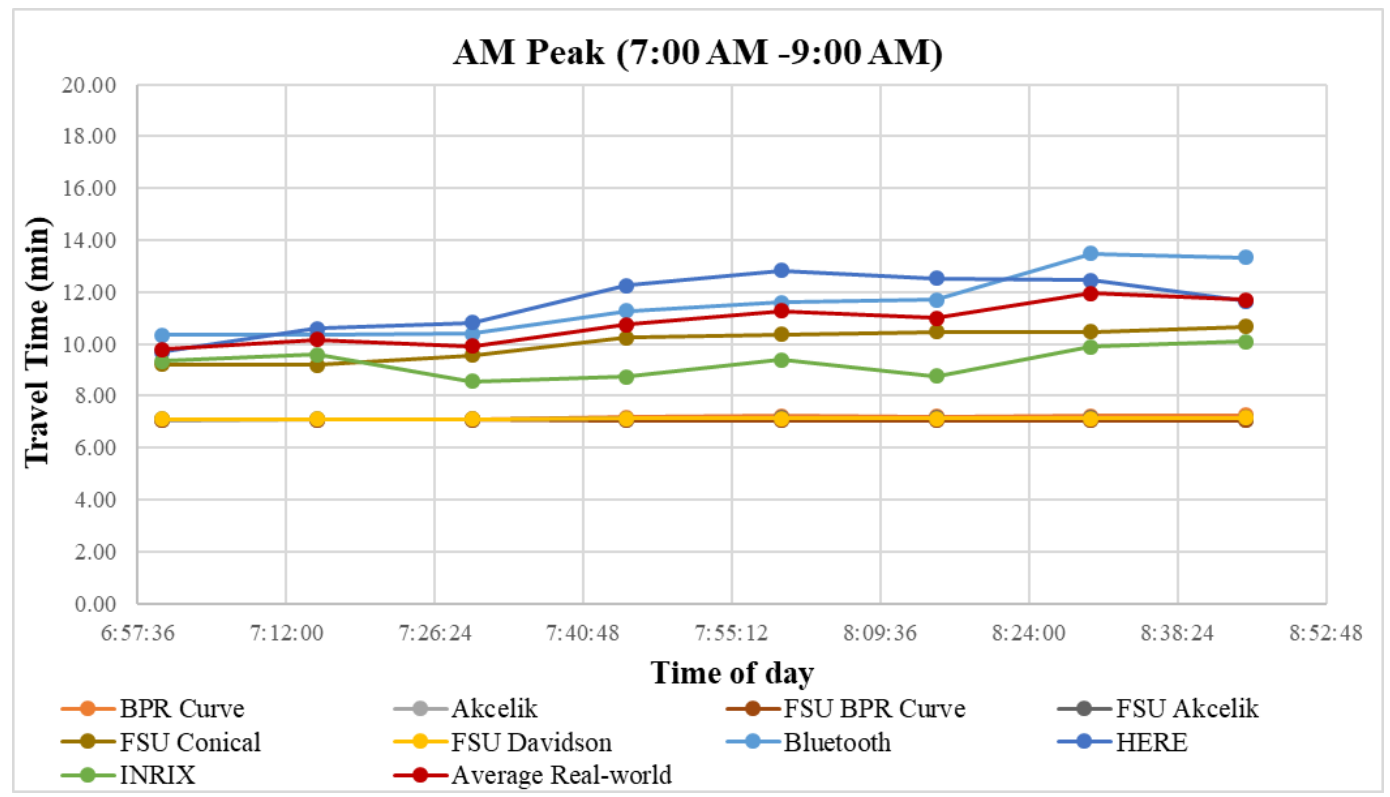

Figure 4-23: Predictive ability of different mobility estimation methods Travel Time (Arterial, AM Peak, Capacity 1370 VPHPL Used in Volume-Delay Functions)

The above figures suggest that only the FSU Conical Delay model predicted travel time closer to the real world. This has also been captured by the performance summary shown in Tables 4-8 to 4-11. All other model predictions were almost similar to each other, but not closer to the real world. There could be many reasons for this difference as the arterial characteristics (e.g., level of service) are completely different than freeways in many ways. For instance, intersection signal timing is a major factor that determines level of service in arterials because the roadway capacity varies depending on the signal timing. If the traffic signal timing is not designed properly at signalized intersections, it can end up forming heavy congestion in arterials. Moreover, arterials are frequently accessed, which also affects travel time. 
Table 4-8: Performance Summary of Mobility Methods (Arterials, AM Peak, Speed) for Capacity 800 VPHPL Used in Volume-Delay Functions

\begin{tabular}{|c|c|c|c|c|c|c|c|c|c|c|c|c|c|c|c|c|c|c|}
\hline \multicolumn{19}{|c|}{ Capacity 800 VPHPL Used in Volume-Delay function } \\
\hline & \multicolumn{6}{|c|}{ ME } & \multicolumn{6}{|c|}{ MAE } & \multicolumn{6}{|c|}{ MAPE } \\
\hline & 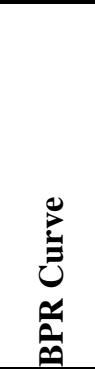 & 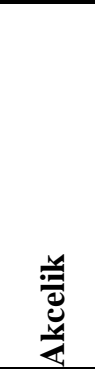 & 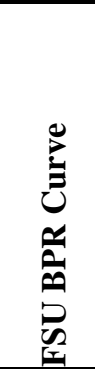 & 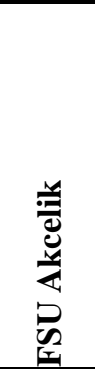 & 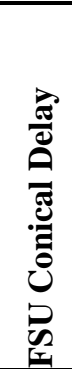 & 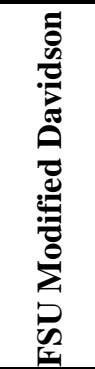 & 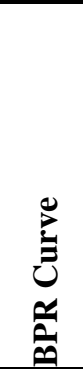 & 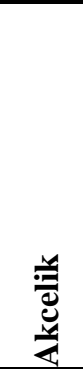 & 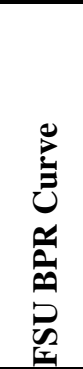 & 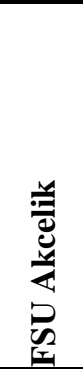 & 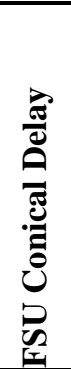 & 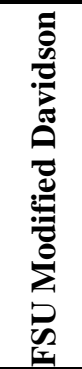 & 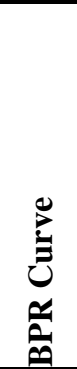 & 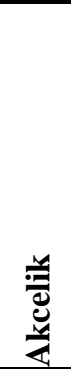 & 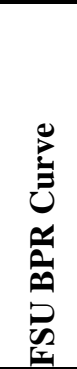 & 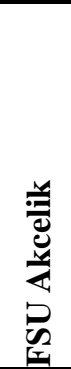 & 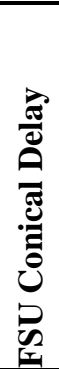 & 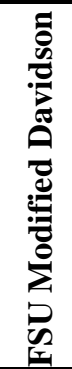 \\
\hline January $18^{\text {th }}$ & -12.9 & -14.1 & -14.5 & -13.4 & 0.7 & -13.8 & 12.9 & 14.1 & 14.5 & 13.4 & 1.3 & 13.8 & 42 & 46 & 47 & 44 & 4 & 45 \\
\hline February $5^{\text {th }}$ & -17.4 & -21.5 & -27.0 & -19.4 & -5.8 & -21.1 & 17.4 & 21.5 & 27.0 & 19.4 & 5.8 & 21.1 & 83 & 104 & 131 & 93 & 28 & 102 \\
\hline February $24^{\text {th }}$ & -18.2 & -22.5 & -26.4 & -20.8 & -6.0 & -23.7 & 18.2 & 22.5 & 26.4 & 20.8 & 6.0 & 23.7 & 88 & 110 & 130 & 101 & 29 & 116 \\
\hline April 11 ${ }^{\text {th }}$ & -17.8 & -21.6 & -24.4 & -20.1 & -5.1 & -21.1 & 17.8 & 21.6 & 24.4 & 20.1 & 5.1 & 21.1 & 81 & 98 & 111 & 91 & 23 & 96 \\
\hline May $10^{\text {th }}$ & -17.3 & -21.3 & -25.3 & -19.4 & -5.0 & -20.7 & 17.3 & 21.3 & 25.3 & 19.4 & 5.0 & 20.7 & 79 & 97 & 116 & 88 & 23 & 95 \\
\hline June $22^{\text {nd }}$ & -14.2 & -17.9 & -21.4 & -16.1 & -1.7 & -17.4 & 14.2 & 17.9 & 21.4 & 16.1 & 1.7 & 17.4 & 55 & 70 & 85 & 63 & 7 & 68 \\
\hline July $5^{\text {th }}$ & -16.8 & -16.8 & -16.8 & -16.6 & -7.9 & -16.7 & 16.8 & 16.8 & 16.8 & 16.6 & 7.9 & 16.7 & 60 & 60 & 60 & 59 & 28 & 59 \\
\hline September $27^{\text {th }}$ & -20.4 & -24.2 & -26.8 & -22.8 & -7.3 & -23.7 & 20.4 & 24.2 & 26.8 & 22.8 & 7.3 & 23.7 & 105 & 125 & 138 & 117 & 38 & 122 \\
\hline October $3^{\text {rd }}$ & -11.9 & -14.4 & -15.4 & -13.4 & 2.0 & -14.0 & 11.9 & 14.4 & 15.4 & 13.4 & 2.0 & 14.0 & 40 & 48 & 52 & 45 & 7 & 47 \\
\hline October $31^{\text {st }}$ & -16.0 & -19.8 & -23.4 & -18.0 & -3.2 & -19.3 & 16.0 & 19.8 & 23.4 & 18.0 & 3.4 & 19.3 & 69 & 85 & 99 & 77 & 15 & 83 \\
\hline Average & -16.3 & -19.4 & -22.1 & -18.0 & -3.9 & -19.2 & 16.3 & 19.4 & 22.1 & 18.0 & 4.6 & 19.2 & 70 & 84 & 97 & 78 & 20 & 83 \\
\hline
\end{tabular}


Table 4-9: Performance Summary of Mobility Methods (Arterials, AM Peak, Speed) for Capacity 900 VPHPL Used in Volume-Delay Functions

\begin{tabular}{|c|c|c|c|c|c|c|c|c|c|c|c|c|c|c|c|c|c|c|}
\hline \multicolumn{19}{|c|}{ Capacity 900 VPHPL Used in Volume-Delay function } \\
\hline & \multicolumn{6}{|c|}{ ME } & \multicolumn{6}{|c|}{ MAE } & \multicolumn{6}{|c|}{ MAPE } \\
\hline & $\underset{ٍ}{ٍ}$ & 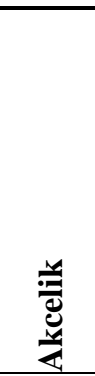 & 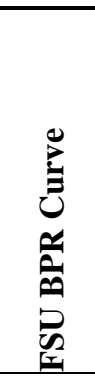 & 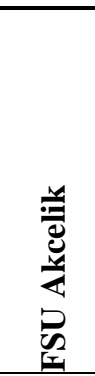 & 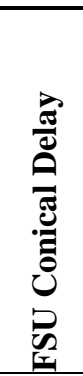 & 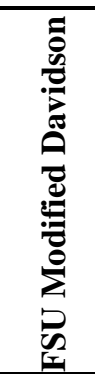 & 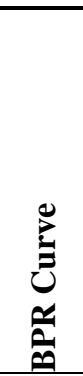 & 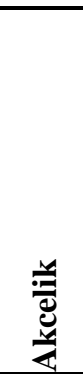 & 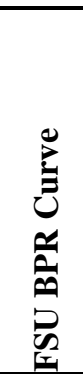 & 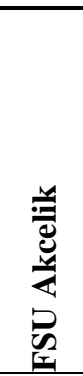 & 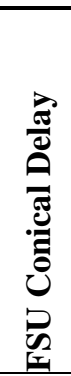 & 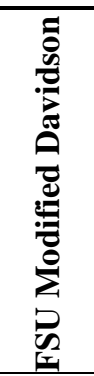 & $\underset{\Xi}{\Xi}$ & 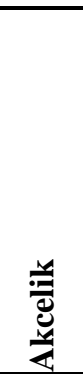 & 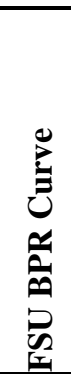 & 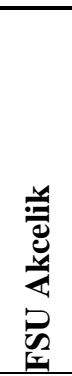 & 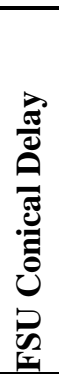 & 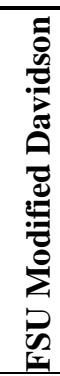 \\
\hline January $18^{\text {th }}$ & -13.1 & -14.2 & -14.5 & -13.5 & 0.5 & -13.9 & 13.1 & 14.2 & 14.5 & 13.5 & 1.2 & 13.9 & 43 & 46 & 47 & 44 & 4 & 45 \\
\hline February $5^{\text {th }}$ & -18.0 & -21.9 & -26.5 & -20.0 & -6.0 & -21.5 & 18.0 & 21.9 & 26.5 & 20.0 & 6.0 & 21.5 & 86 & 105 & 128 & 96 & 29 & 103 \\
\hline February $24^{\text {th }}$ & -18.7 & -22.8 & -26.0 & -21.4 & -6.2 & -22.4 & 18.7 & 22.8 & 26.0 & 21.4 & 6.2 & 22.4 & 91 & 112 & 128 & 104 & 31 & 109 \\
\hline April 11 ${ }^{\text {th }}$ & -18.3 & -21.8 & -24.2 & -20.6 & -5.4 & -21.4 & 18.3 & 21.8 & 24.2 & 20.6 & 5.4 & 21.4 & 83 & 99 & 110 & 93 & 24 & 97 \\
\hline May $10^{\text {th }}$ & -17.8 & -21.6 & -24.9 & -20.0 & -5.2 & -21.1 & 17.8 & 21.6 & 24.9 & 20.0 & 5.2 & 21.1 & 81 & 99 & 114 & 91 & 24 & 96 \\
\hline June 22 ${ }^{\text {nd }}$ & -14.7 & -18.1 & -21.0 & -16.6 & -2.0 & -17.6 & 14.7 & 18.1 & 21.0 & 16.6 & 2.0 & 17.6 & 57 & 71 & 83 & 65 & 8 & 69 \\
\hline July $5^{\text {th }}$ & -16.8 & -16.8 & -16.8 & -16.6 & -8.0 & -16.7 & 16.8 & 16.8 & 16.8 & 16.6 & 8.0 & 16.7 & 60 & 60 & 60 & 59 & 29 & 59 \\
\hline September $27^{\text {th }}$ & -20.9 & -24.4 & -26.5 & -23.2 & -7.6 & -24.0 & 20.9 & 24.4 & 26.5 & 23.2 & 7.6 & 24.0 & 107 & 126 & 137 & 119 & 39 & 123 \\
\hline October $3^{\text {rd }}$ & -12.2 & -14.5 & -15.3 & -13.5 & 1.8 & -14.1 & 12.2 & 14.5 & 15.3 & 13.5 & 1.8 & 14.1 & 41 & 49 & 51 & 45 & 6 & 47 \\
\hline October $31^{\text {st }}$ & -16.5 & -20.1 & -23.0 & -18.5 & -3.5 & -19.6 & 16.5 & 20.1 & 23.0 & 18.5 & 3.5 & 19.6 & 71 & 86 & 98 & 79 & 16 & 84 \\
\hline Average & -16.7 & -19.6 & -21.9 & -18.4 & -4.2 & -19.2 & 16.7 & 19.6 & 21.9 & 18.4 & 4.7 & 19.2 & 72 & 85 & 96 & 80 & 21 & 83 \\
\hline
\end{tabular}


Table 4-10: Performance Summary of Mobility Methods (Arterials, AM Peak, Speed) for Capacity 1120 VPHPL Used in Volume-Delay Functions

\begin{tabular}{|c|c|c|c|c|c|c|c|c|c|c|c|c|c|c|c|c|c|c|}
\hline \multicolumn{19}{|c|}{ Capacity 1120 VPHPL Used in Volume-Delay function } \\
\hline & \multicolumn{6}{|c|}{ ME } & \multicolumn{6}{|c|}{ MAE } & \multicolumn{6}{|c|}{ MAPE } \\
\hline & 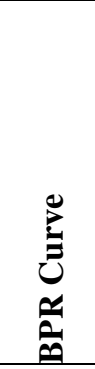 & 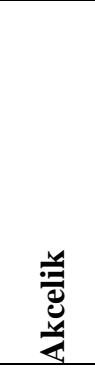 & 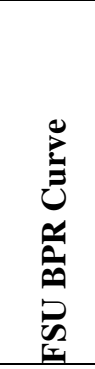 & 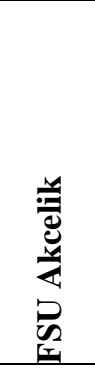 & 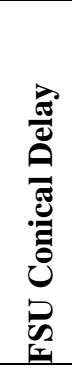 & 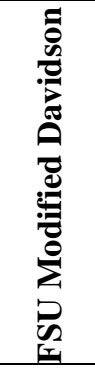 & 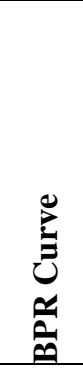 & 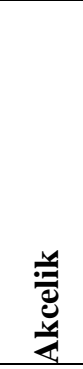 & 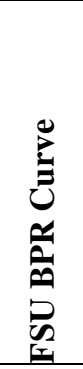 & 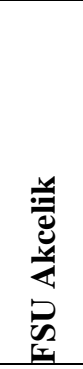 & 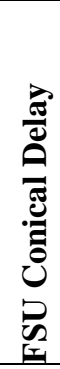 & 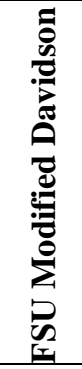 & 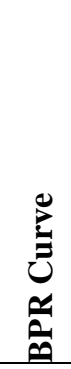 & 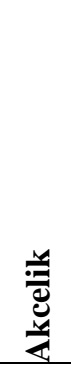 & 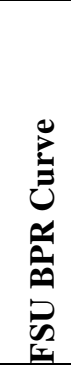 & 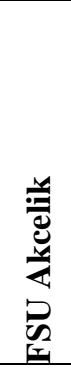 & 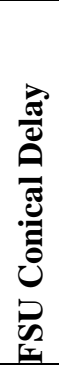 & 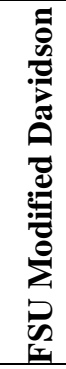 \\
\hline January $18^{\text {th }}$ & -13.9 & -14.2 & -14.3 & -13.9 & -1.6 & -14.0 & 13.9 & 14.2 & 14.3 & 13.9 & 1.6 & 14.0 & 46 & 47 & 47 & 46 & 5 & 46 \\
\hline February $5^{\text {th }}$ & -21.7 & -23.6 & -24.3 & -23.0 & -8.3 & -23.2 & 21.7 & 23.6 & 24.3 & 23.0 & 8.3 & 23.2 & 104 & 114 & 117 & 111 & 40 & 112 \\
\hline February $24^{\text {th }}$ & -22.2 & -24.0 & -24.5 & -23.3 & -8.5 & -23.6 & 22.2 & 24.0 & 24.5 & 23.3 & 8.5 & 23.6 & 109 & 118 & 120 & 114 & 42 & 116 \\
\hline April 11 ${ }^{\text {th }}$ & -21.2 & -22.6 & -23.0 & -22.1 & -7.6 & -22.3 & 21.2 & 22.6 & 23.0 & 22.1 & 7.6 & 22.3 & 96 & 103 & 105 & 100 & 35 & 101 \\
\hline May $10^{\text {th }}$ & -21.1 & -22.9 & -23.3 & -22.2 & -7.5 & -22.4 & 21.1 & 22.9 & 23.3 & 22.2 & 7.5 & 22.4 & 96 & 104 & 107 & 101 & 34 & 103 \\
\hline June $22^{\text {nd }}$ & -17.7 & -19.2 & -19.6 & -18.6 & -4.3 & -18.8 & 17.7 & 19.2 & 19.6 & 18.6 & 4.3 & 18.8 & 69 & 76 & 77 & 73 & 17 & 74 \\
\hline July $5^{\text {th }}$ & -16.8 & -16.8 & -16.8 & -16.7 & -9.5 & -16.7 & 16.8 & 16.8 & 16.8 & 16.7 & 9.5 & 16.7 & 60 & 60 & 60 & 59 & 34 & 60 \\
\hline September $27^{\text {th }}$ & -23.7 & -25.1 & -25.5 & -24.5 & -9.9 & -24.8 & 23.7 & 25.1 & 25.5 & 24.5 & 9.9 & 24.8 & 122 & 130 & 131 & 126 & 51 & 128 \\
\hline October $3^{\text {rd }}$ & -13.9 & -14.7 & -14.9 & -14.2 & -0.4 & -14.4 & 13.9 & 14.7 & 14.9 & 14.2 & 0.9 & 14.4 & 47 & 49 & 50 & 48 & 3 & 48 \\
\hline October $31^{\text {st }}$ & -19.6 & -21.2 & -21.6 & -20.5 & -5.8 & -20.8 & 19.6 & 21.2 & 21.6 & 20.5 & 5.8 & 20.8 & 84 & 90 & 92 & 88 & 25 & 89 \\
\hline Average & -19.2 & -20.4 & -20.8 & -19.9 & -6.3 & -20.1 & 19.2 & 20.4 & 20.8 & 19.9 & 6.4 & 20.1 & 83 & 89 & 91 & 87 & 29 & 88 \\
\hline
\end{tabular}


Table 4-11: Performance Summary of Mobility Methods (Arterials, AM Peak, Speed) for Capacity 1370 VPHPL Used in Volume-Delay Functions

\begin{tabular}{|c|c|c|c|c|c|c|c|c|c|c|c|c|c|c|c|c|c|c|}
\hline \multicolumn{19}{|c|}{ Capacity 1370 VPHPL Used in Volume-Delay function } \\
\hline & \multicolumn{6}{|c|}{ ME } & \multicolumn{6}{|c|}{ MAE } & \multicolumn{6}{|c|}{ MAPE } \\
\hline & 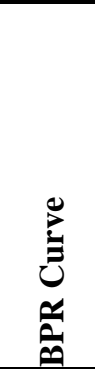 & 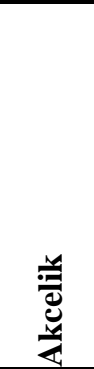 & 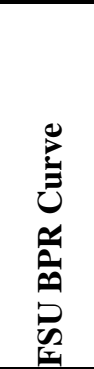 & 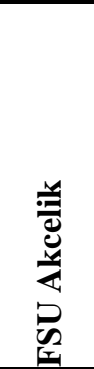 & 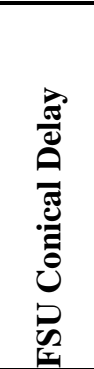 & 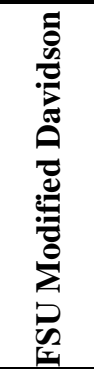 & 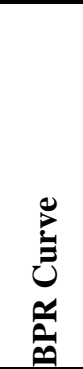 & 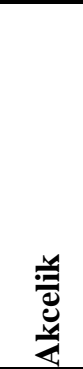 & 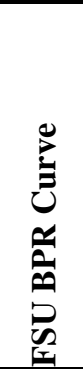 & 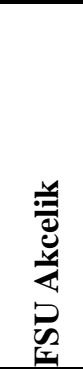 & 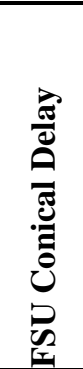 & 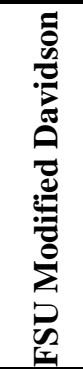 & 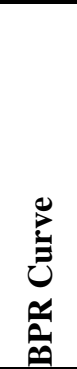 & 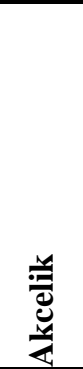 & 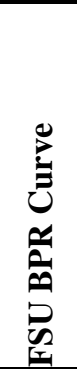 & 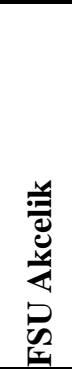 & 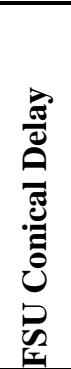 & 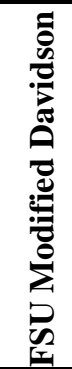 \\
\hline January $18^{\text {th }}$ & -14.2 & -14.3 & -14.3 & -14.1 & -3.4 & -14.1 & 14.2 & 14.3 & 14.3 & 14.1 & 3.4 & 14.1 & 46 & 47 & 47 & 46 & 11 & 46 \\
\hline February $5^{\text {th }}$ & -23.0 & -23.8 & -23.9 & -23.4 & -10.3 & -23.5 & 23.0 & 23.8 & 23.9 & 23.4 & 10.3 & 23.5 & 111 & 115 & 116 & 113 & 50 & 113 \\
\hline February $24^{\text {th }}$ & -23.4 & -24.1 & -24.2 & -23.8 & -10.5 & -23.8 & 23.4 & 24.1 & 24.2 & 23.8 & 10.5 & 23.8 & 115 & 118 & 119 & 117 & 52 & 117 \\
\hline April 11 ${ }^{\text {th }}$ & -22.2 & -22.7 & -22.8 & -22.4 & -9.6 & -22.5 & 22.2 & 22.7 & 22.8 & 22.4 & 9.6 & 22.5 & 101 & 103 & 104 & 102 & 44 & 102 \\
\hline May $10^{\text {th }}$ & -22.3 & -23.0 & -23.1 & -22.6 & -9.5 & -22.7 & 22.3 & 23.0 & 23.1 & 22.6 & 9.5 & 22.7 & 102 & 105 & 106 & 103 & 43 & 104 \\
\hline June 22 $2^{\text {nd }}$ & -18.7 & -19.3 & -19.4 & -19.0 & -6.2 & -19.0 & 18.7 & 19.3 & 19.4 & 19.0 & 6.2 & 19.0 & 74 & 76 & 77 & 75 & 24 & 75 \\
\hline July $5^{\text {th }}$ & -16.8 & -16.8 & -16.8 & -16.7 & -10.6 & -16.7 & 16.8 & 16.8 & 16.8 & 16.7 & 10.6 & 16.7 & 60 & 60 & 60 & 60 & 38 & 60 \\
\hline September $27^{\text {th }}$ & -24.7 & -25.2 & -25.3 & -24.9 & -11.8 & -25.0 & 24.7 & 25.2 & 25.3 & 24.9 & 11.8 & 25.0 & 127 & 130 & 131 & 128 & 61 & 129 \\
\hline October $3^{\text {rd }}$ & -14.5 & -14.8 & -14.8 & -14.5 & -2.3 & -14.5 & 14.5 & 14.8 & 14.8 & 14.5 & 2.3 & 14.5 & 49 & 50 & 50 & 49 & 8 & 49 \\
\hline October $31^{\text {st }}$ & -20.7 & -21.3 & -21.4 & -20.9 & -7.8 & -21.0 & 20.7 & 21.3 & 21.4 & 20.9 & 7.8 & 21.0 & 88 & 91 & 91 & 89 & 34 & 90 \\
\hline Average & -20.1 & -20.5 & -20.6 & -20.2 & -8.2 & -20.3 & 20.1 & 20.5 & 20.6 & 20.2 & 8.2 & 20.3 & 87 & 89 & 90 & 88 & 36 & 88 \\
\hline
\end{tabular}




\section{$\underline{\text { Mid-Day }}$}

Figures 4-25 to 4-28 show the mobility measures (e.g., speed and travel time) for the arterial study corridor during the Mid-Day period. The figures also provide information on the predictive ability of different mobility estimation methods.

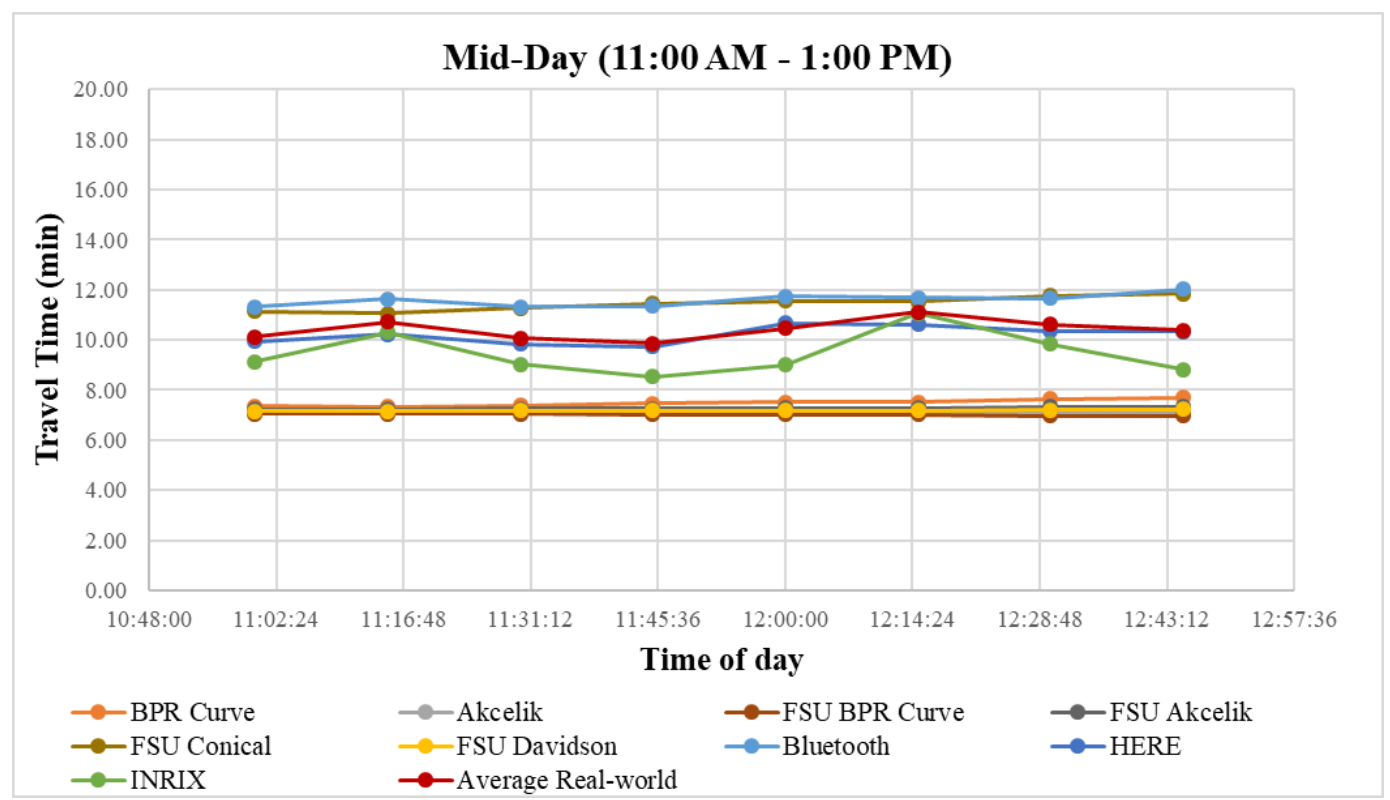

Figure 4-24: Predictive ability of different mobility estimation methods Travel Time (Arterial, Mid-Day, Capacity 880VPHPL Used in Volume-Delay Functions) 


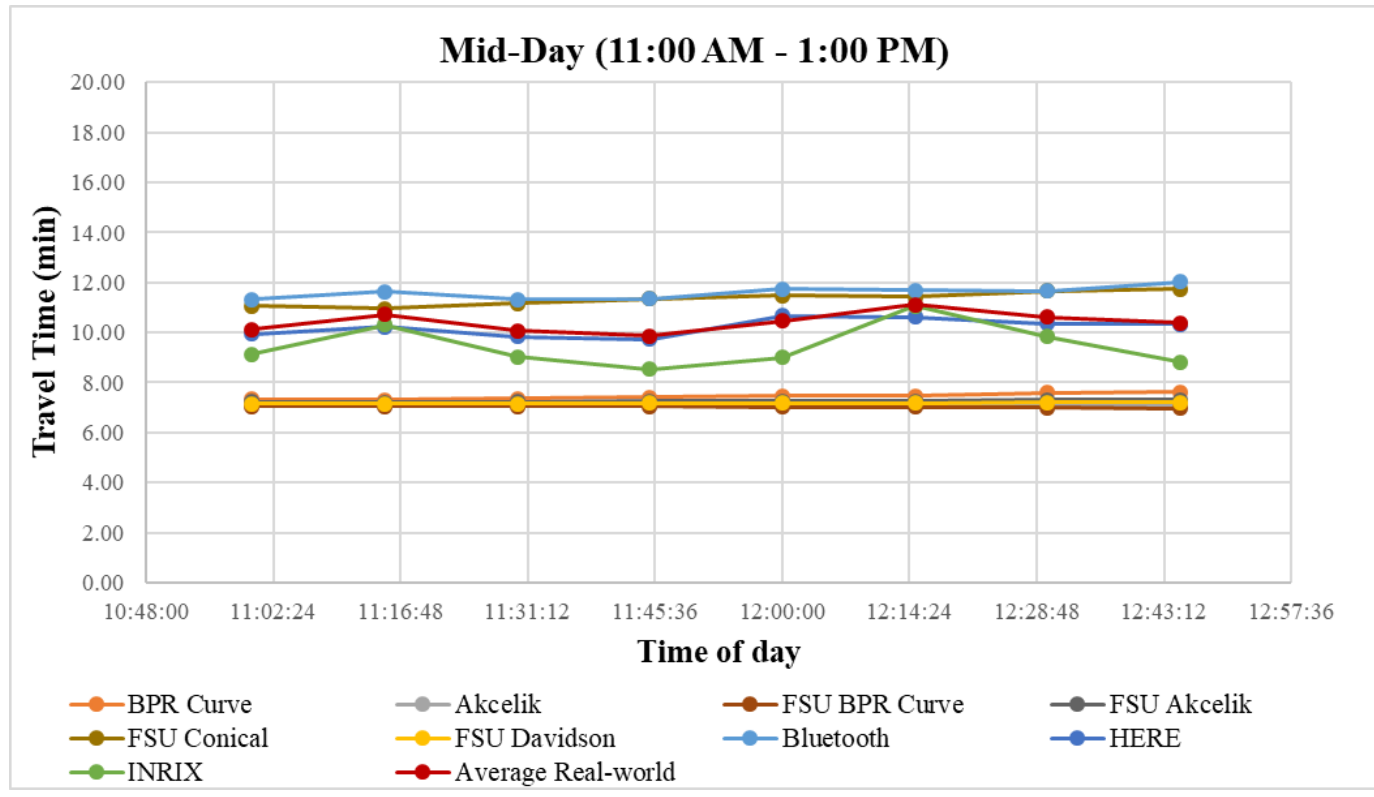

Figure 4-25: Predictive ability of different mobility estimation methods Travel Time (Arterial, Mid-Day, Capacity 900 VPHPL Used in Volume-Delay Functions)

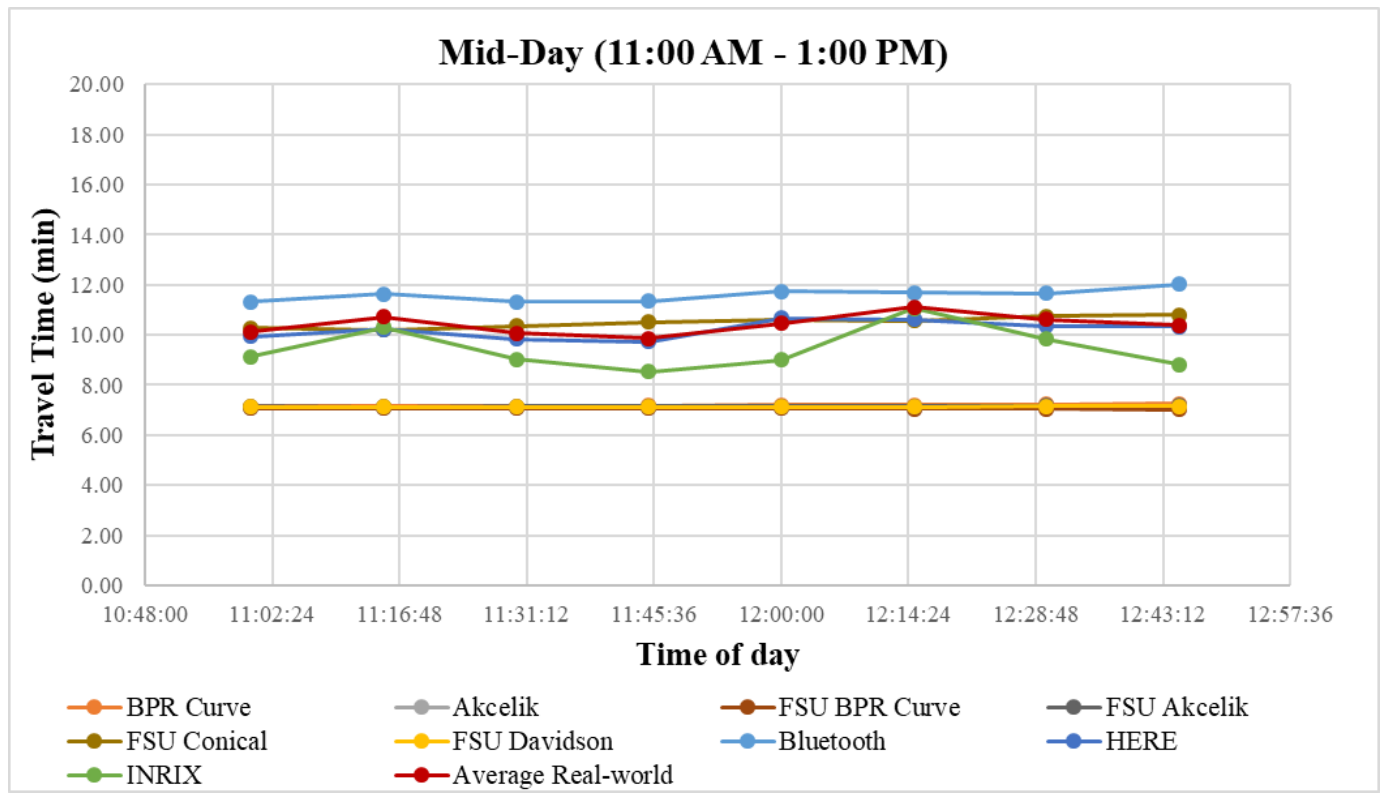

Figure 4-26: Predictive ability of different mobility estimation methods Travel Time (Arterial, Mid-Day, Capacity 1120 VPHPL Used in Volume-Delay Functions) 


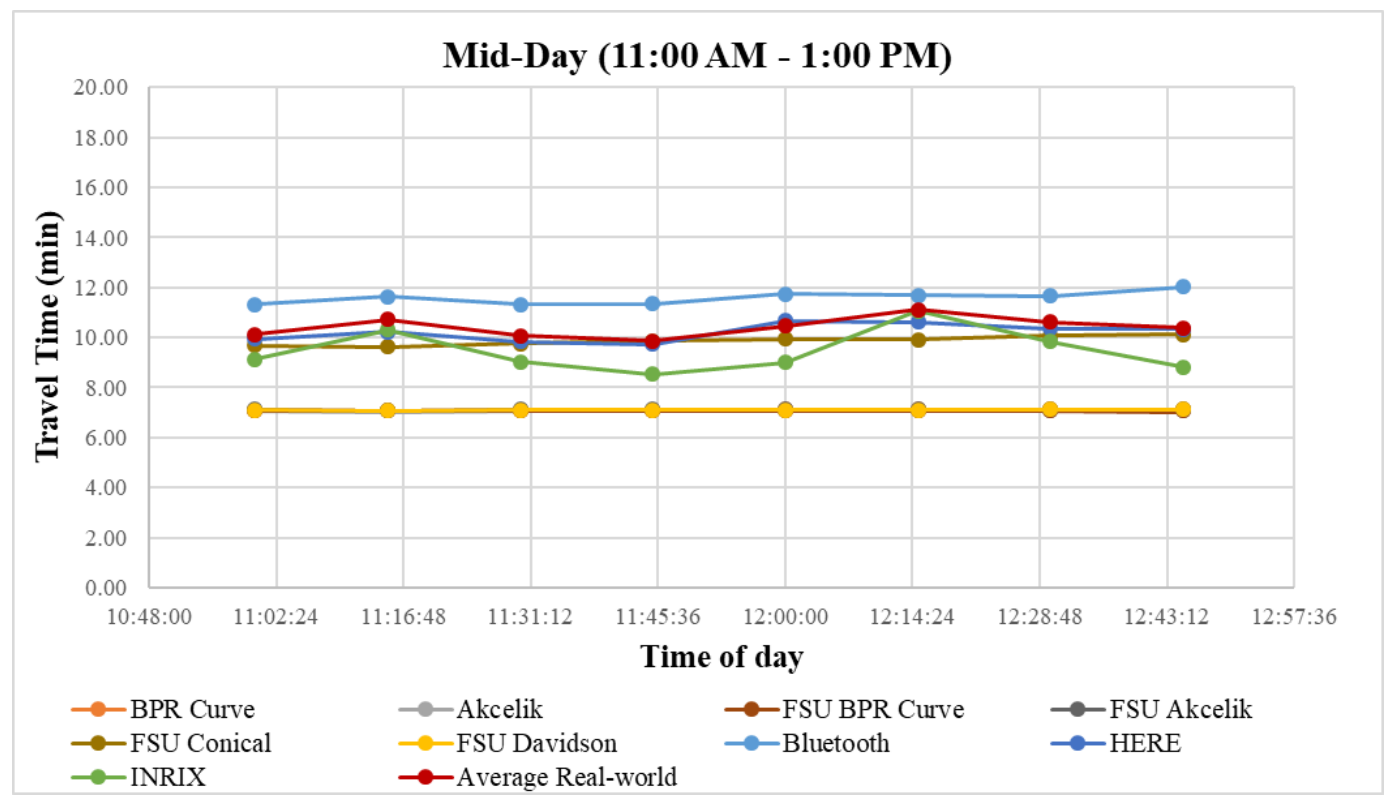

Figure 4-27: Predictive ability of different mobility estimation methods Travel Time (Arterial, Mid-Day, Capacity 1370 VPHPL Used in Volume-Delay Functions)

As shown in the above figures and Tables 4-12 to 4-15, the travel time prediction pattern of mobility estimation methods followed the same pattern as the AM Peak period for all four capacity assumptions. Like the AM Peak, the FSU Conical Delay model predicted closer to the real-world travel time. 
Table 4-12: Performance Summary of Mobility Methods (Arterials, Mid-day, Speed) for Capacity 880 VPHPL Used in Volume-Delay Functions

\begin{tabular}{|c|c|c|c|c|c|c|c|c|c|c|c|c|c|c|c|c|c|c|}
\hline \multicolumn{19}{|c|}{ Capacity 880 VPHPL Used in Volume-Delay function } \\
\hline & \multicolumn{6}{|c|}{ ME } & \multicolumn{6}{|c|}{ MAE } & \multicolumn{6}{|c|}{ MAPE } \\
\hline & 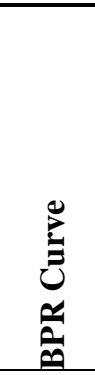 & 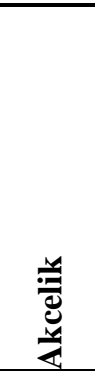 & 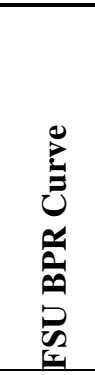 & 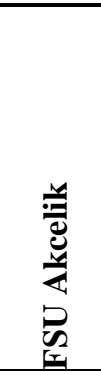 & 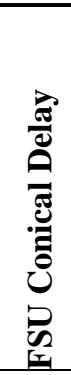 & 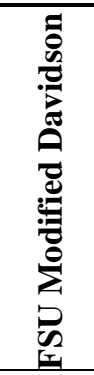 & 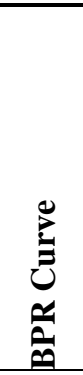 & 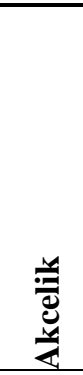 & 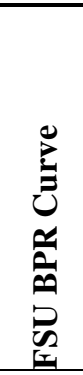 & 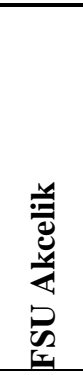 & 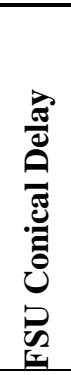 & 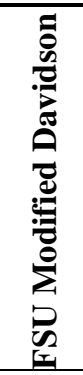 & 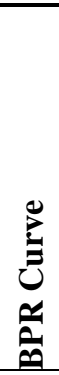 & 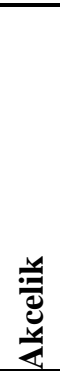 & 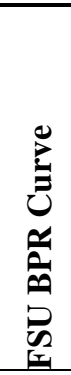 & 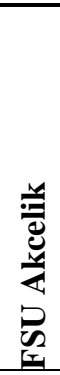 & 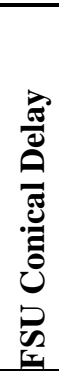 & 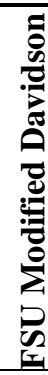 \\
\hline January $18^{\text {th }}$ & -16.9 & -19.4 & -20.1 & -18.3 & -2.4 & -18.9 & 16.9 & 19.4 & 20.1 & 18.3 & 2.4 & 18.9 & 67 & 77 & 80 & 73 & 10 & 75 \\
\hline February $5^{\text {th }}$ & -16.2 & -19.7 & -20.9 & -18.3 & -1.9 & -19.1 & 16.2 & 19.7 & 20.9 & 18.3 & 1.9 & 19.1 & 66 & 80 & 85 & 75 & 8 & 78 \\
\hline February $24^{\text {th }}$ & -18.6 & -21.8 & -22.9 & -20.5 & -4.2 & -21.4 & 18.6 & 21.8 & 22.9 & 20.5 & 4.2 & 21.4 & 82 & 96 & 101 & 90 & 18 & 94 \\
\hline April 11 ${ }^{\text {th }}$ & -16.1 & -18.4 & -19.0 & -17.4 & -1.5 & -17.9 & 16.1 & 18.4 & 19.0 & 17.4 & 1.5 & 17.9 & 61 & 70 & 73 & 66 & 6 & 68 \\
\hline May $10^{\text {th }}$ & -17.6 & -20.1 & -20.8 & -19.0 & -3.0 & -19.7 & 17.6 & 20.1 & 20.8 & 19.0 & 3.0 & 19.7 & 72 & 82 & 85 & 78 & 13 & 81 \\
\hline June $22^{\text {nd }}$ & -16.0 & -18.2 & -18.8 & -17.2 & -1.3 & -17.8 & 16.0 & 18.2 & 18.8 & 17.2 & 1.3 & 17.8 & 60 & 69 & 71 & 65 & 5 & 67 \\
\hline July $5^{\text {th }}$ & -17.5 & -18.7 & -19.0 & -18.0 & -3.2 & -18.4 & 17.5 & 18.7 & 19.0 & 18.0 & 3.2 & 18.4 & 67 & 72 & 73 & 69 & 12 & 71 \\
\hline September $27^{\text {th }}$ & -16.3 & -18.1 & -18.6 & -17.2 & -1.6 & -17.7 & 16.3 & 18.1 & 18.6 & 17.2 & 1.6 & 17.7 & 61 & 68 & 70 & 65 & 6 & 67 \\
\hline October $3^{\text {rd }}$ & -14.0 & -16.2 & -16.8 & -15.2 & 0.6 & -15.7 & 14.0 & 16.2 & 16.8 & 15.2 & 1.4 & 15.7 & 50 & 57 & 59 & 54 & 5 & 56 \\
\hline October $31^{\text {st }}$ & -17.0 & -19.3 & -19.9 & -18.2 & -2.4 & -18.8 & 17.0 & 19.3 & 19.9 & 18.2 & 2.4 & 18.8 & 67 & 77 & 79 & 72 & 10 & 75 \\
\hline Average & -16.6 & -19.0 & -19.7 & -17.9 & -2.1 & -18.5 & 16.6 & 19.0 & 19.7 & 17.9 & 2.3 & 18.5 & 65 & 75 & 78 & 71 & 9 & 73 \\
\hline
\end{tabular}


Table 4-13: Performance Summary of Mobility Methods (Arterials, Mid-day, Speed) for Capacity 900 VPHPL Used in Volume-Delay Functions

\begin{tabular}{|c|c|c|c|c|c|c|c|c|c|c|c|c|c|c|c|c|c|c|}
\hline \multicolumn{19}{|c|}{ Capacity 900 VPHPL Used in Volume-Delay function } \\
\hline & \multicolumn{6}{|c|}{ ME } & \multicolumn{6}{|c|}{ MAE } & \multicolumn{6}{|c|}{ MAPE } \\
\hline & 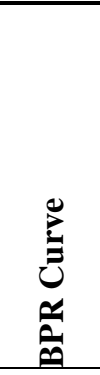 & 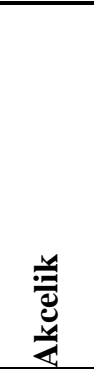 & 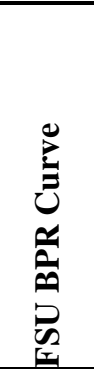 & 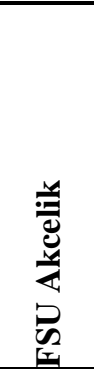 & 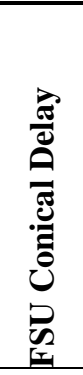 & 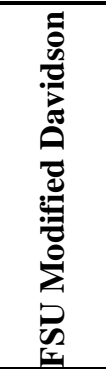 & 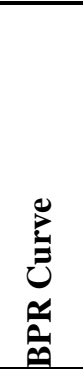 & 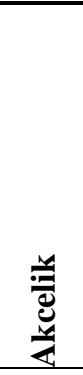 & 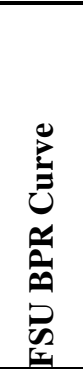 & 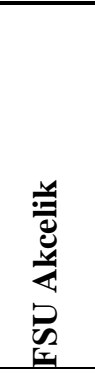 & 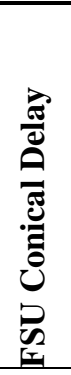 & 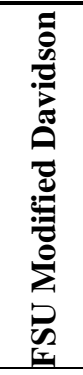 & $\underset{ٍ}{\Xi}$ & 苞 & 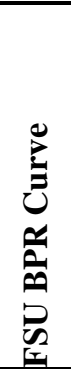 & 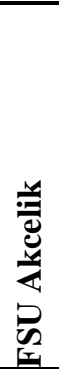 & 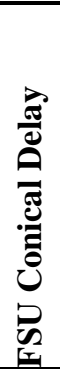 & 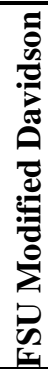 \\
\hline January $18^{\text {th }}$ & -17.2 & -19.4 & -20.0 & -18.4 & -2.6 & -19.0 & 17.2 & 19.4 & 20.0 & 18.4 & 2.6 & 19.0 & 68 & 77 & 80 & 74 & 11 & 76 \\
\hline February $5^{\text {th }}$ & -16.6 & -19.8 & -20.8 & -18.5 & -2.2 & -19.2 & 16.6 & 19.8 & 20.8 & 18.5 & 2.2 & 19.2 & 67 & 80 & 85 & 75 & 9 & 78 \\
\hline February $24^{\text {th }}$ & -18.9 & -21.9 & -22.8 & -20.7 & -4.4 & -21.3 & 18.9 & 21.9 & 22.8 & 20.7 & 4.4 & 21.3 & 83 & 96 & 100 & 91 & 20 & 94 \\
\hline April 11 ${ }^{\text {th }}$ & -16.4 & -18.4 & -19.0 & -17.5 & -1.7 & -18.0 & 16.4 & 18.4 & 19.0 & 17.5 & 1.7 & 18.0 & 62 & 70 & 72 & 67 & 7 & 69 \\
\hline May $10^{\text {th }}$ & -17.9 & -20.2 & -20.8 & -19.2 & -3.3 & -19.7 & 17.9 & 20.2 & 20.8 & 19.2 & 3.3 & 19.7 & 73 & 83 & 85 & 79 & 14 & 81 \\
\hline June $22^{\text {nd }}$ & -16.2 & -18.2 & -18.8 & -17.3 & -1.5 & -17.8 & 16.2 & 18.2 & 18.8 & 17.3 & 1.5 & 17.8 & 61 & 69 & 71 & 65 & 6 & 67 \\
\hline July $5^{\text {th }}$ & -17.7 & -18.7 & -19.0 & -18.0 & -3.4 & -18.4 & 17.7 & 18.7 & 19.0 & 18.0 & 3.4 & 18.4 & 68 & 72 & 73 & 69 & 13 & 71 \\
\hline September $27^{\text {th }}$ & -16.5 & -18.1 & -18.6 & -17.3 & -1.8 & -17.7 & 16.5 & 18.1 & 18.6 & 17.3 & 1.8 & 17.7 & 62 & 68 & 70 & 65 & 7 & 67 \\
\hline October $3^{\text {rd }}$ & -14.3 & -16.2 & -16.7 & -15.3 & 0.3 & -15.8 & 14.3 & 16.2 & 16.7 & 15.3 & 1.4 & 15.8 & 50 & 57 & 59 & 54 & 5 & 56 \\
\hline October $31^{\text {st }}$ & -17.2 & -19.3 & -19.9 & -18.3 & -2.6 & -18.9 & 17.2 & 19.3 & 19.9 & 18.3 & 2.6 & 18.9 & 68 & 77 & 79 & 73 & 11 & 75 \\
\hline Average & -16.9 & -19.0 & -19.6 & -18.1 & -2.3 & -18.6 & 16.9 & 19.0 & 19.6 & 18.1 & 2.5 & 18.6 & 67 & 75 & 77 & 71 & 10 & 73 \\
\hline
\end{tabular}


Table 4-14: Performance Summary of Mobility Methods (Arterials, Mid-day, Speed) for Capacity 1120 VPHPL Used in Volume-Delay Functions

\begin{tabular}{|c|c|c|c|c|c|c|c|c|c|c|c|c|c|c|c|c|c|c|}
\hline \multicolumn{19}{|c|}{ Capacity 1120 VPHPL Used in Volume-Delay function } \\
\hline & \multicolumn{6}{|c|}{ ME } & \multicolumn{6}{|c|}{ MAE } & \multicolumn{6}{|c|}{ MAPE } \\
\hline & 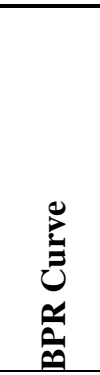 & 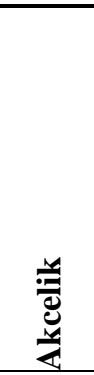 & 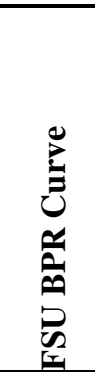 & 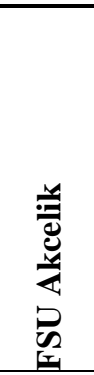 & 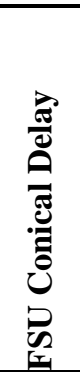 & 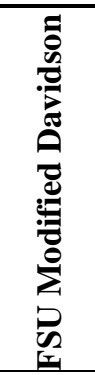 & 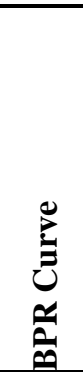 & 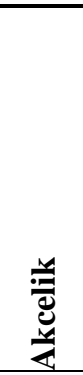 & 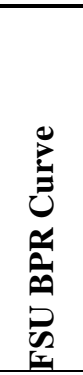 & 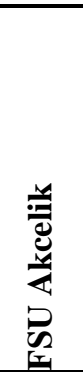 & 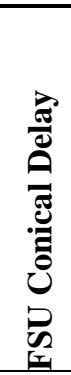 & 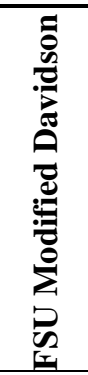 & 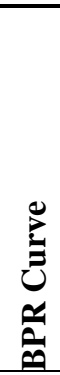 & 产 & 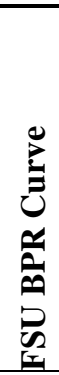 & 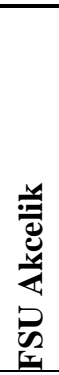 & 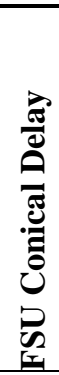 & 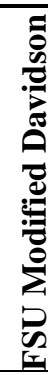 \\
\hline January $18^{\text {th }}$ & -18.8 & -19.6 & -19.7 & -19.1 & -4.9 & -19.3 & 18.8 & 19.6 & 19.7 & 19.1 & 4.9 & 19.3 & 75 & 78 & 79 & 76 & 20 & 77 \\
\hline February $5^{\text {th }}$ & -18.9 & -20.0 & -20.2 & -19.4 & -4.5 & -19.6 & 18.9 & 20.0 & 20.2 & 19.4 & 4.5 & 19.6 & 77 & 81 & 82 & 79 & 19 & 80 \\
\hline February $24^{\text {th }}$ & -21.1 & -22.1 & -22.3 & -21.5 & -6.7 & -21.7 & 21.1 & 22.1 & 22.3 & 21.5 & 6.7 & 21.7 & 93 & 97 & 98 & 95 & 30 & 96 \\
\hline April 11 ${ }^{\text {th }}$ & -17.9 & -18.6 & -18.7 & -18.1 & -4.0 & -18.3 & 17.9 & 18.6 & 18.7 & 18.1 & 4.0 & 18.3 & 68 & 71 & 71 & 69 & 15 & 70 \\
\hline May $10^{\text {th }}$ & -19.6 & -20.3 & -20.5 & -19.8 & -5.6 & -20.0 & 19.6 & 20.3 & 20.5 & 19.8 & 5.6 & 20.0 & 80 & 83 & 84 & 81 & 23 & 82 \\
\hline June $22^{\text {nd }}$ & -17.7 & -18.4 & -18.5 & -17.9 & -3.8 & -18.1 & 17.7 & 18.4 & 18.5 & 17.9 & 3.8 & 18.1 & 67 & 70 & 70 & 68 & 14 & 68 \\
\hline July $5^{\text {th }}$ & -18.5 & -18.8 & -18.9 & -18.4 & -5.5 & -18.6 & 18.5 & 18.8 & 18.9 & 18.4 & 5.5 & 18.6 & 71 & 72 & 73 & 71 & 21 & 71 \\
\hline September $27^{\text {th }}$ & -17.7 & -18.3 & -18.4 & -17.8 & -4.0 & -18.0 & 17.7 & 18.3 & 18.4 & 17.8 & 4.0 & 18.0 & 67 & 69 & 69 & 67 & 15 & 68 \\
\hline October $3^{\text {rd }}$ & -15.7 & -16.4 & -16.5 & -15.9 & -1.9 & -16.1 & 15.7 & 16.4 & 16.5 & 15.9 & 1.9 & 16.1 & 56 & 58 & 58 & 56 & 7 & 57 \\
\hline October $31^{\text {st }}$ & -18.8 & -19.4 & -19.6 & -19.0 & -4.9 & -19.2 & 18.8 & 19.4 & 19.6 & 19.0 & 4.9 & 19.2 & 74 & 77 & 78 & 75 & 20 & 76 \\
\hline Average & -18.5 & -19.2 & -19.3 & -18.7 & -4.6 & -18.9 & 18.5 & 19.2 & 19.3 & 18.7 & 4.6 & 18.9 & 73 & 76 & 76 & 74 & 18 & 74 \\
\hline
\end{tabular}


Table 4-15: Performance Summary of Mobility Methods (Arterials, Mid-day, Speed) for Capacity 1370 VPHPL Used in Volume-Delay Functions

\begin{tabular}{|c|c|c|c|c|c|c|c|c|c|c|c|c|c|c|c|c|c|c|}
\hline \multicolumn{19}{|c|}{ Capacity 1370 VPHPL Used in Volume-Delay function } \\
\hline & \multicolumn{6}{|c|}{ ME } & \multicolumn{6}{|c|}{ MAE } & \multicolumn{6}{|c|}{ MAPE } \\
\hline & 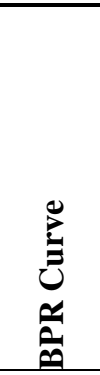 & 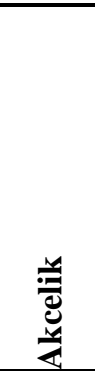 & 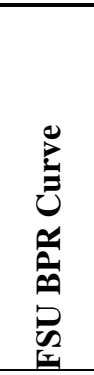 & 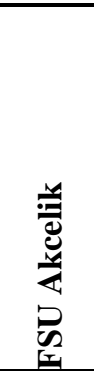 & 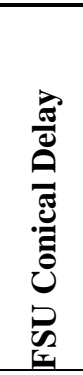 & 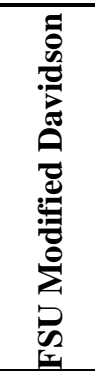 & 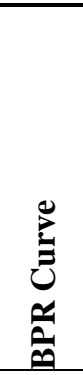 & 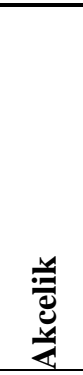 & 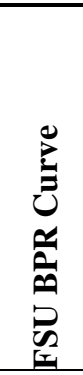 & 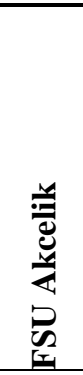 & 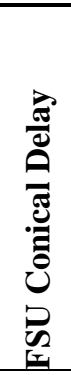 & 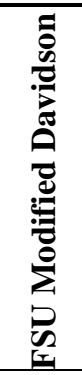 & 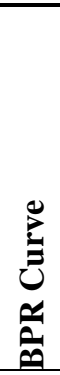 & 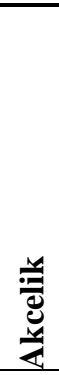 & 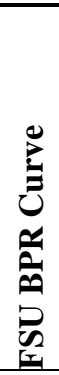 & 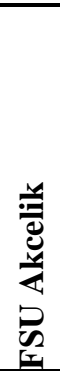 & 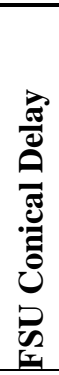 & 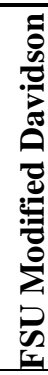 \\
\hline January $18^{\text {th }}$ & -19.4 & -19.6 & -19.7 & -19.3 & -6.9 & -19.4 & 19.4 & 19.6 & 19.7 & 19.3 & 6.9 & 19.4 & 77 & 78 & 79 & 77 & 28 & 77 \\
\hline February $5^{\text {th }}$ & -19.7 & -20.1 & -20.2 & -19.8 & -6.5 & -19.8 & 19.7 & 20.1 & 20.2 & 19.8 & 6.5 & 19.8 & 80 & 82 & 82 & 80 & 27 & 81 \\
\hline February $24^{\text {th }}$ & -21.8 & -22.1 & -22.2 & -21.8 & -8.7 & -21.9 & 21.8 & 22.1 & 22.2 & 21.8 & 8.7 & 21.9 & 96 & 97 & 98 & 96 & 39 & 96 \\
\hline April 11 ${ }^{\text {th }}$ & -18.4 & -18.6 & -18.7 & -18.4 & -5.9 & -18.4 & 18.4 & 18.6 & 18.7 & 18.4 & 5.9 & 18.4 & 70 & 71 & 71 & 70 & 23 & 70 \\
\hline May $10^{\text {th }}$ & -20.1 & -20.4 & -20.4 & -20.1 & -7.5 & -20.1 & 20.1 & 20.4 & 20.4 & 20.1 & 7.5 & 20.1 & 82 & 83 & 84 & 82 & 31 & 83 \\
\hline June $22^{\text {nd }}$ & -18.2 & -18.4 & -18.5 & -18.2 & -5.7 & -18.2 & 18.2 & 18.4 & 18.5 & 18.2 & 5.7 & 18.2 & 69 & 70 & 70 & 69 & 22 & 69 \\
\hline July $5^{\text {th }}$ & -18.7 & -18.8 & -18.9 & -18.6 & -7.4 & -18.7 & 18.7 & 18.8 & 18.9 & 18.6 & 7.4 & 18.7 & 72 & 72 & 73 & 72 & 28 & 72 \\
\hline September $27^{\text {th }}$ & -18.1 & -18.3 & -18.4 & -18.1 & -5.9 & -18.1 & 18.1 & 18.3 & 18.4 & 18.1 & 5.9 & 18.1 & 68 & 69 & 69 & 68 & 23 & 68 \\
\hline October $3^{\text {rd }}$ & -16.2 & -16.4 & -16.5 & -16.1 & -3.8 & -16.2 & 16.2 & 16.4 & 16.5 & 16.1 & 3.8 & 16.2 & 57 & 58 & 58 & 57 & 14 & 57 \\
\hline October $31^{\text {st }}$ & -19.3 & -19.5 & -19.6 & -19.2 & -6.8 & -19.3 & 19.3 & 19.5 & 19.6 & 19.2 & 6.8 & 19.3 & 77 & 77 & 78 & 76 & 27 & 77 \\
\hline Average & -19.0 & -19.2 & -19.3 & -19.0 & -6.5 & -19.0 & 19.0 & 19.2 & 19.3 & 19.0 & 6.5 & 19.0 & 75 & 76 & 76 & 75 & 26 & 75 \\
\hline
\end{tabular}




\section{$\underline{\text { PM Peak }}$}

Figures 4-29 to 4-32 presented the mobility measures (e.g., speed and travel time) for the arterial study corridor during the PM Peak period. The figures also provide information on the predictive ability of different mobility estimation methods.

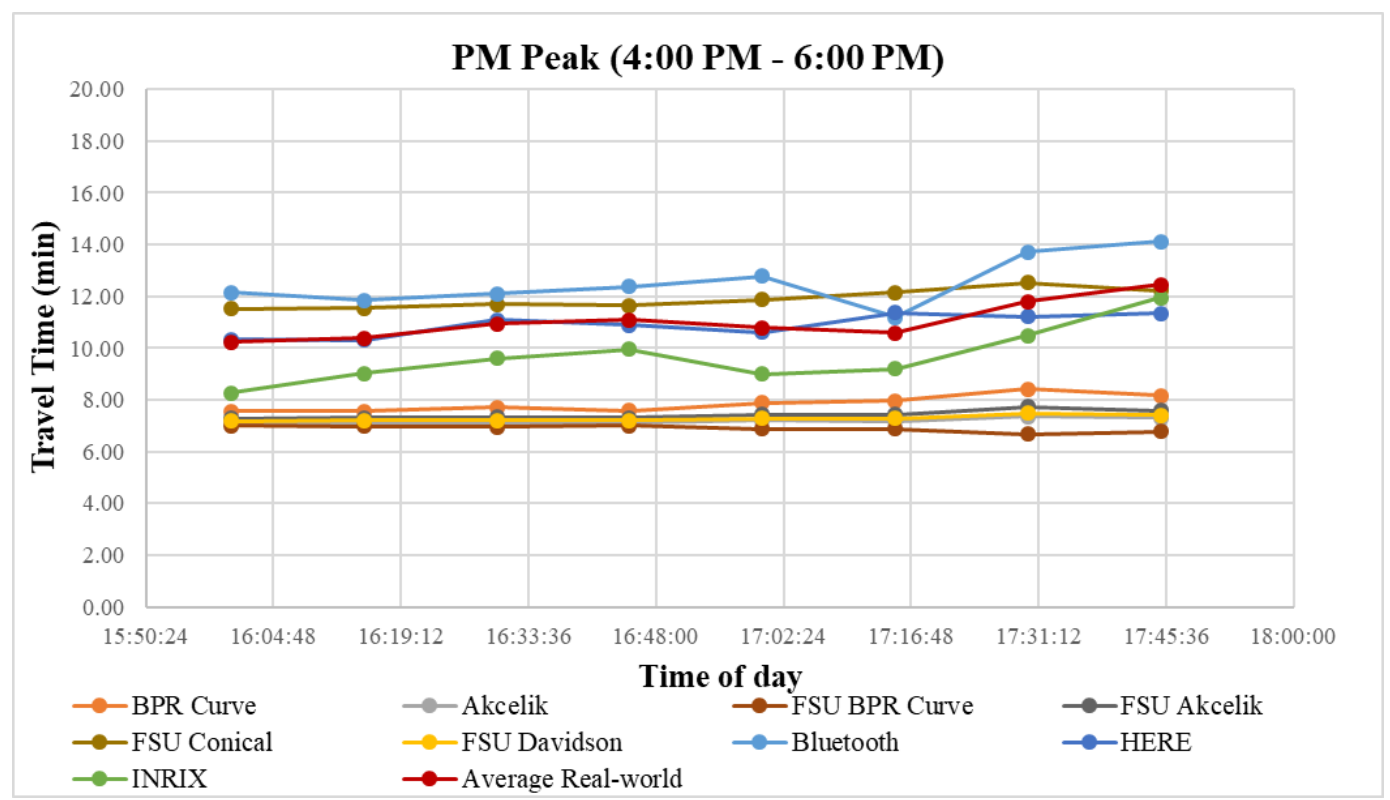

Figure 4-28: Predictive ability of different mobility estimation methods Travel Time (Arterial, PM Peak, Capacity 880 VPHPL Used in Volume-Delay Functions) 


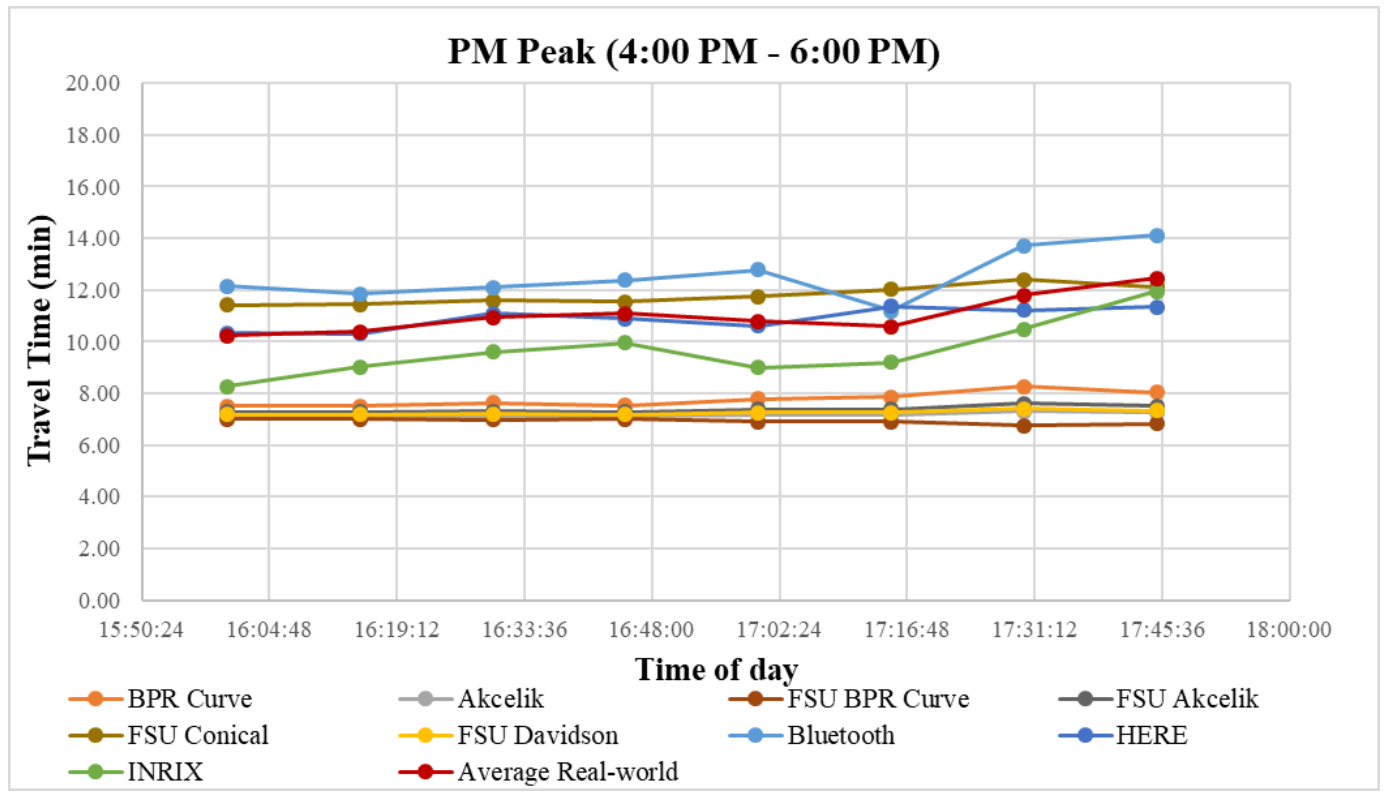

Figure 4-29: Predictive ability of different mobility estimation methods Travel Time (Arterial, PM Peak, Capacity 900 VPHPL Used in Volume-Delay Functions)

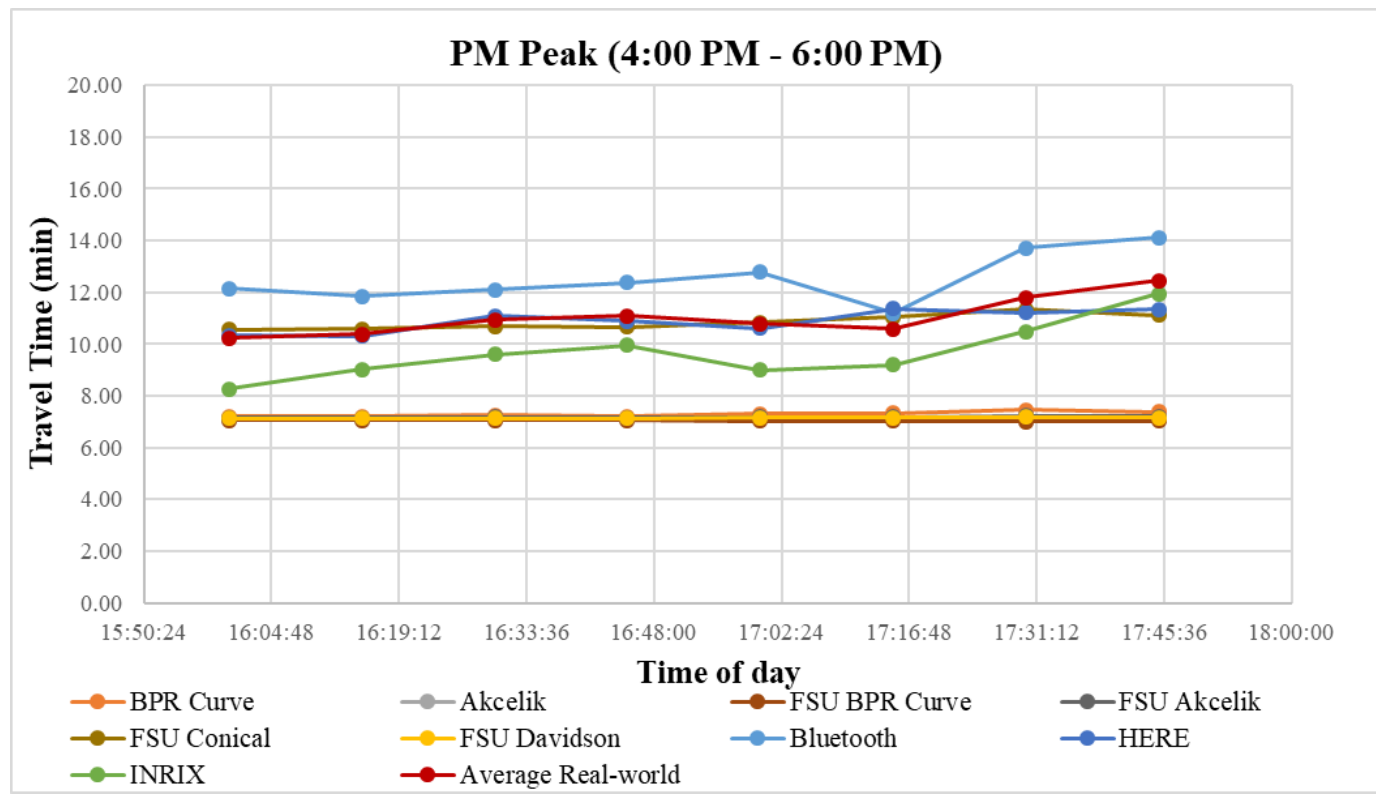

Figure 4-30: Predictive ability of different mobility estimation methods Travel Time (Arterial, PM Peak, Capacity 1120 VPHPL Used in Volume-Delay Functions) 


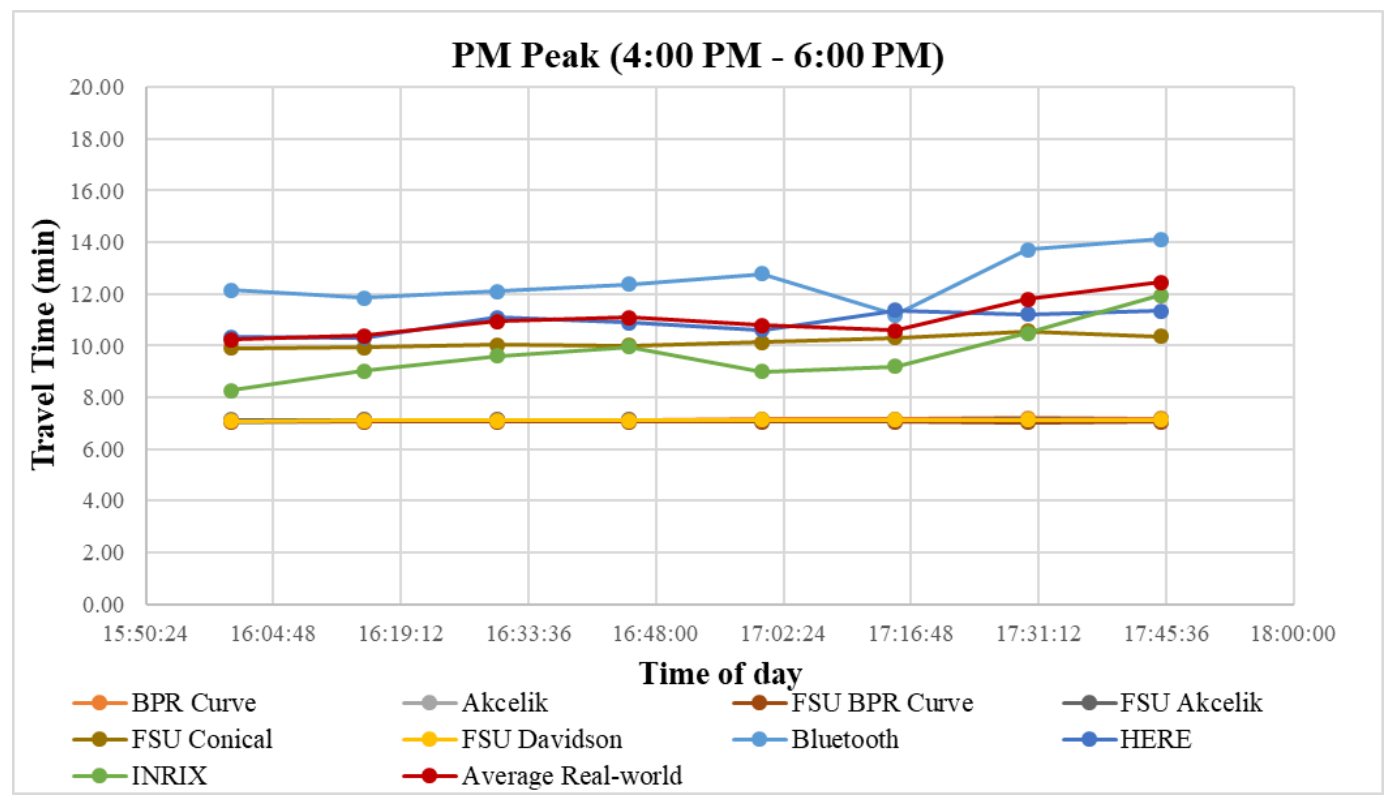

Figure 4-31: Predictive ability of different mobility estimation methods Travel Time (Arterial, PM Peak, Capacity 1370 VPHPL Used in Volume-Delay Functions)

Similar to the AM and Mid-Day time period, only the FSU Conical delay model predicted closer to the real-world measures in the PM peak. Similar to the other two time periods, all other traffic models were predicting closer to each other in the PM peak, but not closer to the real-world. In fact, the predictive models estimated mobility measures at approximately half of the real-world measure values during the PM Peak period (Figures 4-29 to 4-32). 
Table 4-16: Performance Summary of Mobility Methods (Arterials, PM Peak, Speed) for Capacity 880 VPHPL Used in Volume-Delay Functions

\begin{tabular}{|c|c|c|c|c|c|c|c|c|c|c|c|c|c|c|c|c|c|c|}
\hline \multicolumn{19}{|c|}{ Capacity 880 VPHPL Used in Volume-Delay function } \\
\hline & \multicolumn{6}{|c|}{ ME } & \multicolumn{6}{|c|}{ MAE } & \multicolumn{6}{|c|}{ MAPE } \\
\hline & 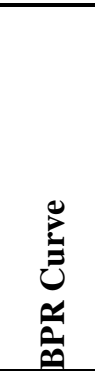 & 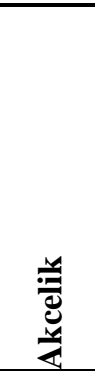 & 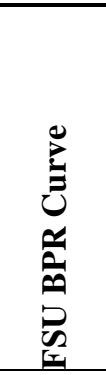 & 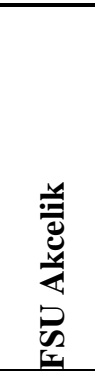 & 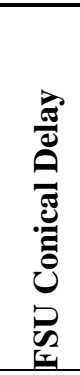 & 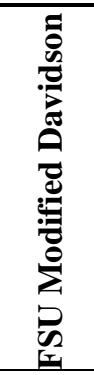 & 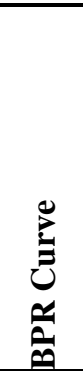 & 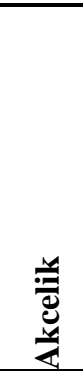 & 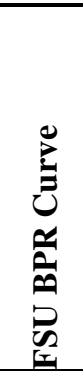 & 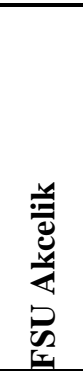 & 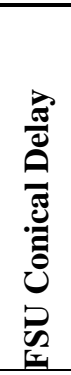 & 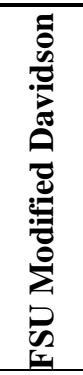 & 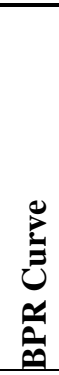 & 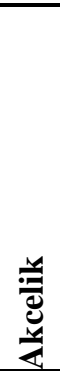 & 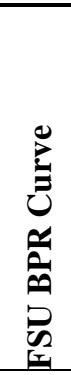 & 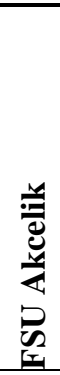 & 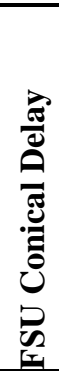 & 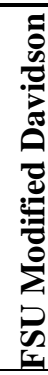 \\
\hline January $18^{\text {th }}$ & -14.9 & -18.1 & -19.3 & -16.9 & -0.8 & -17.6 & 14.9 & 18.1 & 19.3 & 16.9 & 0.9 & 17.6 & 56 & 69 & 73 & 64 & 4 & 67 \\
\hline February $5^{\text {th }}$ & -17.3 & -21.5 & -23.7 & -20.0 & -3.9 & -20.9 & 17.3 & 21.5 & 23.7 & 20.0 & 3.9 & 20.9 & 76 & 95 & 105 & 88 & 17 & 93 \\
\hline February $24^{\text {th }}$ & -17.8 & -21.5 & -23.0 & -20.2 & -3.7 & -21.4 & 17.8 & 21.5 & 23.0 & 20.2 & 3.7 & 21.4 & 78 & 94 & 101 & 88 & 16 & 94 \\
\hline April 11 ${ }^{\text {th }}$ & -17.3 & -20.4 & -21.5 & -19.2 & -3.1 & -19.9 & 17.3 & 20.4 & 21.5 & 19.2 & 3.1 & 19.9 & 72 & 85 & 89 & 80 & 13 & 83 \\
\hline May $10^{\text {th }}$ & -18.3 & -21.9 & -23.6 & -20.5 & -4.7 & -21.4 & 18.3 & 21.9 & 23.6 & 20.5 & 4.7 & 21.4 & 82 & 98 & 105 & 92 & 21 & 95 \\
\hline June $22^{\text {nd }}$ & -15.4 & -19.1 & -21.0 & -17.7 & -1.6 & -18.6 & 15.4 & 19.1 & 21.0 & 17.7 & 1.6 & 18.6 & 62 & 77 & 85 & 71 & 7 & 75 \\
\hline July $5^{\text {th }}$ & -17.1 & -18.8 & -19.3 & -17.9 & -2.5 & -18.4 & 17.1 & 18.8 & 19.3 & 17.9 & 2.5 & 18.4 & 66 & 73 & 74 & 69 & 10 & 71 \\
\hline September $27^{\text {th }}$ & -16.1 & -19.6 & -21.2 & -18.2 & -2.2 & -19.0 & 16.1 & 19.6 & 21.2 & 18.2 & 2.7 & 19.0 & 66 & 80 & 87 & 75 & 11 & 78 \\
\hline October $3^{\text {rd }}$ & -12.6 & -16.1 & -17.7 & -14.8 & 1.2 & -15.6 & 12.6 & 16.1 & 17.7 & 14.8 & 1.2 & 15.6 & 45 & 57 & 63 & 52 & 4 & 55 \\
\hline October $31^{\text {st }}$ & -16.5 & -19.8 & -21.2 & -18.6 & -2.9 & -19.3 & 16.5 & 19.8 & 21.2 & 18.6 & 2.9 & 19.3 & 67 & 81 & 87 & 76 & 12 & 79 \\
\hline Average & -16.3 & -19.7 & -21.2 & -18.4 & -2.4 & -19.2 & 16.3 & 19.7 & 21.2 & 18.4 & 2.7 & 19.2 & 67 & 81 & 87 & 76 & 11 & 79 \\
\hline
\end{tabular}


Table 4-17: Performance Summary of Mobility Methods (Arterials, PM Peak, Speed) for Capacity 900 VPHPL Used in Volume-Delay Functions

\begin{tabular}{|c|c|c|c|c|c|c|c|c|c|c|c|c|c|c|c|c|c|c|}
\hline \multicolumn{19}{|c|}{ Capacity 900 VPHPL Used in Volume-Delay function } \\
\hline & \multicolumn{6}{|c|}{ ME } & \multicolumn{6}{|c|}{ MAE } & \multicolumn{6}{|c|}{ MAPE } \\
\hline & 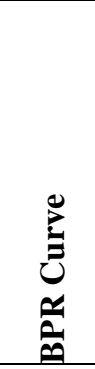 & 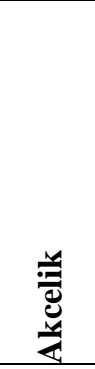 & 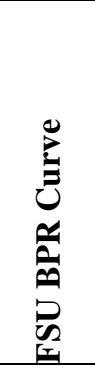 & 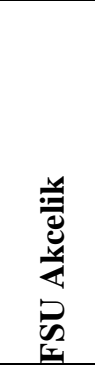 & 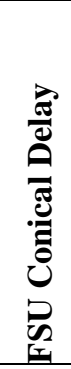 & 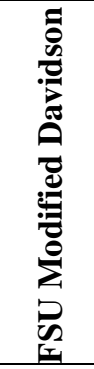 & 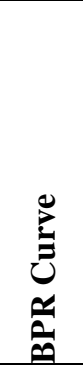 & 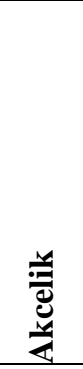 & 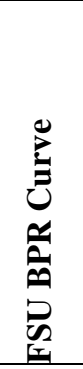 & 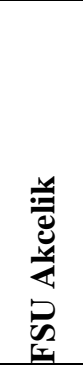 & 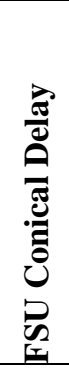 & 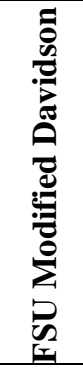 & 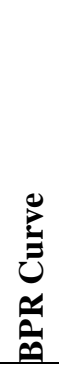 & 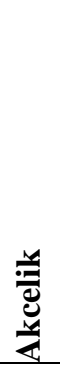 & 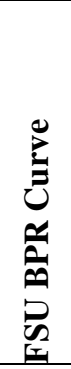 & 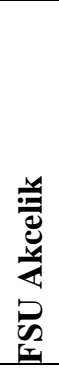 & 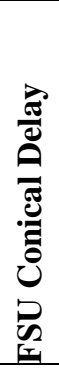 & 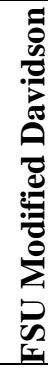 \\
\hline January $18^{\text {th }}$ & -15.3 & -18.2 & -19.2 & -17.0 & -1.1 & -17.7 & 15.3 & 18.2 & 19.2 & 17.0 & 1.1 & 17.7 & 58 & 69 & 73 & 65 & 4 & 67 \\
\hline February $5^{\text {th }}$ & -17.7 & -21.7 & -23.5 & -20.3 & -4.1 & -21.1 & 17.7 & 21.7 & 23.5 & 20.3 & 4.1 & 21.1 & 78 & 96 & 104 & 90 & 18 & 93 \\
\hline February $24^{\text {th }}$ & -18.2 & -21.6 & -22.9 & -20.4 & -4.0 & -21.1 & 18.2 & 21.6 & 22.9 & 20.4 & 4.0 & 21.1 & 80 & 95 & 100 & 89 & 18 & 92 \\
\hline April 11 ${ }^{\text {th }}$ & -17.7 & -20.5 & -21.4 & -19.4 & -3.3 & -20.0 & 17.7 & 20.5 & 21.4 & 19.4 & 3.3 & 20.0 & 73 & 85 & 89 & 80 & 14 & 83 \\
\hline May $10^{\text {th }}$ & -18.7 & -22.0 & -23.4 & -20.8 & -4.9 & -21.5 & 18.7 & 22.0 & 23.4 & 20.8 & 4.9 & 21.5 & 84 & 98 & 105 & 93 & 22 & 96 \\
\hline June $22^{\text {nd }}$ & -15.9 & -19.3 & -20.8 & -18.0 & -1.9 & -18.8 & 15.9 & 19.3 & 20.8 & 18.0 & 1.9 & 18.8 & 64 & 77 & 84 & 72 & 8 & 75 \\
\hline July $5^{\text {th }}$ & -17.3 & -18.8 & -19.2 & -18.0 & -2.7 & -18.5 & 17.3 & 18.8 & 19.2 & 18.0 & 2.7 & 18.5 & 67 & 73 & 74 & 70 & 11 & 71 \\
\hline September $27^{\text {th }}$ & -16.5 & -19.7 & -21.0 & -18.5 & -2.4 & -19.2 & 16.5 & 19.7 & 21.0 & 18.5 & 2.9 & 19.2 & 68 & 80 & 86 & 75 & 12 & 78 \\
\hline October $3^{\text {rd }}$ & -13.0 & -16.2 & -17.5 & -15.0 & 1.0 & -15.7 & 13.0 & 16.2 & 17.5 & 15.0 & 1.1 & 15.7 & 46 & 57 & 62 & 53 & 4 & 56 \\
\hline October $31^{\text {st }}$ & -16.8 & -19.9 & -21.1 & -18.8 & -3.1 & -19.4 & 16.8 & 19.9 & 21.1 & 18.8 & 3.1 & 19.4 & 69 & 82 & 86 & 77 & 13 & 80 \\
\hline Average & -16.7 & -19.8 & -21.0 & -18.6 & -2.7 & -19.3 & 16.7 & 19.8 & 21.0 & 18.6 & 2.9 & 19.3 & 69 & 81 & 86 & 76 & 12 & 79 \\
\hline
\end{tabular}


Table 4-18: Performance Summary of Mobility Methods (Arterials, PM Peak, Speed) for Capacity 1120 VPHPL Used in Volume-Delay Functions

\begin{tabular}{|c|c|c|c|c|c|c|c|c|c|c|c|c|c|c|c|c|c|c|}
\hline \multicolumn{19}{|c|}{ Capacity 1120 VPHPL Used in Volume-Delay function } \\
\hline & \multicolumn{6}{|c|}{ ME } & \multicolumn{6}{|c|}{ MAE } & \multicolumn{6}{|c|}{ МАРЕ } \\
\hline & 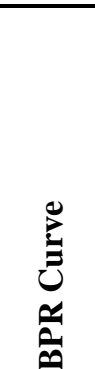 & 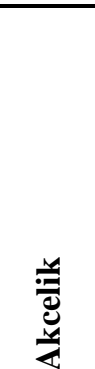 & 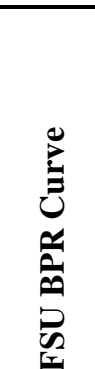 & 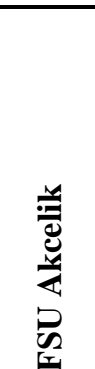 & 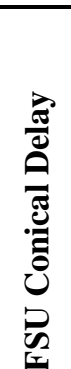 & 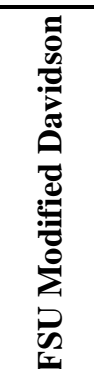 & 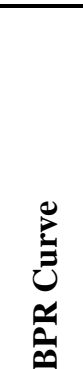 & 资 & 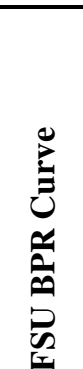 & 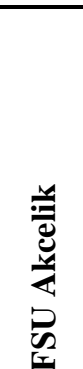 & 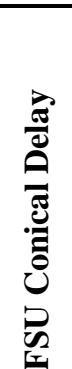 & 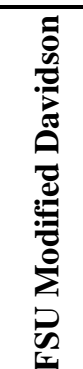 & $\underset{\Xi}{ٍ}$ & 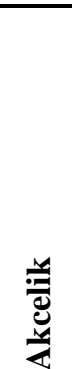 & 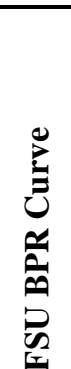 & 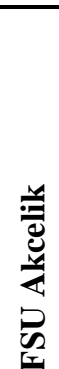 & 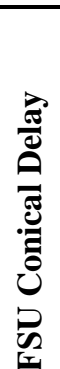 & 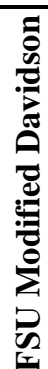 \\
\hline January $18^{\text {th }}$ & -17.4 & -18.4 & -18.7 & -17.9 & -3.4 & -18.1 & 17.4 & 18.4 & 18.7 & 17.9 & 3.4 & 18.1 & 66 & 70 & 71 & 68 & 13 & 69 \\
\hline February $5^{\text {th }}$ & -20.7 & -22.2 & -22.5 & -21.6 & -6.5 & -21.8 & 20.7 & 22.2 & 22.5 & 21.6 & 6.5 & 21.8 & 92 & 98 & 100 & 95 & 29 & 96 \\
\hline February $24^{\text {th }}$ & -20.7 & -22.0 & -22.2 & -21.4 & -6.3 & -21.6 & 20.7 & 22.0 & 22.2 & 21.4 & 6.3 & 21.6 & 91 & 96 & 97 & 94 & 28 & 95 \\
\hline April 11 ${ }^{\text {th }}$ & -19.8 & -20.7 & -20.9 & -20.2 & -5.6 & -20.4 & 19.8 & 20.7 & 20.9 & 20.2 & 5.6 & 20.4 & 82 & 86 & 87 & 84 & 23 & 85 \\
\hline May $10^{\text {th }}$ & -21.2 & -22.4 & -22.7 & -21.8 & -7.2 & -22.1 & 21.2 & 22.4 & 22.7 & 21.8 & 7.2 & 22.1 & 95 & 100 & 101 & 98 & 32 & 98 \\
\hline June $22^{\text {nd }}$ & -18.5 & -19.8 & -20.0 & -19.2 & -4.2 & -19.4 & 18.5 & 19.8 & 20.0 & 19.2 & 4.2 & 19.4 & 74 & 79 & 81 & 77 & 17 & 78 \\
\hline July $5^{\text {th }}$ & -18.4 & -19.0 & -19.1 & -18.5 & -4.9 & -18.7 & 18.4 & 19.0 & 19.1 & 18.5 & 4.9 & 18.7 & 71 & 73 & 74 & 72 & 19 & 72 \\
\hline September $27^{\text {th }}$ & -18.9 & -20.1 & -20.3 & -19.5 & -4.7 & -19.7 & 18.9 & 20.1 & 20.3 & 19.5 & 4.7 & 19.7 & 77 & 82 & 83 & 80 & 20 & 81 \\
\hline October $3^{\text {rd }}$ & -15.4 & -16.6 & -16.8 & -16.0 & -1.3 & -16.2 & 15.4 & 16.6 & 16.8 & 16.0 & 1.5 & 16.2 & 55 & 59 & 60 & 57 & 6 & 58 \\
\hline October $31^{\text {st }}$ & -19.1 & -20.2 & -20.4 & -19.7 & -5.4 & -19.9 & 19.1 & 20.2 & 20.4 & 19.7 & 5.4 & 19.9 & 78 & 83 & 84 & 81 & 22 & 81 \\
\hline Average & -19.0 & -20.1 & -20.4 & -19.6 & -5.0 & -19.8 & 19.0 & 20.1 & 20.4 & 19.6 & 5.0 & 19.8 & 78 & 83 & 84 & 80 & 21 & 81 \\
\hline
\end{tabular}


Table 4-19: Performance Summary of Mobility Methods (Arterials, PM Peak, Speed) for Capacity 1370 VPHPL Used in Volume-Delay Functions

\begin{tabular}{|c|c|c|c|c|c|c|c|c|c|c|c|c|c|c|c|c|c|c|}
\hline \multicolumn{19}{|c|}{ Capacity 1370 VPHPL Used in Volume-Delay function } \\
\hline & \multicolumn{6}{|c|}{ ME } & \multicolumn{6}{|c|}{ MAE } & \multicolumn{6}{|c|}{ MAPE } \\
\hline & 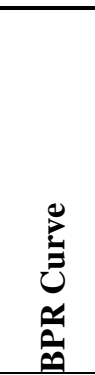 & $\begin{array}{l}\text { 尝 } \\
\frac{8}{4}\end{array}$ & 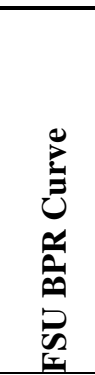 & 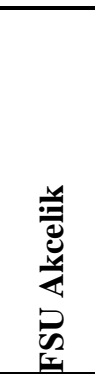 & 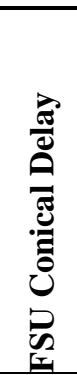 & 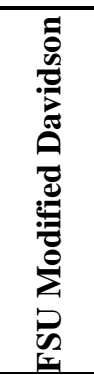 & 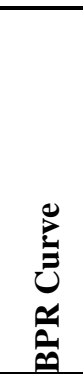 & 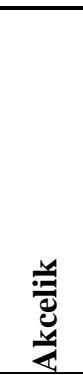 & 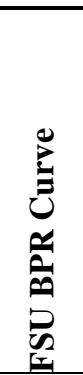 & 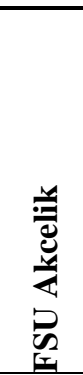 & 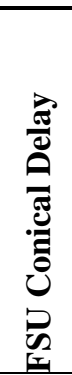 & 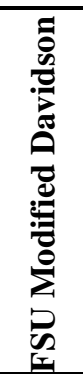 & 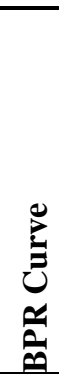 & 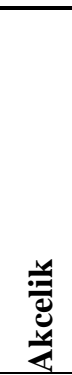 & 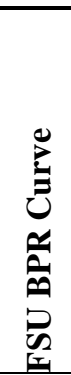 & 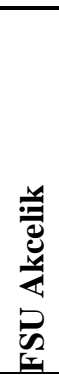 & 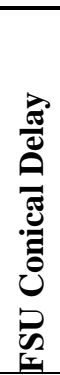 & 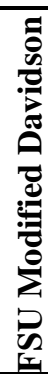 \\
\hline January $18^{\text {th }}$ & -18.1 & -18.5 & -18.6 & -18.2 & -5.3 & -18.3 & 18.1 & 18.5 & 18.6 & 18.2 & 5.3 & 18.3 & 69 & 70 & 70 & 69 & 20 & 69 \\
\hline February $5^{\text {th }}$ & -21.7 & -22.3 & -22.4 & -21.9 & -8.5 & -22.0 & 21.7 & 22.3 & 22.4 & 21.9 & 8.5 & 22.0 & 96 & 98 & 99 & 97 & 38 & 97 \\
\hline February $24^{\text {th }}$ & -21.6 & -22.0 & -22.1 & -21.7 & -8.3 & -21.8 & 21.6 & 22.0 & 22.1 & 21.7 & 8.3 & 21.8 & 95 & 96 & 97 & 95 & 37 & 95 \\
\hline April 11 ${ }^{\text {th }}$ & -20.5 & -20.8 & -20.9 & -20.5 & -7.6 & -20.5 & 20.5 & 20.8 & 20.9 & 20.5 & 7.6 & 20.5 & 85 & 86 & 87 & 85 & 31 & 85 \\
\hline May $10^{\text {th }}$ & -22.1 & -22.5 & -22.6 & -22.2 & -9.2 & -22.2 & 22.1 & 22.5 & 22.6 & 22.2 & 9.2 & 22.2 & 98 & 100 & 101 & 99 & 41 & 99 \\
\hline June 22nd & -19.4 & -19.8 & -19.9 & -19.5 & -6.2 & -19.6 & 19.4 & 19.8 & 19.9 & 19.5 & 6.2 & 19.6 & 78 & 80 & 80 & 78 & 25 & 79 \\
\hline July $5^{\text {th }}$ & -18.8 & -19.0 & -19.1 & -18.8 & -6.8 & -18.8 & 18.8 & 19.0 & 19.1 & 18.8 & 6.8 & 18.8 & 73 & 73 & 74 & 72 & 26 & 73 \\
\hline September $27^{\text {th }}$ & -19.7 & -20.1 & -20.2 & -19.8 & -6.7 & -19.9 & 19.7 & 20.1 & 20.2 & 19.8 & 6.7 & 19.9 & 81 & 82 & 83 & 81 & 28 & 81 \\
\hline October $3^{\text {rd }}$ & -16.2 & -16.7 & -16.7 & -16.3 & -3.3 & -16.4 & 16.2 & 16.7 & 16.7 & 16.3 & 3.3 & 16.4 & 58 & 59 & 59 & 58 & 12 & 58 \\
\hline October $31^{\text {st }}$ & -19.9 & -20.3 & -20.4 & -20.0 & -7.3 & -20.0 & 19.9 & 20.3 & 20.4 & 20.0 & 7.3 & 20.0 & 81 & 83 & 83 & 82 & 30 & 82 \\
\hline Average & -19.8 & -20.2 & -20.3 & -19.9 & -6.9 & -19.9 & 19.8 & 20.2 & 20.3 & 19.9 & 6.9 & 19.9 & 81 & 83 & 83 & 82 & 29 & 82 \\
\hline
\end{tabular}


The above analysis and findings suggest that mobility estimation methods are able to more accurately predict for freeways compared to the arterial facility. This study also found that the mobility estimation method's prediction is relatively better in less congested periods.

\subsection{Reliability Analysis}

This section provides the application details of SHRP2 products (e.g., L03, L07, and $\mathrm{C} 11$ ) to estimate reliability measures (e.g., travel time index). The study considered three forms of the travel time index as reliability measures: $50^{\text {th }}$ percentile travel time index, $80^{\text {th }}$ percentile travel time index, and $95^{\text {th }}$ percentile travel time index. The reliability measures were estimated based on the L03, L07, and C11 procedures for both freeway and arterial facilities. This section also includes a comparison of these estimated reliability measures and real-world reliability measures.

Unlike mobility, estimation of reliability measures requires full years of data. Therefore, this study included full years of data (including incident days) instead of only 10 randomly selected days of data. The incident day data were included since the incidents are random events and may occur in any given day. Thereby, it is always recommended to include incident day data in the reliability analysis. However, this study excluded weekends data as the focus of this study was to estimate reliability measures for weekdays. 


\subsubsection{Freeway Reliability}

This study derived travel time distribution from RITIS data for the freeway study corridor (i.e., I-95 NB between NW $32^{\text {nd }}$ Street and NW $103^{\text {rd }}$ Street). From the travel time distribution, the study estimated travel time index (TTI) and considered it as the real-world reliability measure. RITIS data (e.g., volume, speed, travel time), incident data (e.g., lane hour lost), and weather condition (e.g., rainfall intensity) data were utilized in this study to estimate reliability measures based on the SHRP2 L03, L07, and C11 procedures.

As with the mobility analysis, reliability analysis was also conducted for the following three time periods for the freeway facility.

- AM Peak (07:00 AM - 09:30 AM)

- Mid-Day (12:00 PM- 02:30 PM)

- PM Peak (02:30 PM - 04:30 PM)

Figures 4-33 to 4-35 below presented the reliability measures (e.g., travel time index) for the freeway study corridor during the AM Peak, Mid-Day, and PM Peak periods. As mentioned before, the study estimated three sets of reliability measures (e.g., $50^{\text {th }}$ percentile TTI, $80^{\text {th }}$ Percentile TTI, and $95^{\text {th }}$ percentile TTI) and compared the estimated measures with real-world measures. 


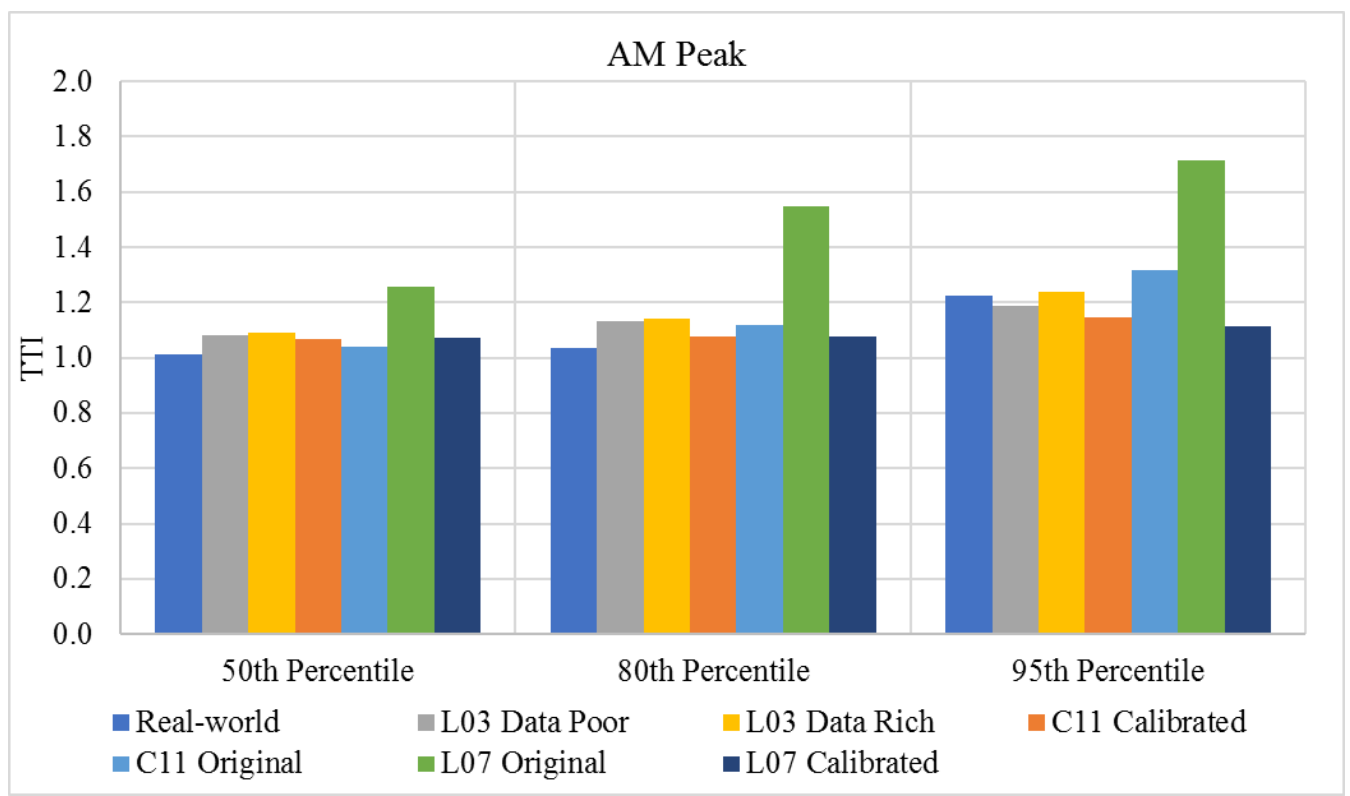

Figure 4-32: Reliability Measures on Freeways for AM Peak

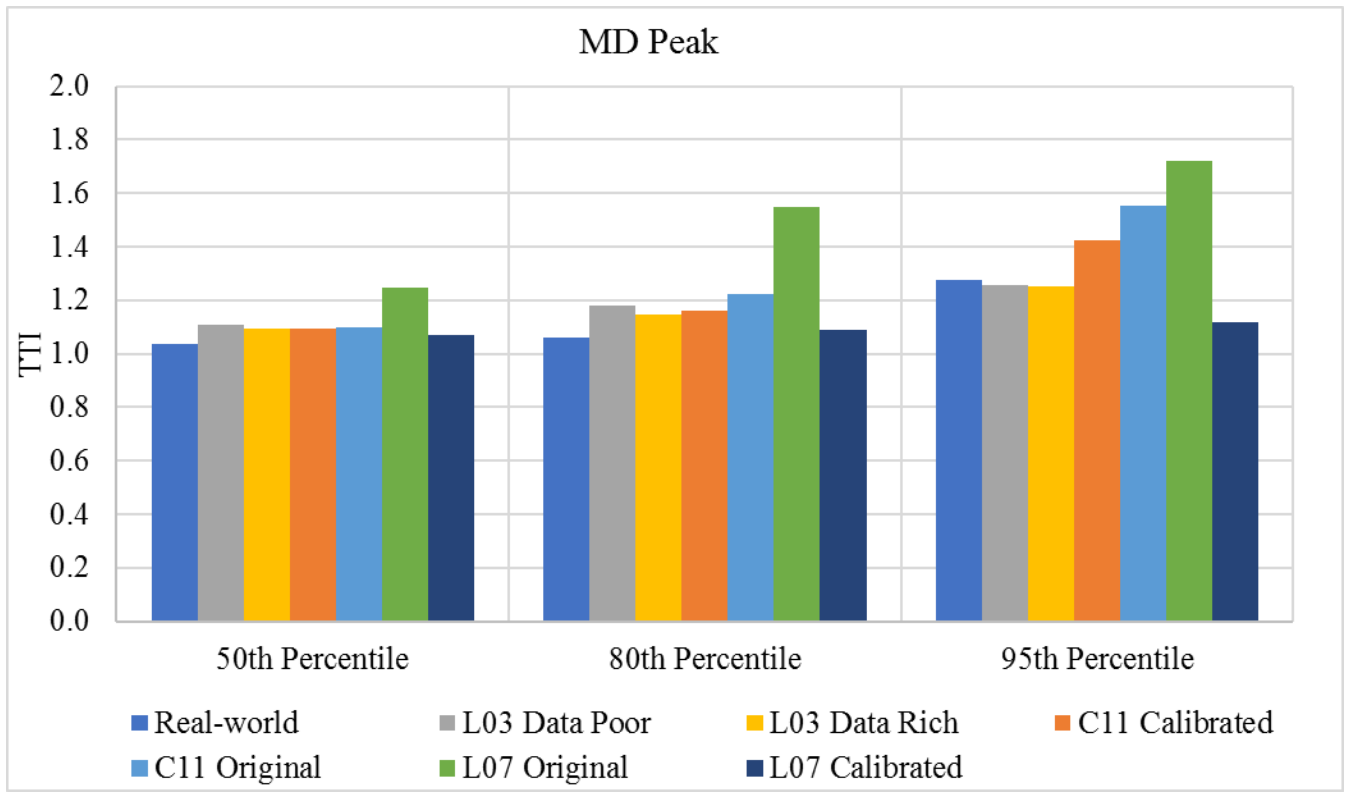

Figure 4-33: Reliability Measures on Freeways for Mid-Day 


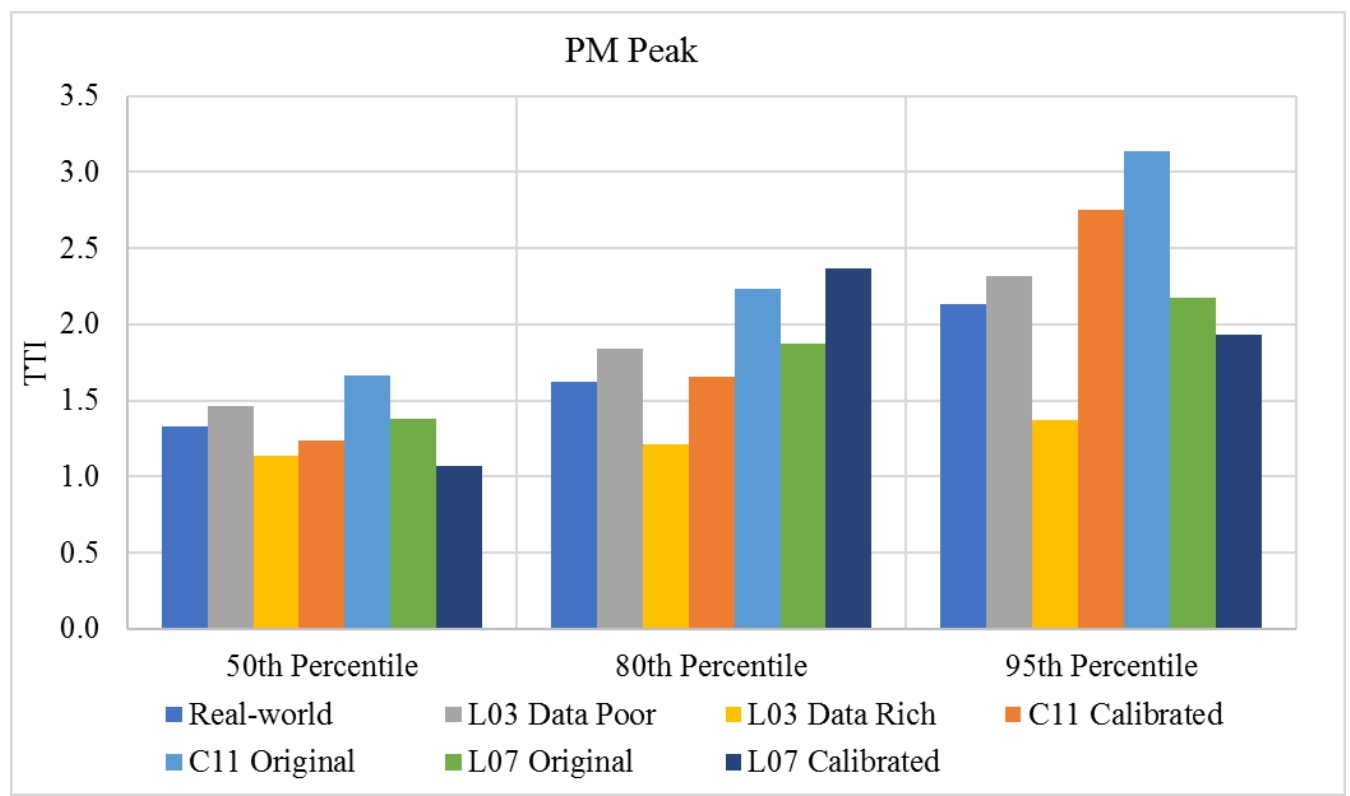

Figure 4-34: Reliability Measures on Freeways for PM Peak

As shown in the above figures, the estimated reliability measures were found to be similar to real-world measures for the AM Peak and Mid-Day periods. However, the estimated reliability measures were different than the real-world measures during the PM Peak for all three indices $\left(50^{\text {th }}\right.$ percentile TTI, $80^{\text {th }}$ Percentile TTI, and $95^{\text {th }}$ percentile TTI).

The differences between real-world TTI and L03 Data Poor model-predicted TTI were relatively smaller in all time periods for all percentiles. Though the L03 Data Rich model predicted well in the AM and Mid-Day periods, the prediction was significantly lower than the real-world TTI during the PM peak period. The Calibrated C11 predicted TTI better than the original C11 model in all three time segments. Regarding L07, the calibrated L07 predicted TTI better than the original L07 during AM and Mid-Day, but the original L07 predicted better during PM Peak. 


\subsubsection{Arterial Reliability}

This study obtained real-world reliability measures from three different real-world sources: Bluetooth, INRIX, and HERE data for the arterial study corridor (i.e., Sunrise Boulevard between US 441 and US 1). Traffic data (e.g., volume, speed, travel time), incident data (e.g., lane hours lost), and weather condition (e.g., rainfall intensity) data were utilized in this study to estimate arterial reliability measures based on the SHRP2 L03, L07, and C11 procedures. Similar to mobility analysis, reliability analysis was also conducted for the following three time periods for the arterial facility.

- AM Peak (07:00 AM - 09:00 AM)

- Mid-Day (11:00 AM - 01:00 PM)

- PM Peak (04:00 PM - 06:00 PM)

Figures 4-36 to 4-38 below show the reliability measures (e.g., travel time index) for the arterial study corridor during the AM Peak, Mid-Day, and PM Peak periods. The study estimated three sets of reliability measures (e.g., 50th percentile TTI, 80th Percentile TTI, and 95th percentile TTI) and compared the estimated measures with real-world measures for each set. Real-world reliability measures (e.g., TTI) from all three sources were similar to one other: Bluetooth, INRIX, and HERE data. 


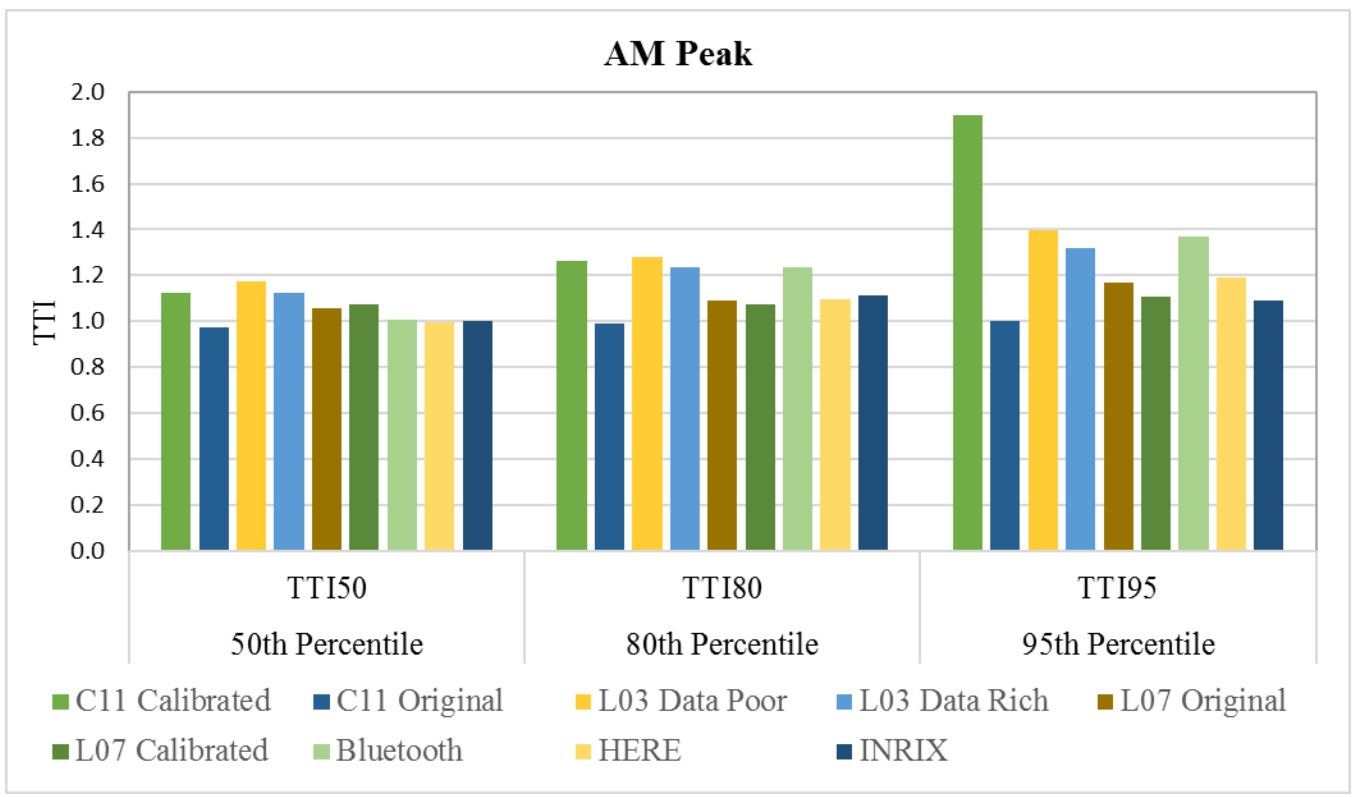

Figure 4-35: Reliability Measures on Arterial for AM Peak

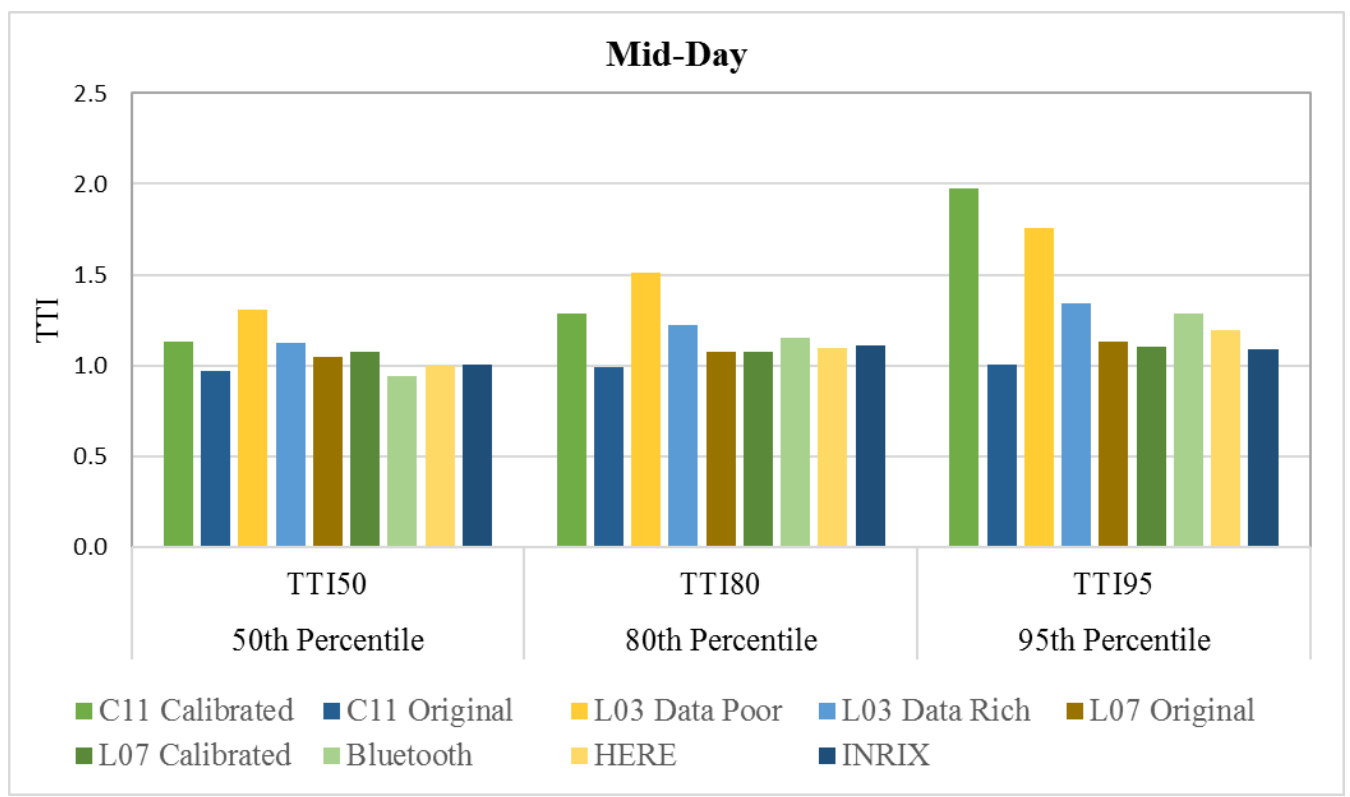

Figure 4-36: Reliability Measures on Arterial for Mid-Day 


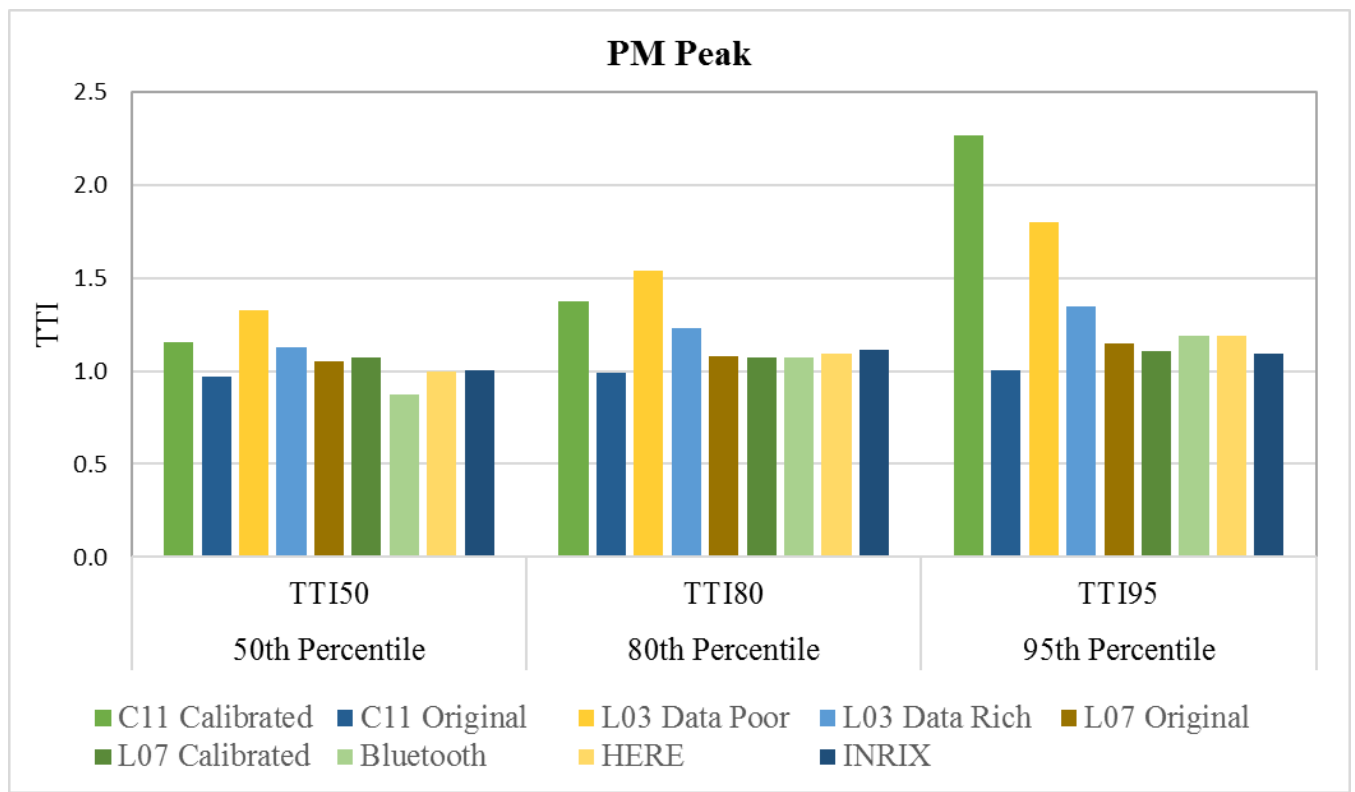

Figure 4-37: Reliability Measures on Arterial for PM Peak

Among the SHRP2 products, L03 Data Rich, L07 Original, L07 Calibrated, and C11 Original predicted TTI reasonably closer to the real-world TTI measures during all time periods for all percentiles. The C11 calibrated and L03 Dara Poor produced fair results for the $50^{\text {th }}$ and $80^{\text {th }}$ percentiles, but for the $95^{\text {th }}$ percentile, the prediction was very high compared to the real world for all of the peak periods. 


\subsection{Summary}

This study conducted a detailed investigation of the predictive ability of different mobility and reliability estimation methods. The study analyzed mobility predictions on freeways with the use of five different methods: BPR curve, Akcelik function, FSU Model, FREEVAL, and Queuing Theory. Out of these five, only three methods (BPR curve, Akcelik function, and FSU Model) can be applied to arterials since the FREEVAL method is only applicable to freeways, and the Queuing Theory cannot be applied to arterials due to traffic flow interruption at the traffic signal.

In general, the analysis implied that mobility estimation methods were able to accurately predict mobility measures (e.g., speed and travel time) on freeways, particularly when there was no congestion and the volume was less than the capacity (i.e., AM Peak and Mid-Day). However, the FSU Conical Delay model did not provide good predictions in any time period (AM, Mid-Day and PM). In the presence of congestion (e.g., PM Peak), FREEVAL exhibited the best predictions, whereas the predictions from FSU Conical Delay and FSU Akcelik were the worst.

In the case of arterials, none of the mobility estimation methods were able to predict measures closer to the real world regardless of time periods, except for the FSU Conical Delay model. Interestingly, among all of the estimation methods, the FSU Conical Delay model predicted reasonably closer to real-world measures. There could be many reasons for this difference because the arterial characteristics (e.g., level of service) are completely different than freeways in many ways. For instance, intersection signal timing is a major factor used to determine level of service in arterials because the roadway capacity varies depending on the signal timing. If the traffic signal timing is not designed properly at the 
signalized intersections, it can end up forming heavy congestion in arterials. Moreover, arterials are frequently accessed, which also affects the travel time.

This study applied SHRP2 products (e.g., L03, L07, and C11) to estimate reliability measures. The study considered three forms of travel time index as the reliability measures: $50^{\text {th }}$ percentile travel time index, $80^{\text {th }}$ percentile travel time index, and $95^{\text {th }}$ percentile travel time index. A major distinction between the mobility estimation process and reliability estimation process lies in the fact that mobility can be estimated on any particular day, but the reliability estimation requires a full year of data. Inclusion of incident days and weather conditions are other important considerations for reliability measurements.

The study found that SHRP2 products predicted reliability measures on freeways similarly to real-world measures during the AM Peak and Mid-Day periods. However, the estimated reliability measures were different than the real-world measures during the PM Peak for all three indices $\left(50^{\text {th }}\right.$ percentile TTI, $80^{\text {th }}$ Percentile TTI, and $95^{\text {th }}$ percentile TTI). The differences between real-world TTI and L03 Data Poor model-predicted TTI were relatively smaller in all time periods for all percentiles.

In the case of arterials, among the SHRP2 products, L03 Data Rich, L07 Original, L07 Calibrated, and C11 Original predicted TTI reasonably closer to real-world TTI measures during all time periods for all percentiles. 


\section{Chapter 5 CONCLUSIONS}

This research applied several widely acceptable and frequently used traffic flow prediction models, discussed methods and data requirements of these models, and investigated the predictive ability of these models with respect to real-world data. The study presented an in-depth analysis on the predictive ability of these traffic flow models by estimating two fundamental types of traffic flow measures for freeways and arterials: mobility measures and reliability measures.

\subsection{Summary and Conclusions}

The study analyzed mobility predictions from five different methods; BPR curve, Akcelik function, FSU Model, HCM-based analysis, and Queuing Theory. Mobility is relatively a mature concept in the traffic engineering field. Therefore, many mobility measure methods are already available and widely accepted among practitioners and researchers. However, each method has their inherent weakness, particularly when applied to and compared with real-world data. For instance, BPR curves are very popular in route choice assignment, but this method is often criticized for underperforming in congested traffic conditions where demand exceeds capacity. The Davidson function is another example, which was very popular as a volume delay function (VDF) in the early days of travel demand modeling because of its flexibility and accommodation of a wide range of traffic conditions. However, the Davidson function had an inherent weakness as it could not define the travel time in a situation where link volume exceeds link capacity. Rahmi Akcelik proposed a function to overcome the conceptual and calibration issues associated 
with Davidson's function (Akcelik, 1991). Mtoi and Moses also came up with another modification and developed a piecewise modified Davidson volume-delay function that was able to provide a reasonable match between model-estimated counts and real-world counts (Mtoi and Moses, 2014).

The study findings implied that mobility estimation methods were able to accurately predicted mobility measures (e.g., speed and travel time) on freeways, particularly when there was no congestion and the volume was less than the capacity (i.e., AM Peak and Mid-Day). However, the FSU Conical Delay model did not provide good prediction in AM and Mid-Day periods. In the presence of congestion (e.g., PM Peak), FREEVAL exhibited the best predictions, whereas the predictions from the FSU Conical Delay and FSU Akcelik were the worst.

In the case of arterials, none of the mobility estimation methods were able to predict measures closer to the real world regardless of time periods. Interestingly, the FSU Conical Delay model predicted reasonably closer to real-world measures among all of the estimation methods. There could be many reasons for this difference as the arterial characteristics (e.g., level of service) are completely different than freeways in many ways.

The study applied several SHRP2 products (e.g., L03, L07, and C11) to estimate reliability measures. Reliability is a relatively novel concept to transportation agencies. Historically, only travel time benefits were accounted for while assessing highway improvement projects. Understanding the importance of precisely estimating reliability measures, the FHWA created the SHRP2 program to find strategic solutions to major national transportation challenges, where reliability is one of the four major focus areas. Several SHRP2 reliability products have already been developed. Among the SHRP2 
reliability products, the study selected $\mathrm{L} 03, \mathrm{~L} 07$, and $\mathrm{C} 11$ to investigate the applicability of these methods with real-world data. This study reviewed and identified the data requirements and estimation approaches for each of these SHRP2 products. In addition, this study also summarized reliability definition, reliability measures, and reliability measurement approaches for all relevant SHRP2 products. The study considered three forms of travel time index as the reliability measures: $80^{\text {th }}$ percentile travel time index, $90^{\text {th }}$ percentile travel time index, and $95^{\text {th }}$ percentile travel time index. A major distinction between the mobility estimation process and reliability estimation process is that mobility can be estimated on any particular day, but reliability estimation requires a full year of data. Inclusion of incident days and weather conditions are other important considerations for reliability measurements.

In freeways, the estimated reliability measures were found to be similar to realworld measures for the AM Peak and Mid-Day periods. However, the estimated reliability measures were different than the real-world measures during the PM Peak for all three indices $\left(50^{\text {th }}\right.$ percentile TTI, $80^{\text {th }}$ Percentile TTI, and $95^{\text {th }}$ percentile TTI). The differences between real-world TTI and L03 Data Poor model-predicted TTI were relatively smaller in all time periods for all percentiles. Though the L03 Data Rich model predicted reasonably well in the AM and Mid-Day periods, the prediction was significantly lower than the real-world TTI during the PM peak. The Calibrated C11 predicted TTI better than the original C11 model in all three time segments. Regarding L07, the Calibrated L07 produced better results than original L07 during AM and Mid-Day, but the original L07 produced better results than the Calibrated L07 during the PM Peak period. 
For arterials, among the SHRP2 products, the L03 Data Rich, L07 Original, L07 Calibrated, and C11 Original predicted TTI reasonably closer to the real-world TTI measures during all time periods for all percentiles. The C11 calibrated and L03 Data Poor produced fair results for $50^{\text {th }}$ and $80^{\text {th }}$ percentiles, but for $95^{\text {th }}$ percentile, the prediction was very high compared to the real world for all peak periods.

The analysis performed in this research provides transportation agencies with a clear picture of how widely accepted and frequently used methods can be applied to their local need to estimate mobility and reliability measures. The study portrayed the predictive ability of widely accepted mobility estimation methods for freeways and arterials by time periods. The study also estimated reliability measures based on the procedures described in the SHRP2 products. The study reached a general conclusion that mobility and reliability measures can be more accurately predicted on freeways compared to arterials. In general, the predictions are more precise on uncongested time periods than congested time periods.

\subsection{Research Contributions}

This research presented the accuracy of widely accepted and used mobility and reliability estimation methods and demonstrated the applications of these methods on arterial corridors and freeways. This research is perhaps the most comprehensive study that investigated the predictive ability of these models, relative to real-world data. In particular, the study investigated the predictive accuracy of mobility and reliability estimated methods and portrayed how the accuracy differs by facility and time periods. 


\subsection{Recommendations for Future Research}

Future studies to extend this research could focus on the following:

- Inclusion of multiple freeways and arterials in different geographic regions to investigate the predictive ability of these widely accepted mobility and reliability estimation methods.

- Develop or update the coefficients to calibrate the models based on available data from recent years.

- Expand the investigation of other MAP-21 performance areas (e.g., Safety, Freight). 


\section{REFERENCES}

Federal Highway Administration (FHWA). (2012). Moving Ahead for Progress in the 21st Century Act: A Summary of Highway Provision. Office of Policy and Governmental Affairs. Retrieved November 2018 from https://www.fhwa.dot.gov/map21/summaryinfo.cfm

North Florida Transportation Planning Organization (NFTPO). (2015). Calibration and Validation Report Northeast Regional Planning Model: Activity Based. Retrieved November 2018 from http://northfloridatpo.com/images/uploads/docs/Tech_Memo_4_-_Validation_Report.pdf

Florida Department of Transportation (FDOT). (2015). SHRP 2 Travel Time Reliability Analytical Product Implementation. Retrieved November 2018 from http://www.floridampms.com/pdf/Task\%2022\%20Report\%20SHRP2\%20TTR\%20Analy tical\%20Product\%20Impl\%20Final.pdf

National Cooperative Highway Research Program (NCHRP). (1999). A Planning Applications for the Year 2000 Highway Capacity Manual. Retrieved November 2018 from

http://onlinepubs.trb.org/onlinepubs/archive/NotesDocs/appxa.pdf

Arnold, M. (2015). Friction Factors and Trip Lengths; BPR Curves and Speeds. FSUTMS Webinar. Retrieved November 2018 from http://www.fsutmsonline.net/images/uploads/fsutms_training/FSUTMS_Webinar_Series_ Friction_Factors,_BPR_Curves,_Speed,_and_Trip_Length_20150903.pdf

Florida Department of Transportation (FDOT). (2014). Source Book Calculations Documentation. Retrieved November 2018 from http://www.fdot.gov/planning/FTO/mobility/Task4-Documentation.pdf

Akcelik, R. (1991). Travel Time Functions for Transport Planning Purposes:

Davidson's Function, Its Time-Dependent Form and an Alternative Travel Time Function. Australian Road Research 21 (3), pp. 49-59. Retrieved November 2018 from https://www.researchgate.net/publication/242258239

Skabardonis, A. and Dowling, R. (1997). Improved Speed-Flow Relationships for Planning Applications. Transportation Research Record, vol 1572, page 18-23. Retrieved November 2018 from

https://trrjournalonline.trb.org/doi/10.3141/1572-03

Singh, R. (1999). Improved Speed-Flow Relationships: Application to Transportation Planning Models. Proceedings of $7^{\text {th }}$ TRB Conference Application of Transportation Planning Methods, Boston, 7-11 March 1999, page 340-349. 
Florida Department of Transportation (FDOT). (2016 a). Express Lanes Time of Day Model - User Guide and Documentation.

Davidson, K.B. (1978). The Theoretical Basis of a Flow-Travel Time Relationship for Use in Transportation Planning. Australian Road Research, 8(1), pp. 32-35; Discussion, pp.45.

Taylor, M.A.P. (1997). The Effects of Lower Urban Speed Limits on Mobility, Accessibility, Energy and The Environment: Trade-Offs with Increased Safety? Federal Office of Road Safety.

Retrieved November 2018 from

https://infrastructure.gov.au/roads/safety/publications/1997/pdf/lower_urb_speed.pdf

Tisato, P. (1991). Suggestion for an Improved Davidson Travel Time Function. Australian Road Research, 21(2), pp. 85-100.

Mtoi, E. T., and Moses, R. (2014). Calibration and Evaluation of Link Congestion Functions: Applying Intrinsic Sensitivity of Link Speed as a Practical Consideration to Heterogeneous Facility Types within Urban Network. Journal of Transportation Technologies, 2014, 4, 141-149. Retrieved November 2018 from https://file.scirp.org/pdf/JTTs_2014042110593828.pdf

Rakha, H., and Zhang, W. (2015). Consistency of Shock-Wave and Queuing Theory Procedures for Analysis of Roadway Bottlenecks. Presented at 84th Annual Meeting of the Transportation Research Board, Washington, D.C., 2005.

Hadi, M., Xiao, Y., Qomn, S. F., and Cabrera, E. (2014). Performance Measurements of Transportation Systems Based on Fine-Grained Data Collected by AVI and AVL Systems. National Center for Transportation Systems Productivity and Management.

Trask, L., Aghdashi, B., Schroeder, B., and Rouphail, N. (2015). Freeway Facilities and Reliability Analysis Computational Engine for The HCM 6th Edition: A Guide for Multimodal Mobility Analysis. Institute for Transportation Research and Education, North Carolina State University. Retrieved November 2018 from http://freeval.org/docs/FREEVAL_2015e_User_Guide_Final.pdf

Cambridge Systematics, Texas A\&M Transportation Institute, University of Washington, Dowling Associates, Street Smarts, Levinson, H., and Rakha, H. (2013). Analytical Procedures for Determining the Impacts of Reliability Mitigation Strategies. SHRP2 Report S2-L03-RR-1, National Academy of Sciences. Retrieved November 2018 from http://nap.edu/22806.

Potts, I.B., Harwood, D.W., Hutton, J. M., Fees, C.A., Bauer, K.M., Lucas, L.M., Kinzel, C.S., and Frazier, R.J. (2014). Identification and Evaluation of the Cost-Effectiveness of Highway Design Features to Reduce Nonrecurrent Congestion. SHRP2 Report S2-L07RR-1, National Academy of Sciences. Retrieved November 2018 from 


\section{http://nap.edu/224076}

Hadi, M., Xiao, Y., Wang, T., Hu, P., Jia, J., Edelstein, R., and Lopez, A. (2015). Pilot Testing of SHRP 2 Reliability Data and Analytical Products: Florida. SHRP 2 Reliability Project L38C. National Academy of Sciences. Retrieved November 2018 from http://nap.edu/22331

Economic Development Research Group, Cambridge Systematics, ICF International, Texas A\&M Transportation Institute, and WERIS. (2013). Development of Tools for Assessing Wider Economic Benefits of Transportation. SHRP2 Report S2-C11-RW-1, National Academy of Sciences. Retrieved November 2018 from http://nap.edu/22502

Florida Department of Transportation (FDOT). (2016 b). SHRP2 C11 Post-Processor Tool Technical Manual. 